STUDIES

in in
UNIVERSITY OF OREGON LIBRARY Received on: 06-02-89

Studies in African

linguistics

\title{
AFRICAN LINGUISTICS
}

\section{AUGUST 1988}

Volume 19, Number 2

blished by the Department of Linguistics

d the African Studies Center

iversity of California, Los Angeles 


\section{STUDIES IN AFRICAN LINGUISTICS}

Published by the Department of Linguistics and the African Studies Center

The University of California, Los Angeles

\section{Editor}

Russe11 G. Schuh

Executive Board

Michael Lofchie

Paul Schachter
Editorial Board

Eyamba G. Bokamba

George N. Clements

Gerard M. Dalgish

David J. Dwyer

Victoria A. Fromkin

Talmy Givón

Robert Hetzron

Jean-Marie Hombert

Larry M. Hyman

Hilda Koopman

William R. Leben

Carol Lord

Ian Maddieson

Olasope 0. Oyelaran

Carol Myers Scotton

John V. Singler

Fumio Omori

Maxine H. Schuh

Studies in African Linguistics is published three times a year. Occasional supplements are published at irregular intervals and are available to current subscribers at reduced rates. Contributors please see "Guidelines for Contributors" inside the back cover. All correspondence and contributions to the journal should be sent to:

The Editor, Studies in African Linguistics

Department of Linguistics

University of California

Los Angeles, CA 90024

Subscriptions: Individuals: $\$ 12.00$ per year, $\$ 22.00$ for two years

Institutions: $\$ 20.00$ per year

Single issue: \$7.00 for single back issues

Supplements: $\quad \$ 12.00$ (if ordered separate from subscription)

(Add $\$ 15.00$ per year for overseas Air Mail subscriptions.)

Make checks payable to the Regents of the University of California.

Volume 19, Number 2, August 1988

Copyright 1989

by the Regents of the University of California 
Volume 19, Number 2 August 1988

TABLE OF CONTENTS

R.J. Hayward, IN DEFENCE OF THE SKELETAL TIER . . . . . . . . . . . 131 Out1 Bat-E1, DISTINCTIVE NASALITY IN KWAWU:

A PROSODIC ACCOUNT ................... 173

Richard Campbell, VERBAL INFLECTION IN KWAWU AKAN . . . . . . . . . 205

E11zabeth G. Weber, THE BONDEI OBJECT PRONOUN

IN CLEFTS AND PSEUDO-CLEFTS . . . . . . . . . . . . . . 233

Guidelines for Contributors ............. Inside back cover 

IN DEFENCE OF THE SKELETAL TIER*

\author{
R.J. Hayward \\ School of Oriental and African Studies \\ University of London
}

\begin{abstract}
This paper investigates empirically the viability of a hypothesis (advanced by Lowenstamm \& Kaye [1986]) that morphological classes (In particular, those typical in languages with nonconcatenative morphologies) are fully definable in terms of syllabic structure. This hypothesis has theoretical significance, for, if correct, the skeletal tiergenerally regarded as a core object in autosegmental phonology-becomes a derivative and, consequently, redundant entity. Data from four Ethiopian Semitic languages are presented as evidence that it is not always possible to posit unique syllabifications for morphological classes and that underlyingly many such classes are only partially syllabified, full syllabiflability beIng secured by processes occurring later in the derivation. Analyses are proposed for the data, which demonstrate the necessity for a non-derivative skeletal tier.
\end{abstract}

1. The Skeletal Tier vs. Syllable-Based Templates

For the past eight or so years a substantial portion of the success that has been enjoyed within Autosegmental Phonology has been due to the recognition of the "CV tier". The CV tier (or some functionally similar entitysee section 2) serves within a multitiered phonological representation as

*A preliminary version of this paper was first presented at the Easter Meeting of the Linguistics Association of Great Britain in 1987. I am happy to acknowledge here my gratitude for valuable comments made by John Harris and John McCarthy. 
the base to which elements of otherwise mytually independent tiers are assoclated. It has, then, a mediating role in interrelating reciprocally autonomous tiers. The most important aspect of such a function is that the CV tier furnishes the programe for temporal coordination within phonology, and for this reason the $\mathrm{CV}$ tier is often referred to as the "timing tier". Referring all matters involving phonological timing to the CV tier (rather than treating them as properties of segments) has provided satisfying solutions for such longstanding problems as the analysis of vowel and consonant length and the analysis of complex segments of various sorts. Most recent literature on the subject has been at pains to point this out. For a particularly clear overview see Clements [1986].

A number of arguments justifying the recognition of the $\mathrm{CV}$ tier are advanced by Clements and Keyser in Chapter 3 of their 1983 monograph. Their first argument (pp. 64-66) is based upon McCarthy's extensions of the principles of Autosegmental Phonology to handing the problems of non-concatenative morphology of the type commonly (though not exclusively) found in Semitic languages [McCarthy 1979, 1981, 1983]. For the present purpose it is not necessary to go beyond this first argument, for it is precisely on account of purportedly simpler analyses that have recently been advanced for problems of this type that the CV tier has been declared redundant.

The essential insight of McCarthy's model consists in distinguishing three morphemic elements at the level of phonological representation for stems exhibiting non-concatenative morphology: ${ }^{1}$

(1) The "Consonantal Melody": In Semitic languages this consists of two, three, or four consonants bearing the basic lexical identity of the root.

(11) The "Vocalic Melody": In Semitic languages this consists of one or more vowels which together with the "prosodic template" bear grammatical (and sometimes lexical) information.

(1i1) The "Prosodic Template": This defines the canonical shape of a given stem form in terms of $C$ and $V$ elements.

l"Non-concatenative morphology" is morphological structure exhibiting discontinuity, infixation, etc. 
It is not possible simply to recognize only a consonantal skeleton within which vowels are interdigitated any more than it is possible to posit a basic vocalic skeleton between the elements of which the various components of the consonantal melody are slotted. The reciprocal discontinuities of consonantal and vocalic melodies require the intermediation of the prosodic template because both melodies give evidence of having autosegmental status. For example, each of them is independently subject to principles governing autosegmental entities. ${ }^{2}$

The linking of elements of the two melodic tiers to the $C$ and $V$ elements of prosodic templates is accomplished for the most part by means of conventions of association that within the theory of Autosegmental Phonology are concelved of as belonging to Universal Grammar, so that language specific rules are kept to a minimum. For a general account of this the reader is referred to van der Hulst and Smith [1985:11-29].

In a recent paper, however, Lowenstamm and Kaye [1986] have argued that the CV tier is redundant since its function can be adequately performed by the syllabic structure, which, of course, has often been conceived of as an Independently necessary autosegmental level (cf. Clements and Keyser [1983], Halle and Vergnaud [1980]). The essential premise for Lowenstamm and Kaye's argument is their assumption that phonological representations have full prosodic, 1.e. syllabic, structure from the outset. This assumption is one which has been advanced in earlier publications of theirs (see in particular Kaye \& Lowenstamm [1982]). Since in the analysis of very many languages there is a considerable degree of mismatch between phonological and phonetic structures as far as syllabification (or, Indeed, syllabifiability) is concerned, the claim that phonological representations have full prosodic structure needs to be explained. For example, we expect processes such as epenthesis to create prosodic structure that does not exist at a more underlying level. Lowenstamm and Kaye's claim is made possible by positing null elements in the prosodic structure of phonological representations: prosodic

${ }^{2}$ For example, both consonantal and vocalic melodies are independently subject to the Obligatory Contour Principle. 
structure is erected fully with the inclusion of null elements at those nodes of structure where they are required, $i . e$. at sites where epenthesis will occur. 3

In spite of appearing to create an enormous degree of redundancy with respect to lexical entries, such an approach promises high dividends as far as epenthesis is concerned since it would enable us to dispense with the multifarious detail of language specific and context sensitive rules, replacing them by a maximally simple characterization of the process, which would be made available by Universal Grammar, viz. Insert Segment [Lowenstamm \& Kaye 1986:102, 7i1].

An illustrative example would be provided by the East Cushitic language Arbore, which exhibits a process which we may refer to as "post-1aryngeal epenthesis". An epenthetic copy of a single vowel preceding a laryngeal $(h, ?)$ is inserted after the latter when it is followed within a word by any non-glottalized obstruent or a nasal, e.g.
(1) /leh-t-aw/ ewe-fem.-1st sg. possessive
$\rightarrow \quad[\text { lẹfẹtaw }]^{4} \quad$ 'my ewe'
/se?-t/aw/ cow-fem.-1st sg. possessive
$\rightarrow \quad[\text { se?etaw }]^{4} \quad$ 'my cow

The same language displays another process which may be labelled "I-epenthesis", which occurs at the juncture of a sequence of two (dissimilar) consonants with a third consonant or at a word boundary, e.g.

${ }^{3}$ Epenthesis is not the only means whereby null elements may be resolved. The other means which is specifically mentioned by Lowenstamm and Kaye is resyllabification [1986:101ff.]. Although Lowenstamm and Kaye adopt the Idea that epenthesis involves the substitution of a null element in the prosodic structure by a real segment, the proposal is not without precedents. The Idea can be traced back to an unpublished paper by Halle and Vergnaud [1978], and is also made use of in work by Selkirk [1981]. A comprehensive survey of the notion of null elements and related issues in syllable theory is furnished by Itô [1986].

${ }^{4}$ Diaresis under a segment symbolizes breathy phonation (according to IPA usage). A single dot under a vowel letter symbolizes laryngealization. 
(3)

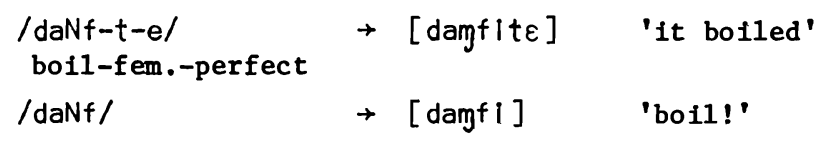

(4) /daNf/

Rules that might be proposed for these processes would probably need to refer to the specific syllable structure constraints of the language and (in the case of the first process at least) to particular features of segments in the environment. In other words, the essential similarity of the two processes could hardly be expressed without reference also to certain presupposed or attendant factors. Under the proposal made by Lowenstamm and Kaye, however, the quintessential generalization is given straightforward expression. Thus, appropriate underlying representations for [sẹẹtaw] 'my cow' and [damfite] 'it (feminine) boiled' might be as follows:

$$
\bigwedge_{s e}^{\sigma} \bigwedge_{\emptyset}^{\sigma} \bigwedge_{t}^{\sigma} \lambda_{w}
$$

In both cases the null elements $(\emptyset)$ in the underlying prosodic structure come to be "associated with" ("replaced by" ?) ${ }^{5}$ an epenthetic segment. The simplicity and generality of all this is very attractive. ${ }^{6}$

The redundancy inherent in distinguishing a two-term vocabulary of $C$ and $V$ in the skeletal tier has been criticized on several occasions (see Levins [1983], Archangeli [1984]), and the analyses presented in the second part of this paper give recognition to that criticism. For the present purpose, however, whether the skeletal tier contains differentiated $C$ and $V$ elements or

${ }^{5}$ It is not exact1y clear to me what is implied by diagrammatic representations such as

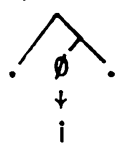

(cf. Lowenstamm and Kaye [1986:101]; cf. also (18), (34), and (36) in the present paper, which are based on the original diagram).

${ }^{6}$ If such a proposal proved to be properly motivated, it would further enhance Archangeli's insightful suggestion that epenthesis inserts segments that from the point of view of distinctive content (within a given language) require the absolute minimum of specification (cf. Archangeli [1984:58]). 
not is irrelevant; the real question is whether the skeletal tier itself is a redundancy, for if underlying canonical shapes can be defined fully by means of prosodic structure, where this is provided with a suitably constrained device of null elements, any form of skeletal tier will be unnecessary.

The relevance of this issue comes very much to the fore in the analysis of morphology of the Semitic type. Lowenstamm and Kaye report McCarthy as saying that the representation of his prosodic templates in terms of elements of the CV tier or in terms of elements of syllable structure were simply notational variants. They deny, however, that this is the case. They pinpoint the difference by envisaging a "Semitic hybrid" having an Arabic-type prosodic template of the form CVCCVC but incorporating the possibility of a certain type of branching onset for syllables, which is a feature permitted by Modern Hebrew (though not by Arabic). In such a language a triliteral radical such as $k-t-b$ might license only one syllabification (as in (7)) whereas a radical such as $s-b-r$ would be syllabifiable in two ways (as in (8) and (9)) on account of the fact that the sequence br is a permissible onset cluster, and given the markedness hierarchy for syllables in Modern Hebrew, (9) would present a less marked option than (8).

(7)

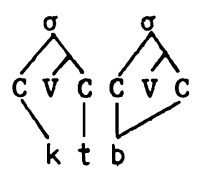

(9)

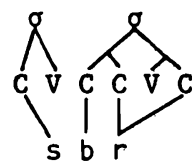

(8)

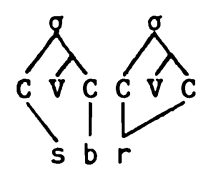

What the argument demonstrates is that in terms of the CV tier the potential for ambivalence for syllabification with a radical such as $s-b-r$ is simply not captured and, furthermore, that since the prosodic structure on its own does capture it, the CV tier is unnecessary. Clearly McCarthy was incorrect In supposing that the two ways of representing prosodic templates were notational variants. But whether the ability to express such a distinction as 
that illustrated by the hypothetical language example will make for any greater overall insight may not necessarily be the consequence. Among the languages to be considered below is one which exhibits a situation closely akin to that elaborated by means of the hypothetical language, but it will be concluded that in this case a significant generalisation would have to be forfeited by an insistence that prosodic templates be defined syllabically. Lowenstamm and Kaye [1986:122] then proceed to propose the following principle ("Principle (55)"):

"Morphological classes defined canonically must observe syllabic homogeneity."

The full context of the article makes it abundantly clear that when speaking of "morphological classes" the authors are referring to entities of the type for which McCarthy (and subsequently others) have taken over the term binyanim from traditional Hebrew studies cf. sq. binyân, pl. binyānî́m). The terms imposed by "Principle (55)" are very restrictive. The principle requires a unique syllabification for all members of a particular morphological class (hereafter abbreviated $M C$ ).${ }^{7}$ As its proposers point out, the princtple makes predictions as to how a process such as epenthesis will operate for a given MC. The operation of epenthesis with respect to certain MC's of Arabic (discussed in McCarthy [1982]) is adduced as support for the principle. Defined in terms of the CV tier the MC's in question have in common the fact that they begin with the sequence CC: they are CCVCVC, CCVVCVC, and CCVCCVC. Lowenstamm and Kaye (pace McCarthy) note

"...that the initial consonant is resyllabified as the coda of the preceding syllable when the stem follows a vowel-final word or prefix. ... Now consider the case where no vowel precedes the CC-initial stem. Since Arabic has no branching onsets, epenthesis must occur. But where? "In fact, the vowel is inserted before the cC-cluster. It could have been inserted between the two consonants. Principle (55) predicts

${ }^{7}$ It seems clear that since in Lowenstamm and Kaye's theory units of skeletal structure are, in fact, syllables which dominate various sets and configurations of segmental terminal points, a conclusion such as that embodied in Principle (55) is quite inescapable. 
this state of affairs; if the vowel were inserted to the right of the first consonant, 1.e., CiC- instead of iCC-, the initial consonant would constitute the onset of the first syllable; while in all other cases, this consonant occupies a coda position." (p. 123)

The point is made very clearly; a MC defined in terms of the CV tier is neutral with respect to where epenthesis will occur. If we consider the case of the CCVCVC template the potential violation of the syllable structure constraint in Arabic against branching onsets would be obviated just as well by the epenthesis in (10) as by that in (11).

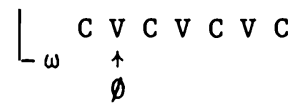

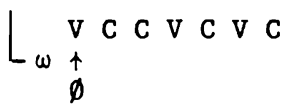

A syllable-based definition of the same MC (making use of a null element in a nuclear position), as in (12), predicts only one possibility for epenthesis, and so provides a more adequate grammar.

$$
\bigwedge_{0}^{\sigma} \bigwedge_{c}^{\sigma} \bigwedge_{c}^{\sigma}
$$

The behaviour of epenthesis in Arabic then certainly appears to come out in support of Principle (55). I believe, however, that this is purely fortuitous. This opinion rests upon the fact that in some languages having the same type of morphology as Arabic there are epenthetic processes which simply do not permit us to posit a unique underlying syllabification for a MC.

The data to be considered come from certain Semitic languages spoken in Ethiopia, namely, Amharic, Chaha, Tigrinya, and Harari.

1.1. Case 1: The Amharic Jussive (Type A) Stem. Comparison of surface forms of the affirmative paradigms of the Imperfect and Jussive show that the latter lacks forms for the second person. ${ }^{8}$ The paradigms presented are those

${ }^{8}$ The main function of the Jussive is the expression of indirect commands and (when interrogative), requests for permission. Triliteral verbs in Ethiopian Semitic belong to two main classes, which have commonly been referred to in the literature as Types $A$ and $B$. The division goes back to the protolanguage, where the characteristics of the two classes (represented by $s-b-r$ 
of the triliteral (Type A) radical $z-f-n$ 'dance'.

(13) Affirmative Imperfect

'I (etc.) dance'

1s izäfnallähu

2ms tizäfnalläh

2fs tizäfñalläs

3ms yłzäfnall

3fs tizäfnalläc

1p innizäfnallän

2p tizäfnal lačcthu

3p $y \dot{t z a ̈ f n a l l u}$
(14) Affirmative Jussive

'let me (etc.) dance!'

1s lizfän

$2 \mathrm{~ms}$

2fs

$3 m s \quad y \dot{t} z$ än

3fs tizfän

1p inntzfän

2p

3p $y+z f a ̈ n u$

The affirmative paradigm of the Imperative given in (15) could also be regarded as defective, since it has only second person forms.

(15) Affirmative Imperative

'dance!'

2ms zifän

2fs żfän̆i

$2 \mathrm{p} \quad z+\dot{+}$ änu

To "fill the gap" in the paradigms of (14) and (15) by merging them is an obvious move and one which gives recognition to the long established practice of scholars of the language (cf. Cohen [1936:179], Dawkins [1960:26]).

The claim that Jussive and Imperative forms make up a single paradigm

'break' and $f-s$ '-m 'finish') have been reconstructed as follows (Hetzron 1972:22ff.]:

\begin{tabular}{|c|c|c|}
\hline & Perfect & Imperfect \\
\hline ype A & *säbärä & *y+säbbir \\
\hline Type B & * fäs's'ämä & ${ }^{*} y+f e s^{\prime} s^{\prime}+m$ \\
\hline
\end{tabular}

Subsequent developments in the two main groups of Ethiopian Semitic, i.e. North Ethiopic (the group to which Tigrinya discussed as Case 3 in this paper belongs) and South Ethiopic (the group to which the remaining languages discussed here belong), have obscured some of the original features, but the classes have nevertheless remained distinct throughout much of their paradigms. 
would lead us to expect the stem to constitute a single unitary MC. This explanation holds very obviously for other paradigms such as the Perfect, where each verb type seems to present an invariant stem form. (In the following examples the canonical shapes are presented in an informal way.)

\section{triliteral}

Types A \& B $c_{1} \ddot{a ̈ c}_{2} \mathrm{C}_{2} \ddot{a} \mathrm{c}_{3}-$

\section{Type C}

$c_{1} a c_{2} c_{2} a ̈ c_{3}-$

\section{quadriliteral}

$$
c_{1} \ddot{a} c_{2} a ̈ c_{3} c_{3} a ̈ c_{4}-
$$

But an examination of (14) and (15) reveals stem allomorphy, viz. -zfän$z \dot{f}$ än- (* $\dot{i} f a ̈ n)$. If we assume that the stem form (defined in terms of $C$ and V) is CCVC, the longer alternant can be accounted for by means of epenthesis. Amharic syllabic structure permits no branching onsets (cf. Part II, Case 1.). In affirmative Imperative forms, where a CC cluster might otherwise occur initially in the word (and syllable), epenthesis operates to split the sequence. To handle this alternation with reference to syllable structure would require us to define the stem shape with an onset consonant Initially, as in (17). The surface alternant zifän would be derived as in (18).9

(17)

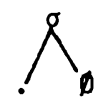

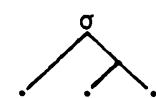

(18)

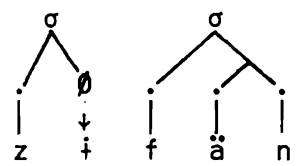

The prefixed forms, however, would require the initial stem consonant to belong to the coda, viz.

(19)

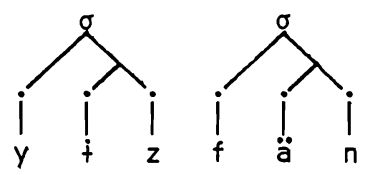

${ }^{9}$ In representing the $\mathrm{CV}$ skeleton as a series of dots in this section of the paper, I am simply following the practice of Lowenstam and Kaye, viz.

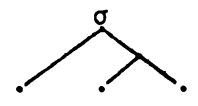


Now the $\dot{i}$ in $y \dot{t} z$ än can itself be regarded as epenthetic, for comparison of the forms of this same morpheme show the $\dot{t}$ to be in alternation with zero, e.g

$$
\begin{aligned}
& \text { (20) yizäfnall 'he is dancing' } \\
& \text { ayzäfnimm 'he is not dancing' }
\end{aligned}
$$

Furthermore, in the form

$$
\begin{aligned}
& b\left[i^{\cdot}\right] z a ̈ f+n ~(\leftarrow b \dot{t} z a ̈ f i n \leftarrow b-y-z a ̈ f n) \\
& \text { if he dances }
\end{aligned}
$$

we find further complications: (1) there appears to be a third alternant of the 3ms pref $1 x,\left[i^{-}\right]$, which derives from an epenthetic $\dot{t}$ preceding the $y-$ (by a late phonetic rule the two segments undergo coalescence); (1i) there is an alternant for the Imperfect stem, 1.e. zäfin. This alternant is also accounted for by epenthesis. Although Amharic word structure does permit syllables with multiply-branched rhymes in final position, Amharic syllable structure does not allow this kind of rhyme structure when the ultimate segment has greater sonority than the penultimate one. Once more epenthesis saves the day! If, however, we attempt to define the Imperfect stem in a syllable-based way, we again find that the final consonant behaves sometimes as an onset (22) and sometimes as a coda (23). 10

In section 2 I represent the Skeletal Tier employed there as a series of $\mathrm{X}$ slots. The distinction, however, is not simply one of graphic notation. Lowenstamm and Kaye's dots are totally derivative since each one corresponds to a terminal node of prosodic structure. Furthermore, their contention is that if this proves always to be the case (and they stress that this is an empirical issue), then the Skeleton, in whatever way it is symbolized, is redundant. In the representations used in section 2 some $X$ slots occur that do not correspond to terminal nodes of prosodic structure and are, therefore, not derivative.

${ }^{10}$ One suspects that exactly the same ambivalence with respect to syllablc categaries must also arise in the Arabic examples discussed by Lowenstamm and Kaye [1986:123] since the addition of a vowel-initial inflection to a consonant-final stem would automatically require resyllabification of the final consonant. Thus, a template such as CCVCVC with the prosodic structure hypothesized in (12) would presumably take a vowel-initial suffix such as $-u(n),-0$, etc. In the $3(m) p$, and then resyllabification would be neces- 
(22)

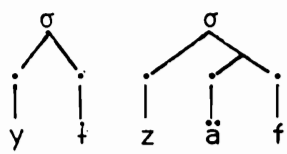

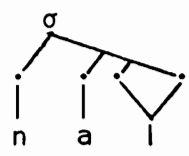

(23)

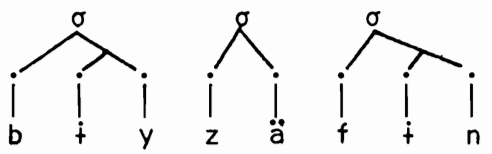

Elsewhere I have attempted to demonstrate that the overwhelming majority of occurrences of the high central vowel $\dot{f}$ in Amharic have to be regarded as epenthetic [Hayward 1986]. The important thing about this process is that it scans word-sized ${ }^{1}$ strings of segments rectifying any prosodic deficiencies by the creating of syllable heads but without any regard to predesignated prosodic categories, e.g. onset or coda, of stem consonants.

of course, the initial identification of the Imperative and Jussive as one MC might be objected to; after all, the Imperative forms not only have a different stem shape, they also differ from Jussive forms in having no prefixes. Inspection of the following Negative Imperative forms shows ( 1 ) the presence of prefixes throughout and (ii) the same stem alternant, viz. -zfän-, as that found In the affirmative Jussive.

(24) Negative Imperative 'do not dance!'

2ms attizfän 2p attizfänu

2fs attizfän̆i

Consideration of other verb types also points solidly to the conclusion that the Imperative and Jussive stems do indeed belong to one MC.

Type B 'hide (tr.)' Quadriliteral 'overturn'

3ms Jussive $y \dot{+} d a ̈ b b \dot{t} k^{\prime} \quad y \dot{g} a ̈ l b \dot{t}{ }^{\prime}$

2ms Imperative däbbłk' gälbłt'

1.2. Case 2: The Chaha Jussive II Stem. According to Leslau [1983], there are two Jussives in Chaha. ${ }^{12}$ One of them has the generalized stem shape

sary, viz.

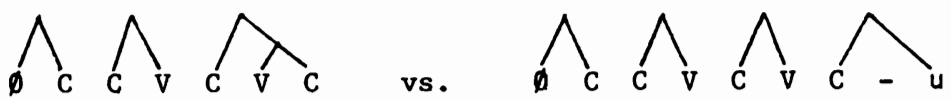

${ }^{11}$ By "word-sized" I mean that such strings are morphologlcally complete, even if only partially syllabifiable.

${ }^{12}$ Chaha is one of the more important and better studied of the "Gurage" 
$-C_{1} C_{2} \ddot{a}_{3}-$ and is virtually confined to intransitive verbs. The other one (here termed Jussive II), which is found for all other simple triliteral verbs, has two stem shapes, viz. $-C_{1} C_{2}+C_{3}-$ and $-C_{1}+C_{2} C_{3}-$. In his original descriptions Leslau [1951a, 1951b] presented these two as distinct types, but in his later accounts [1964, 1983], he provides a wealth of data to justify his analysis that the two forms are in complementary distribution. Quite clearly the variability relates to the position of the $\dot{i}$ vowel, and, as Leslau shows, this is determined by phonetic features inherent to the consonant radicals. In section 2 I try to motivate an analysis of this stem based on syllabification procedures and epenthetic processes which have a high degree of sensitivity to the relative sonorities of the root consonants. Typical (3ms) forms of Jussive II exhibiting the two stem shapes are given in (26).

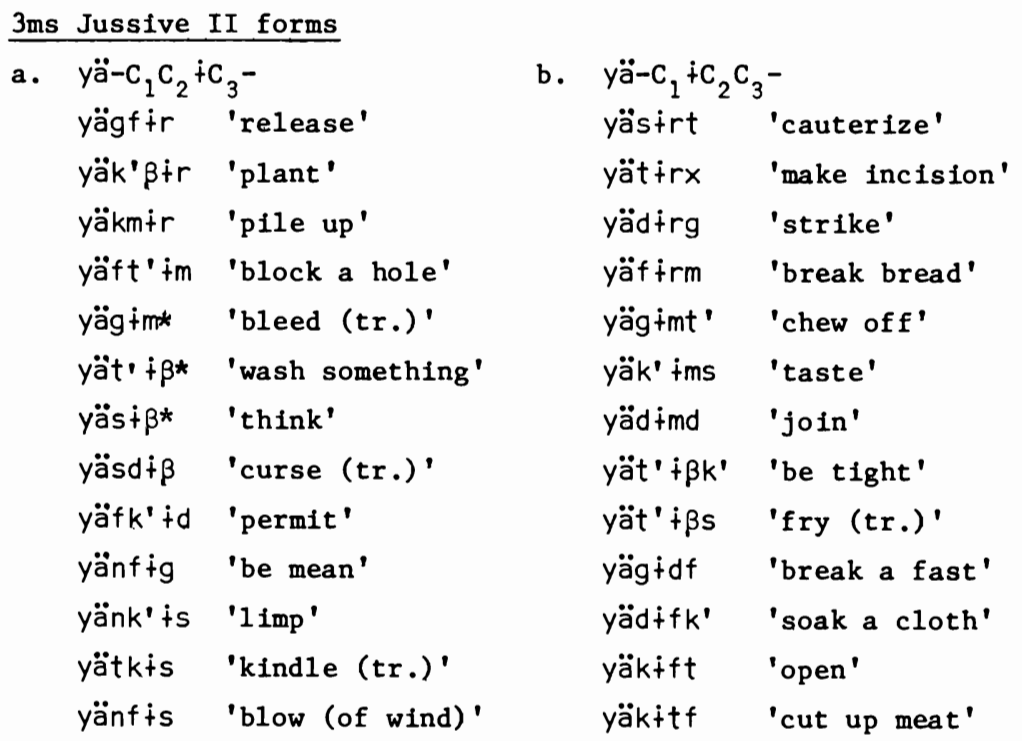

(An effort has been made to select verbs displaying a wide range of consonant types in the $\mathrm{C}_{2}: \mathrm{C}_{3}$ sequences. This has necessitated

languages. According to Hetzron's classification of Ethiopian Semitic, Chaha belongs to the Central Western Gurage group of his Outer South Ethiopic division [Hetzron 1972, 1977]. 
utilizing some verbs (marked with an asterisk) which on the surface do not appear to be triradicals. At a more abstract level of representation, however, I would claim that these verbs have indeed to be analysed as triradicals. The analysis of parallel forms to these which are found in Amharic is taken up in Alemayehu Haile and Hayward [in preparation].)

Without entering into details (which are taken up in section 2), it can be seen that in the forms of $(26 a), C_{3}$ has a greater sonority than $C_{2}$, while in the forms of (26b) this is not the case.

Assuming Leslau to be correct in setting up a single MC for forms such as those presented in (26) obliges us to relinquish any insistence on sy1labic homogeneity for such classes. The mismatch between the syllable structures of (27a) and (27b) is most striking.

(27) a.

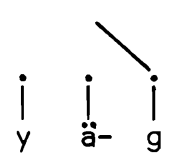

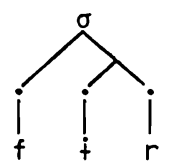

b.

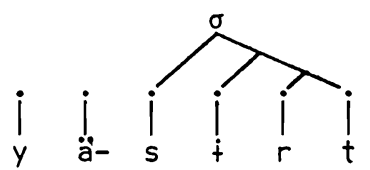

It should be noted that Chaha provides an example of a scenario of the sort sketched by Lowenstamm and Kaye for their "Semitic hybrid", for we have what purports to be a single morphological class with two distinct possibilities for syllabification.

In a synchronic analysis utilizing the CV tier-at least a generative one operating with morpheme invariance-we might seem obliged to choose between (28a) and (28b) when positing a unique underlying morphological template for Jussive II.

(28) a. - -CCVC-

$$
\text { b. - CVCC- }
$$

Expressed in terms of syllable structure, these entities would have to be analyzed as in (27a) and (27b) respectively. It will be noted that in (27a) the initial $\mathrm{C}$ has to be syllabified as a coda of some preceding syllable. Now a consideration of syllable markedness might lead us to opt for (28a), since it contains a simpler syllable type, viz. C.CVC, and CVCC syllables are not only universally more marked [Kaye and Lowenstamm 1982], but are recognized as such by Chaha word structure, which tolerates them only finally. 
It would not seem possible to derive surface alternants containing the -CVCCstem without invoking a transformational rule of metathesis. Faced with an analysis requiring recourse to this sort of rule might incline us to drop the analysis of Jussive II as a single MC in favour of one with two MC's, thus reverting to Leslau's earlier analysis.

There is, in fact, another possibility open to us. I believe that it is not only possible but independently desirable to analyze occurrences of the high central vowel $i$ in Chaha verb forms as resulting from epenthesis, just as in Amharic. Thus, we are enabled to set up a unitary morphological template, viz. (29) - CCC-

A rule of epenthesis, which is sensitive to the relative sonorities of consonants that come to be associated with the last two $\mathrm{C}$ slots, derives the two alternants (cf. the case taken up in 2.2). It should be noted, however, that even with $\dot{\dagger}$ supplied epenthetically, no unique (homogeneous) syllabic structure can be assigned to (29).

1.3. Case 3: The Tigrinya (Type A) Imperfect. The Imperfect stem of the so-called Type A triliteral verbs in Tigrinya poses an interesting problem. An examination of the paradigm of $s-b-r$ 'break' given in (30) (pace Leslau [1941:Tableau VI]) reveals two stem alternants, the shorter of the two occurring whenever an inflectional suffix is added.

(30) Type A Imperfect

'I (etc.) am breaking'

\begin{tabular}{|c|c|c|}
\hline$? \dot{+}$ säbbłr & $1 p$ & $n \dot{t} a ̈ a ̈ b b \dot{+} r$ \\
\hline 2ms tisäbbir & $2 m p$ & $t$ tsäbru(ta) \\
\hline 2fs tisäbri & $2 \mathrm{fp}$ & $t \dot{t} s a ̈ b r a(t a)$ \\
\hline ns $y \dot{t}$ säbbir & $3 \mathrm{mp}$ & $y \dot{+s a ̈ b r u(t a)}$ \\
\hline Es $t \dot{t} s a ̈ b b \dot{t} r$ & $3 f_{p}$ & $y \dot{+s a ̈ b r a(t a)}$ \\
\hline
\end{tabular}

If we were to assume that the short alternant is closer to the underlying stem form, we should need to derive the gemination of the second radical, which would be an operation for which there would certainly be no motivation 
in the phonology of Tigrinya; word forms terminating in sequences of single $C+\dot{t}+C$ being not at all uncommon. If, however, we start with the longer form and (as for Amharic and Chaha) assume $\dot{t}$ to be epenthetic, a plausible analysis is available. This means that in terms of $C$ and $V$ the prosodic template would be -CVCCC-.13 Tigrinya syllable structure permits neither branching onsets nor multiply-branching rhymes; thus given a morphological representation for the $3 \mathrm{mp}$ such as

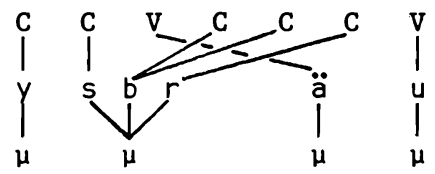

a rule degeminating the second radical and the insertion (post-lexically) of $\ddagger$ between the prefix and stem would render the form fully syllabifiable, viz.

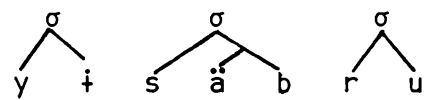

The other alternant preserves the gemination and achieves syllabification by means of $\dot{t}$-Epenthesis. (The relationship between degemination and $\dot{t}$-Epenthesis as alternative modes of rectifying inadequate prosodic structure is discussed in the case taken up in 2.3).

The stem alternations of the Tigrinya (Type A) Imperfect pose considerable difficulties for "Principle (55)". Making use of the theoretical device of null elements for handling gemination as proposed in Lowenstamm and Kaye's treatment of Tiberian Hebrew and Arabic (see especially pp. 117ff), we may posit a syllable-based definition for this MC such as (33),

13 I have made use of a simplified symbolization for gemination here, 1.e. as $C$. The fuller symbolization appears in example (38). Arguments which justify treating gemination as involving a special configuration on the Skeletal Tier are presented in Hayward [in preparation]. A brief discussion of the matter appears in the present paper in the introductory portion of section 2 . 
(33)

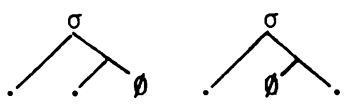

and derive the long alternant as in (34).

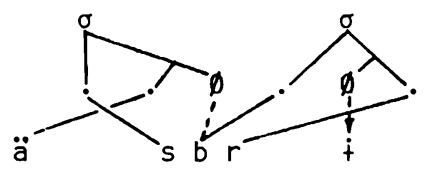

But it would seem 1ikely that whatever means we adopt for deriving the short alternant, we shall not be able in doing it to avoid changing the prosodic categories (onset, coda) for both the second and third radicals.

1.4. Case 4: The Harari (Type A) Imperfect. Like Tigrinya Harari does not permit multiply-branching rhymes; potential violations of this syllable structure condition are avoided by an epenthesis involving the vowel $i$. According to Kenstowicz and Kisseberth [1979:223-225], who follow Leslau [1958:17ff.], one situation where epenthesis is needed arises in those forms of the Imperfect that lack a (word-final) inflectional vowel, i.e. all members of the paradigm except $2 \mathrm{fs}, 2 \mathrm{p}$, and $3 \mathrm{p}$. Expressed in terms of $\mathrm{C}$ and $\mathrm{V}$, the template for the (Type A) triliteral Imperfect is -CVCC-. In the following paradigm of $\iota^{\prime}-m-k$ ' 'squeeze' epenthetically inserted vowels appear in phonetic brackets. ${ }^{14}$

(35) Type A Imperfect

'I (etc.) am squeezing'

1s ič'ämk'[i] $1 p \quad n[i] c^{\prime} a ̈ m k '[i]$

$2 m s \quad t[i] c{ }^{\prime}{ }^{\prime} a ̈ m k^{\prime}[i] \quad 2 p \quad t[i] c^{\prime}$ 'ämk'u

2fs $t[i] c^{\prime}$ ämk'i

$3 m s \quad y[i] c^{\prime} a ̈ m k^{\prime}[i] \quad 3 p \quad y[i] c^{\prime} a ̈ m k^{\prime} u$

3fs $t[i] c^{\prime} a ̈ m k^{\prime}[i]$

${ }^{14}$ It is not unlikely that the prethematic $i$ in the $1 \mathrm{~s}$ is also epenthetic. This can be maintained if we posit an underlying $X$ slot for the is prefix. This may be linked to the minimally specified consonantal segment, viz. [?] under certain conditions. Leslau [1958:3] does list glottal stop among 
The fact that epenthetic i appears word-finally means that throughout the paradigm the stem-final consonant maintains its prosodic categorization as an onset, viz.

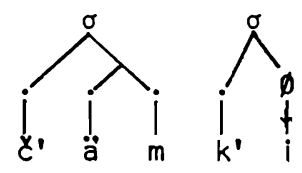

Harari then joins the Arabic case adduced by Lowenstamm and Kaye as evidence for their principle. But what does it amount to? Sometimes the principle holds, sometimes it doesn't. A statistical count of all the avallable relevant language data might or might not allow us to conclude that non-conformity to Principle (55) was the marked situation; this remains an empirical issue. We are, however, obliged to conclude that since a syllable-based defInition for morphological classes cannot be consistently applied, some form of Skeletal Tier is still necessary.

2. Analyses of the Amharic, Chaha, and Tigrinya Cases

In the remainder of the paper I present analyses of the cases in 1.1-1.3 and consider further data from Hararl which suggests that the analysis presented in the preceding section is not the entire story.

In the approach we have just reviewed, full prosodic structure is assumed to be present at an underlying level, with the result that an entity such as the Skeletal Tier turns out to be entirely derivative and, in consequence, redundant. The wholly opposite view would, of course, be to start with the Skeletal Tier and, after proper association of consonantal and vocalic melodies, derive prosodic structure by means of redundancy rules. However, given an Autosegmental approach to non-concatenative morphology such as McCarthy's, it does not seem possible that prosodic structure could be made entirely redundant. 15 The differential association of consonantal and vocalic

the phonemes of Harari, but he does not set one up for the 1 s prefix, nor, indeed, for any otherwise vowel-initial situations in words. I leave the matter open here since our concern for the moment is with word-final vowels.

${ }^{15}$ It is presumed, however, that prosodic structure could be erected en- 
melodies will require the presence of some differentiating mechanism in the Skeletal Tier. McCarthy's V and C elements, which serve to anchor the voca1ic and consonantal melodies, are, by definition, [+syllabic] and [-syllabic] respectively. Such an intrinsic distinction also provides the information required for an algorithm of syllabification. But, as the various examples discussed in Part I will have made clear, there is no guarantee that syllabification will be complete until the entire surface word is derived.

The arguments levelled against a CV skeleton of the type proposed by McCarthy (see Levins [1983:I2ff.], Archangeli [1984:183-185]), seem to the present writer to be quite compelling. The main point of the argument is that [syllabic] is not really a distinctive feature in the way that, say [coronal] or [1ow] are, and that "syllable-headedness", i.e. syllabicity, is expressed by means of the prosodic structure itself. Thus, it is claimed that a skeletal tier in which syllable heads are distinguished will provide just enough information for the association of vocalic and consonantal melodies, and will, at the same time, constitute an embryonic prosodic structure. Accordingly, CV-based morphological templates ${ }^{16}$ such as, for example, that of (37a), which defines the Jussive stem for Amharic quadriliteral verbs, will be replaced by a partially syllabified template such as that of (37b).
(37) a
CVCCVC
b. $\stackrel{1}{\operatorname{xxxxxx}}$

In fact, I would maintain that entities with such a limited vocabulary are not always adequate for the association of autosegmental melodies and that certain cases call for an enrichment of the representation [Hayward, in preparation]. It is marginally necessary to enter into this here because a discussion of the Tigrinya data confronts us with gemination. Let it suffice here simply to observe that geminate consonants are represented as two (nonsyllable head) skeletal slots linked to one element of the consonantal melody.

tirely by redundancy rules in languages not operating with distinct consonantal and vocalic melodies: cf. remarks by Levins [1983:22].

${ }^{16}$ Since it is being argued here that prosodic structure may be incomplete at the levels where morphological structure is assembled, it seems preferable to speak of "morphological" rather than "prosodic" templates, which was McCarthy's original term. 
However, rather than achleving this configuration by means of spreading (which presents certain technical difficulties), the two skeletal slots are prelinked to a single "receptor matrix". This is symboltzed as in (38).17 (38)<smiles>[X]CC([X])(I)I</smiles><smiles>[AlH2]</smiles>

Properly associated representations for the Perfect stem of an Amharic quadrilateral such as $g-\mid-b-t$ ' 'overturn' would appear as in (39).

(39) Perfect stem ( gäläbiät'- )

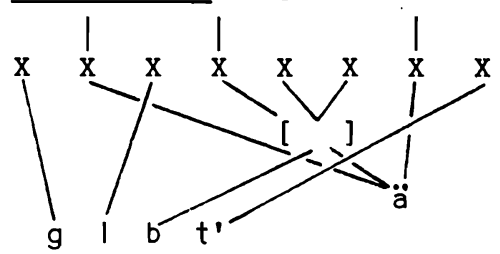

The arguments for this mode of representing gemination are too detailed to rehearse here. They appear in full in the paper referred to above.

We return now to an account of the Amharic data presented earlier.

2.1. Case I: The Amharic Jussive (Type A) Stem. In an earlier paper [Hayward 1986] I discuss a number of issues concerning Amharic syllable structure, but for the present purpose it is only necessary to note that there are no complex onsets in the language. This point, however, needs some clarification since there are many instances of word-initial (and hence syllable-initial) consonant $+w$ sequences, e.g.

(40) $[\hat{\mathrm{kw}}] \mathrm{as}$ 'ball'

[ ĝ̣ ]äddälä 'it got less'

[ $\widehat{b W}] a m[\widehat{b W}] a$ 'pipe'

$\left[t^{\top} w\right]$ at 'morning'

${ }^{17}$ Cf. also Smith's [1985] proposals vis à vis the representation of Invariant gemination. 


\section{[ mw ]äräd 'file'}

However, these are analysed as complex segments, rather than as complex (or branching) onsets, 1.e. as (41) rather than as (42) or (43).

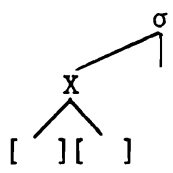

(42)

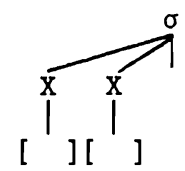

(43)

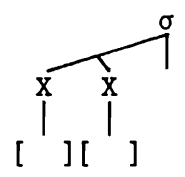

It is of interest that the capacity to express such a distinction formally is by no means unimportant. Differential behaviour is predicted by such structural distinctions. ${ }^{18}$ Thus, we might well expect the leftmost elements of the structure depicted in (42) or (43) to be capable of resyllabification (as a coda) word-internally, whereas we should not expect it for (41). With the exception of consonant $+w$ all types of consonant sequences in Amharic may be split by epenthetic processes and so require resyllabification [Hayward 1986:316-317]. This behaviour supports the analysis of such phonetic complexes according to the configuration of (41). It is not immediately obvious how the complex segment vs. complex/branching onset distinction would be expressed within a theory operating without a skeletal tier.

Although Amharic syllable structure does permit syllables with certain types of multiply-branching rhymes, no syllable of this type is permitted other than in word-final position. Onset-less syllables are also permitted, but are restricted to word-initial position. These distributional constraints can be expressed by means of Negative Word Structure Conditions such as the following ${ }^{19}$ (cf. Clements and Keyser's [1983:29] Negative Syllable

${ }^{18}$ It is clear that the configurations of (42) and (43) also present different structures, and if both are not available, which of the two best represents the nature of pre-rhyme complexity is an important theoretical issue. This is not taken up here.

${ }^{19}$ Idiosyncrasies of syllable distribution both here in Amharic and in Chaha (see (65)) are handled as word-structure properties. I have preferred this approach to one invoking considerations of extrametricality. Many languages appear to furnish phenomena requiring the recognition of the word as a domain exercising distinct phonotactic constraints. I suggest that such con- 
Structure Constraints):

(44)

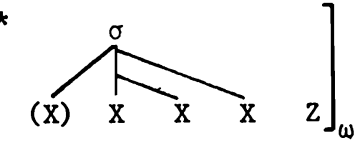

( $Z$ represents any permitted structure but may not be null.)

(That is, syllables with multiply-branching rhymes may not occur non-final$1 \mathrm{y.)}$

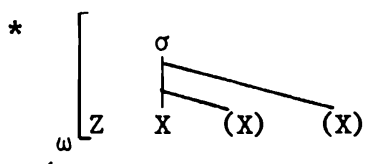

( $Z$ represents any permitted structure but may not be nu11.)

(That is, onset-less syllables may not occur non-initially.)

I assume a maximally general algorithm for syllabification such as (46).

(46) Syllabification

(1) Co-syllabify all skeletal slots to the left of a syllable head, subject to the (language-specific) constraints governing (a) onsets and (b) word structure.

(ii) Co-syllabify all skeletal slots to the right of a syllable head, subject to the (1anguage-specific) constraints governing (a) codas and (b) word structure.

As far as prosodic structure is concerned, morphological templates distinguish only those syllable heads that define the morphological class. Syllabification operates at all levels in the morphology (after the association of consonantal and vocalic melodies has taken place) as well as post-1exical1y. Unsyllabified elements (marked with a tick) are accomodated by the creation of syllable heads, i.e. by epenthesis. The epenthetic vowel is [ $\dot{\dagger}]$, which (following Archangeli [1984:38-64]) can be regarded as the maxima11y underspecified vowel of the language. Except when its derivation is impinged upon by some phonological rule (such as assimilation), all the distinctive feature values for the epenthetic vowel are supplied by redundancy rules.

straints govern the distribution of syllable types in the languages discussed here, though there seem to be cases where the distribution of particular segments requires reference to word structure. 
The template for the Type A Jussive stem is assumed to be as in (47).

(47)

$$
\mathrm{x} \quad \mathrm{x} \quad \mathrm{x} x
$$

Application of (46) to the underlying forms of the prefix-less second person forms of the paradigm, represented by the $2 \mathrm{~ms}$ form of (48), fails to accomodate the initial element.

$$
\left.\left.\int_{\mathrm{z}}^{\mathrm{x}}\right|_{\mathrm{a}} ^{\mathrm{x}}\right|_{\mathrm{n}} ^{\mathrm{x}} \quad \text { 'dance!' (2ms) }
$$

Creation of a syllable head after the unsyllabified element renders the latter syllabifiable as an onset, viz.

(49)

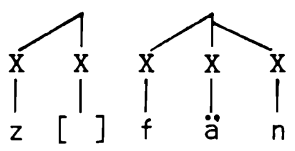

The prefixes of the remaining forms of the paradigm are single consonants underlyingly, with the result that there are two unsyllabified elements, viz. (50)

$$
\left.\left.\left.\left.\right|_{y} ^{x}\right|_{f} ^{x}\right|_{a} ^{x}\right|_{n} ^{x} \text { 'let him dance!' (3ms) }
$$

A single syllable head created after the leftmost element renders both of them syllabifiable, viz.

(51)

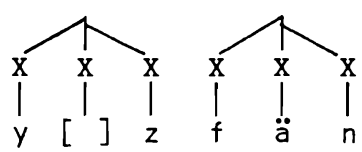

Since most occurrences of $\dot{t}$, which is a very common vowel in Amharic, are of an epenthetic nature, it is instructive to examine the rule(s) involved. In my earlier account it seemed necessary to distinguish as many as five distinct rules. Subsequent consideration, however, has made it appear 
possible to reduce this number. ${ }^{20}$ One matter that originally appeared to present a complication was gemination. Allowing syllabification to apply at all points in the derivation makes a rule such as (52) (operating progressively from left to right) perfectly adequate for items such as those in (53) :

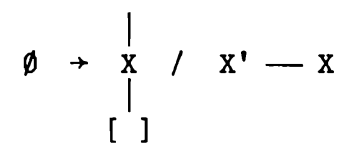

(That is, a syllable head is created after an unsyllabified skeletal slot.)

$$
\begin{array}{ll}
z[\dot{+}] \mathrm{fän} & \text { 'dance' } \\
y[\dot{+}] z f a ̈ n & \text { 'let him dance!' } \\
\mathrm{s}[\dot{+}] \mathrm{nt} & \text { 'how many/much?' } \\
\text { ayzäfn[ }[\dot{+}] \mathrm{m}(\mathrm{m}) & \text { 'he is not dancing' } \\
t[\dot{+}] \mathrm{nn}[\dot{+}] \mathrm{s} & \text { 'small' } \\
\text { etc. } &
\end{array}
$$

${ }^{20}$ One type of \pm -Epenthesis, described in Hayward [1986:317], Rule (39), remains intractable as far as unification is concerned. It is a rule that inserts $\dot{t}$ in front of words beginning with $r$, creating surface words such as irob 'Wednesday', †rguz 'pregnant', irk'ät' 'distance', etc. It might appear that this rule could be accommodated if we were to propose a Negative Word Structure Condition prohibiting syllables with $r$ as their onset consonant in word-initial position. However, the rule is optional for some lexical items, but obligatory for others. This is quite unlike the operation of of other i-Epenthesis rules, which are exceptionless. Furthermore, the pre$r i$-Epenthesis rule operates as an alternative to the regular $i$-Epenthesis

\begin{tabular}{|c|c|c|}
\hline & Case 1 & Case 2 \\
\hline Underlying Representation & $r g b$ & $r g b$ \\
\hline \pm -Epenthesis (lexical) & trgb & --- \\
\hline i-Epenthesis (post-1exica1) & trgib & $r \dot{t g} \dot{+} b$ \\
\hline
\end{tabular}
in words such as $\dot{t r g}+b \sim r \dot{+g}+b$ 'pigeon'. Pre-r $\dot{i}-$ Epenthesis might be analysed as a late lexical rule. This would explain the obligatory nature of its operation in some items only. In cases such as the word for 'pigeon' above, where the rule could optionally apply but happens not to (Case 2 below), we find that regular $i$-Epenthesis applies post-lexically, viz. 
Consider the derivation of the final item in the list in (53)

(54) Underlying Representation 21

Epenthesis (Rule 52)<smiles>[Y]C([Y])[Y]</smiles>

Syllabification (46)<smiles>[X]C([X])CC([Y])[X]</smiles>

Epenthesis (Rule 52)<smiles>[Y][X]C([Y])[X]C([Y])[Y]</smiles>

Syllabification (46)<smiles>[X][X]([Tl])CC([X])[X]</smiles>

Surface Form (after the redundancy rules have supplied features for the epenthetic vowel)

Rule (52) makes wrong predictions, however, in items such as the following.

${ }^{21}$ As used here the term "Underlying Representation" defines a form in which consonantal and vocalic melodies are already associated with the template and the erection of prosodic structure has proceeded as far as possible. Unsyllabified skeletal slots are marked with a tick. 
(55)
$[\dot{t}] \mathrm{dd}[\dot{\mathrm{t}}] \mathrm{I}$
$\left({ }^{*} \mathrm{~d}[\dot{+}] \mathrm{d}[\dot{+}] 1\right)$
'luck, lot, chance'
$[\dot{+}] z z[\dot{t}] \mathrm{h}$
$\left({ }^{*} z[\dot{+}] z h,{ }^{*}[\dot{+}] z[\dot{+}] \mathrm{h}\right)$
'here'
$[\dot{\dagger}] \mathrm{kkw}^{\mathrm{w}}[\mathrm{o}] \mathrm{l}$
$\left({ }^{*} k[+] k w[0] 1\right)$
'equal'
$\mathrm{t}[\dot{+}] \mathrm{n}[\dot{+}] \mathrm{nn}[\dot{\mathrm{t}}] \mathrm{s}$
$\left({ }^{*}+[\dot{\dagger}] \mathrm{nn}[\dot{\dagger}] \mathrm{n} s\right)$
'small (intensive, distribu- etc. tive)'

For this reason it was deemed necessary to provide a further rule, such as (56), which would be sensitive to the geminate configuration [Hayward 1986: 316]:

(56)

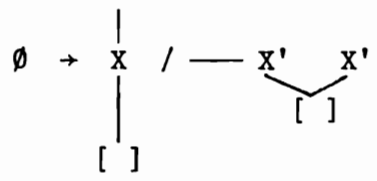

The derivation of the 1 tem $[\dot{\dagger}] \mathrm{dd}[\dot{\dagger}] \mid$ 'luck, lot, chance' would proceed as in (57).

(57) Underlying Representation

Epenthesis (Rule 56)
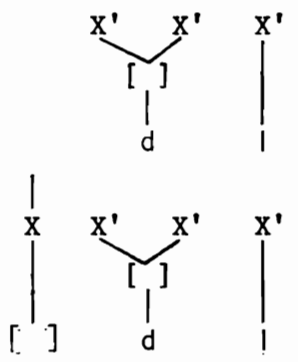

Syllabification (46)

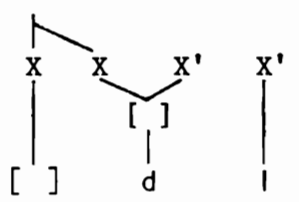

Epenthesis (Rule 52)

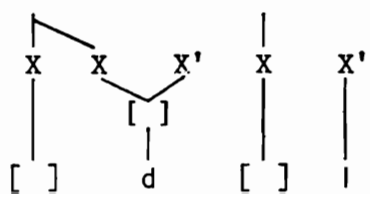


Syllabification (46)

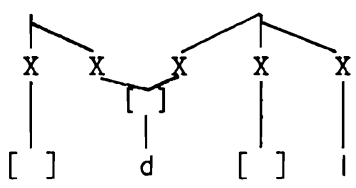

Surface form (after all

redundancy rules have applied) $\quad \dot{+d d} \dot{+}$

The real question, however, is whether Rule (56) is necessary. Rules such as (56) are devised in an essentially ad hoc way to prevent a general rule of epenthesis from "splitting" a geminate. But are geminates ever split? One of the surest universals we have in phonology concerns the "integrity" of geminates. 22 A constraint, stated tentatively as in (58), must surely be part of Universal Grammar.

Geminate Integrity Constraint

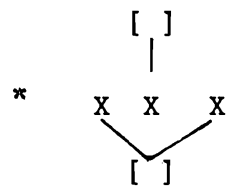

In dealing with the facts of Amharic may we not simply rely upon this universal constraint to overrule any mis-application of epenthesis rules such as (52)? Thus, while a grammar containing (56) might achieve a measure of descriptive adequacy, one without it, appealing intrinsically to Universal Grammar with (58), comes closer to achieving explanatory adequacy.

Rule (59) represents a fully revised rule for $i$-Epenthesis in Amharic. (It may be noted that another special rule, which had been set up for dealing with unsyllabified elements word-finally [Hayward 1986:314-315] is incorporated here according to the Elsewhere Condition.

$$
\left.\left.\emptyset \rightarrow\right|_{[} ^{\mid} /\left\{-x^{\prime}\right]_{\omega}\right\} \begin{aligned}
& a . \\
& b .
\end{aligned}
$$

${ }^{22} \mathrm{Claims}$ to this effect have been made repeatedly ever since the appearance of Kenstowicz and Pyle's classic article in 1973. 
(That is, if an unsyllabified skeletal slot occurs word-finally, create a syllable head to its left; otherwise, create a syllable head to its right.) 2.2. Case 2: The Chaha Jussive II Stem. According to Leslau [1964:53] the historical developement of Jussive II involved the merging of jussive forms with distinct vocalic melodies. This is illustrated here with reconstructed 3ms forms.

$$
{ }^{*}{ }^{*} y a-c_{1} c_{2} i c_{3} c_{2} u c_{3} \rightleftharpoons y a ̈-c_{1}+c_{2} c_{3} \sim y a ̈-c_{1} c_{2}+c_{3}
$$

For Chaha synchronically, as for Amharic, it seems entirely plausible to claim (for verbs at least) that $\dot{t}$ has now to be regarded as generated by epenthesis. No doubt neutralisation of the original contrast between the short high vowels in Jussive II forms contributed to this phonological restructuring. Elimination of $\dot{f}$ from the inventory of underlying elements in verb forms enables us to re-interpret the phonological history of the Jussive II stem depicted in (60) as in (61).

$$
{ }^{*}{ }^{*}{ }_{y a-c_{1}} c_{2} u c_{3} \rightarrow c_{3} \rightarrow y a ̈-c_{1} c_{2}+c_{3} \rightarrow y a ̈-c_{1} c_{2} c_{3}
$$

What then are the conditions under which \pm -Epenthesis in Chaha operates so as to generate the two surface variants? It should be pointed out straightaway that the distribution of the present-day -CC+C- and -CiCCalternants shows no correlation whatsoever with the original distinction in vocalism. That distinction is irrecoverable from internal reconstruction. The modern alternation relates entirely to considerations of syllable structure. A generalized syllable template for Chaha appears to be exactly like what one would propose for Amharic, viz.

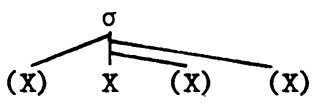

The template permits CV, CVC, CVCC, V, VC, and VCC syllable types. What is of immediate interest concerns the types of consonant clusters that are per- 
mitted within the rhyme. Earlier it was observed that the key determinant for the differential distribution of $\dot{t}$ in Jussive II forms seemed to be the relative sonorities of the second and third radicals. To account for this state of affairs formally requires reference to some scale of sonority. of the various suggestions that have been made for evaluating sonority and for making use of such values in linguistic description, e.g. Hankamer \& Aissen [1974], Hooper [1976], etc., Selkirk's [1984] proposal appears promising. Selkirk sets up a scale of sonority with numerical indices ranging from 10 (for the open vowel a ) to 0.5 (for the voiceless stops). Selkirk is careful to say that such indices are a "provisional assignment", but adds (p. 112):

"It is not clear whether the absolute integer value of the sonority indices assigned to each of these segment types is important. I assign absolute values for expository convenience, though for the moment I will assume that only the sonority relations expressed by the indices are important. Later we will see that in fact a purely relational characterization of the sonority hierarchy is inadequate and that some indication of absolute sonority values is needed after all."

Thus, she is fully aware that a successful exploitation of such a sonority hierarchy by linguists presupposes that definite sonority values for all segment types will eventually be established. An even more fundamental problem concerns the definition of sonority itself. Here, I believe that Selkirk [1984:111-112] is correct in stating that the programme of research that will provide the basis for such a necessarily phonetic definition will be the observation of the relative sonority values assigned to various segments in the phonologies of natural languages. For the present, however, I am only concerned with relative sonority in Chaha, and the hierarchy presented in (63) facilitates the expression of relevant patterning in rhyme clusters in that language. It will be observed that the scale starts with an assignment of an index of 1 to a class of segments that behave as the least sonorous sounds in the phonology of Chaha, an index of 2 is assigned to the next set, and so on. However, having insisted that the scale is language specific, it will nevertheless be immediately obvious that the classes defined correspond well with 
classes defined for simflar purposes in the phonologies of other languages. ${ }^{23}$

(63)

\begin{tabular}{|c|c|c|c|}
\hline \multicolumn{4}{|c|}{ obstruents } \\
\hline 1 & 2 & 3 & 4 \\
\hline$f$ & $s$ & $d$ & $\beta$ \\
\hline$t$ & & $\mathrm{~g}$ & (z) \\
\hline$x$ & & & \\
\hline $\mathrm{k}$ & & & \\
\hline$t^{\prime}$ & & & \\
\hline$k^{\prime}$ & & & \\
\hline
\end{tabular}

nasals iiquids glides

$\begin{array}{lll}5 & 6 & 7\end{array}$

m $\quad r \quad w$

n $y$

Utilizing (63) the following Negative Syllable Structure Condition is proposed for Chaha.

(64)

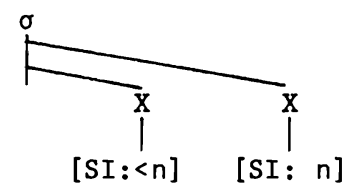

(That is, a rhyme cluster is not permitted in which the sonority index (SI) of the first (leftmost) member is less than that of the second member.)

Chaha shares with Amharic the two Negative Word Structure Conditions given in (44) and (45). The template in (65), which is proposed for the Jussive II stem, terminates in three consonants, i.e. a structure which does not allow an associated representation such as that in (66) for the $3 \mathrm{~ms}$ of $g-f-r$ 'release' to be fully syllabified.

(65)

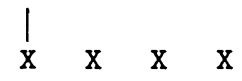

(66)

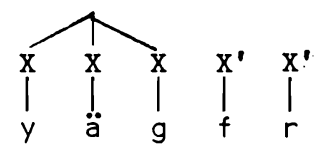

${ }^{23}$ The scale used here is set up then solely with the description of Chaha in mind. Although there is no intention here to attack Selkirk's Sonority Hierarchy, it may be of interest to note that in Chaha voiced and voiceless 
The presence of the final consonant ensures that only the $g$ will be cosyllabified with the initial syllable head; leftward co-syllabification of the $f$, even if (64) did not obtain, would be barred by Word Structure Condition (44).

As far as epenthesis is concerned the issue may be whittled down to the simple question of whether the relative sonorities of $\mathrm{C}_{2}$ and $\mathrm{C}_{3}$ are such as to allow them to constitute a rhyme cluster. If they can form such a cluster, 1.e. If (64) is not violated, epenthesis will create a syllable head after $C_{1}$, but if they cannot, epenthesis creates a syllable head after $C_{2}$. A Rule of epenthesis formulated for sensitivity to these conditions is proposed in (67).

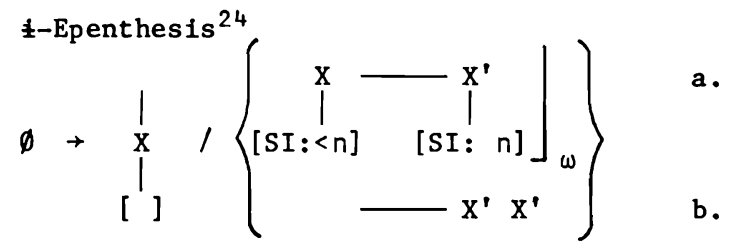

(That is, if an unsyllabified skeletal slot occurs word-finalily and it is linked to a segment which has greater sonority than that of the segment linked to the preceding skeletal slot, create a syllable head to its left; otherwise, create a syllable head to the left of two unsyllabified skeletal slots.) 25

fricatives do not pattern in accordance with her proposal [Selkirk 1984:112].

${ }^{24}$ The leftmost $X$ slot in the more specific environment of the rule is not marked as unsyllabified. This is because the same process applies in word-final sequences even when the string consists of only two consonants. In other words, it does not matter whether the penultimate consonant is unsyllabified or not.

25 One point to note is that rule (67) for Chaha makes final consonant clusters in Jussive forms the unmarked member of the pair of stem alternants, whereas if we follow Leslau, we must assume that their historical antecedent was uniformly of the shape *VCCVC. This evidence of reversal of the dominant pattern provides strong suppart for the interpretation advanced here to the effect that restructuring of the vowel system simply eliminated $\dot{t}$ phonologically. 
The operation of this rule is illustrated in the derivations of the $3 \mathrm{~ms}$ forms yäfk'łd. 'let him permit!' and yäk'tms 'let him taste!'.

(68). Underlying

Representations
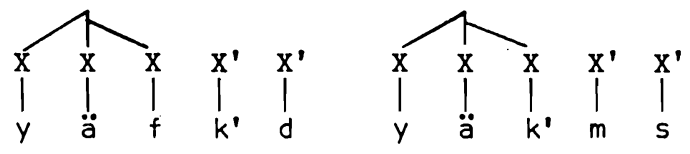

Epenthesis (67)
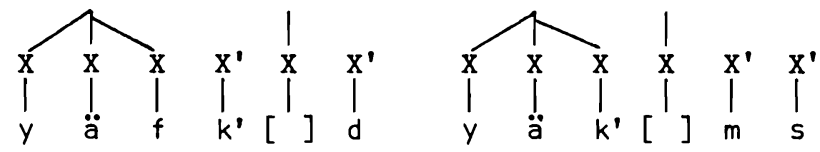

Syllabification
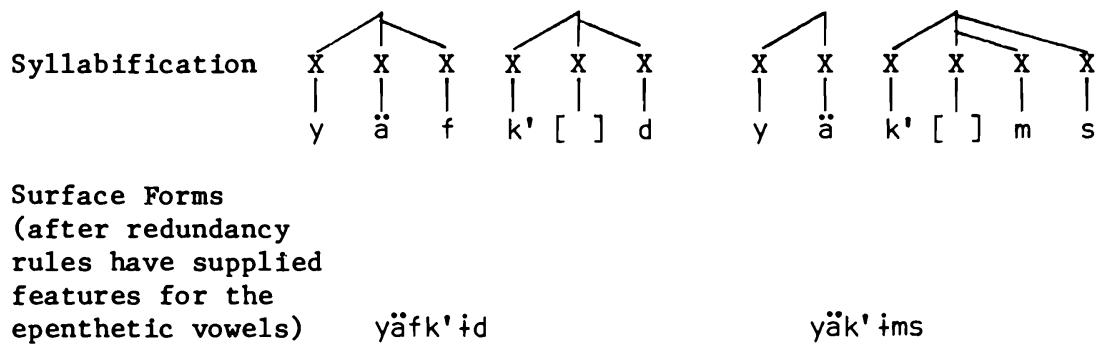

In Hayward [1986:314-315] some cases of epenthesis in Amharic were also described for word-final clusters. But Amharic does not employ the delicate selection mechanism of Chaha, where obstruents need several subdivisions. A gross distinction between obstruents and non-obstruents, i.e. "sonorants", is all that is required. Since both languages allow syllables with multiplybranched rhymes in word-final position, the difference between them reduces to one of Syllable Structure Conditions. The Amharic counterpart of the Chaha Negative Syllable Structure Condition in (64) is (69a), which could also be expressed as in (69b).
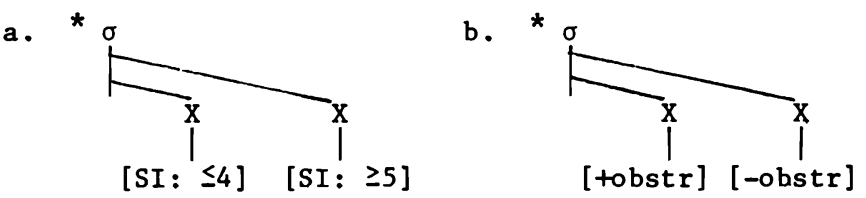

2.3. Case 3: The Tigrinya Imperfect. For three of the Ethioplan Semitic languages considered in this paper epenthesis rules that insert a high central vowel $\dot{f}$ have been postulated. In the fourth case (Harari) the epen- 
thesis involved the high front vowel ${ }^{\prime} i .26$ Furthermore, it has been claimed that every one of these rules is motivated by considerations of syllabification. The analysis sketched out in section 1 for the stem in the Imperfect of Type A verbs in Tigrinya raises an important question concerning the stage in the morphology/phonology at which \pm -Epenthesis takes place because an alternative to \pm -Epenthesis is available for Tigrinya in the shape of a rule of Degemination. Since both rules "conspire" towards the same end, 1.e. the complete syllabification of the surface word, it is necessary to determine the precise conditions under which each rule operates. The template hypothesized for the stem in question is shown in (70):

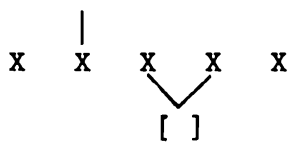

Seen from the point of view of phonology per se there is no obvious reason why suffixation of the vowel-initial suffixes in $2 \mathrm{fs}$, etc. (see (30)) should trigger Degemination; $\pm-E p e n t h e s i s$ would have been just as effective in rendering these forms syllabifiable, as can be seen by a consideration of the $2 \mathrm{fs}$ form. (In the derivation in (71) an \pm -Epenthesis rule is assumed to operate very much as in Amharic, and, as far as the verb forms under discussion are concerned, this assumption seems to be a reasonable one.)

(71) Underlying Representation

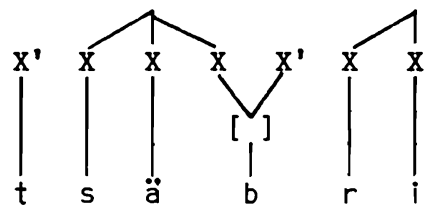

Epenthesis (two applications)

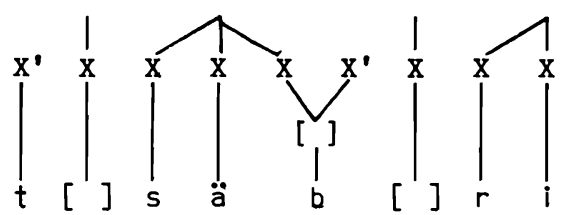

${ }^{26}$ Even in Harari this vowel is often centralized in its pronunciation. 
Syllabification (46)

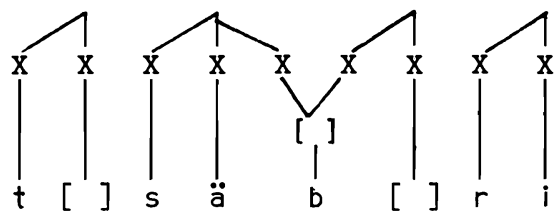

Eventual surface form

tłsäbbłri

In fact, $t+i$ äbbiri is incorrect, but there is nothing 111 -formed about the word phonologically. The 2fs form of the Jussive of a Type $B$ word such as $f-s^{\prime}-m$ 'finish (tr.)' in Tigrinya presents just such a surface structure, viz. (?ay)tifäs's'tmi. The non-occurrence of such a form as *tisäbbiri must be attributed in part to morphological factors. 27 The conjunction of the vocalic suffixes (found in $2 \mathrm{fs}, 2 \mathrm{mp}, 2 \mathrm{fp}, 3 \mathrm{mp}, 3 \mathrm{fp}$ ) together with (imperfect] and [Type A] defines the conditions under which Degemination takes place. Together with the appropriate suffixes the degeminated alternant offers no obstacle to a satisfactory syllabification. (It will be noted, however, that 1 -Epenthesis will still be required to handle the junctural clusters of prefix and stem.) The remaining forms, in which the full set of requisite morphological features do not co-occur, do not undergo Degemination, though subsequently they all undergo \#-Epenthesis.

Given the model of Lexical Phonology, this sort of behaviour can be ac-

"...the Harari vowel $i$ is often interchanged with $\partial[=\dot{t}$ as employed here-RJH in Harari itself and corresponds to the vowel $a[=\dot{R} \mathrm{RH}]$ of the other Ethiopic languages." [Leslau 1958:4]

${ }^{27}$ Kenstowicz [1982:110] also clearly regards the stem shape alternation in the Tigrinya Type A Imperfect as morphological, though he does not suggest that it is in any way motivated by concerns of syllable structure. I assume Degemination to be something like the following. (The rule is illustrated with 2 fs tisäbri 'you(f) broke (sthg)'.

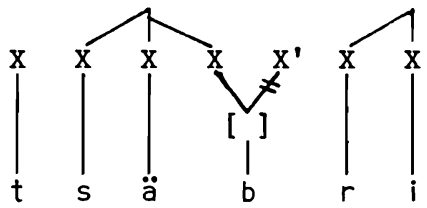


commodated without difficulty. ${ }^{28}$ Tigrinya Degemination is clearly a rule constrained to apply only at a particular lexical level, in this case the level at which inflectional suffixes are introduced. For Tigrinya, as indeed for all the languages discussed here, i-Epenthesis has to be seen as a postlexical rule, 1.e. a truly exceptionaless phonological rule triggered by purely phonological determinants.

The same model explains very well the problem in Harari discussed by Kenstowicz and Kisseberth [1979:233-235]. Examination of the Type A Imperfect of Harari (given above in (35)) shows that the final $i$ of the $2 \mathrm{fs}$ form is hypothesized as an underlying vowel. (It is, in fact, cognate with the $2 \mathrm{fs}$ $-i$ suffix of Tigrinya, which we have just considered.) For many verbs $2 \mathrm{fs}$ and $3 \mathrm{fs}$ forms are identical, though in the latter, final $i$ is claimed to be epenthetic. However, in triliteral verbs in which $\mathrm{C}_{3}$ is a coronal, palatalization occurs in $2 \mathrm{fs}$ forms, but not in $3 \mathrm{fs}$ forms, e.g.

2fs Imperfect
tič'ämk'i
tilämy i
tiläbši
tinädyi

Moreover, as Leslau [1958:18] observes:

"The palatalization can also affect the 1 st or 2 nd radical of the root if it is a dental, liquid or sibilant. Thus, tišäbri, from sbr 'break'; tikäčbi, from ktb 'write'; tič'älfi, from t'lf' 'rob'; ..."

Very clearly palatalization, occasioned by suffixation of the $2 \mathrm{fs}$ inflection, is a rule restricted to a specific lexical level-probably the same level as that at which Degemination takes place in Tigrinya.

It will be recalled that the discussion of the Harari Type A Imperfect in Part I conceded that the phonology of the language provide support for the putative "Principle (55)". I should like finally to look at a further aspect

${ }^{28}$ For a good overview of the model the reader is referred to Kaisse and Shaw [1985]. 
of Harari verb morphology that suggests that Harari too is at heart a nonconformist with respect to the said principle.

A side-by-side inspection of the Jussive and Imperative forms for Type A verbs in Harari, as in (73), would seem to suggest that postulation of a single paradigm as argued for Amharic (see the case in section 1.1) would be fraught with difficulties.

\begin{tabular}{|c|c|c|}
\hline & Jussive & Imperative \\
\hline 1s & näć'mäk' & \\
\hline $2 \mathrm{~ms}$ & & č' Imäk' \\
\hline $2 f s$ & & c'imäk' l \\
\hline $3 \mathrm{~ms}$ & yäč'mäk' & \\
\hline $3 \mathrm{fs}$ & täč'mäk' & \\
\hline $1 \mathrm{p}$ & näč'mäk' & \\
\hline $2 p$ & & č'imäk'u \\
\hline $3 p$ & yäc'mäk'u & \\
\hline
\end{tabular}

In fact Leslau [1958:25-26] does make precisely this claim. He achieves this by analyzing the prethematic $\ddot{a}$ (in the non-Imperative forms) as part of the prefix, rather than as part of the stem, 1.e. as 1s nä-č'mäk', 3ms, yä-č'mäk', 3fs tä-č'mäk', etc. This enables him to set up the common canonical form $-\mathrm{C}_{1}(\mathrm{i}) \mathrm{C}_{2} \mathrm{a}_{3}$ - for the Jussive/Imperative of Type A triliteral verbs. The longer stem alternant E'Imäk'-, found in Imperative forms, ${ }^{29}$ can wel1 be accounted for by epenthesis. ${ }^{30}$ If this is the case, then we have a further instance of a consonant in a morphological class behaving at certain times as a coda and at others as an onset, viz. (74)

a.<smiles>[Y][C]([CH])[CH]</smiles><smiles>[Y][C]([CH])[TlH]</smiles>

a.<smiles>[Te]CI</smiles><smiles>[Y][C]([Te])[TlH]</smiles>

${ }^{29}$ It is also found throughout the negative.

${ }^{30}$ Leslau does not actually say this, but his representation of the $i$ in parenthesis, plus his explicit recognition of final $i$ as "euphonic" in forms with consonant clusters stem-finally, suggests a tacit recognition of the status of this vowel. 
The crux of Leslau's analysis is the analysis of $\ddot{a}$ with the prefixes. But is this either desirable or necessary? I believe it is undesirable since it obliges us to posit morphologically determined allomorphy for these prefixes, i.e. yä-, tä-, etc. with the affirmative Jussive stem, but $y^{-}$, $t-$, etc. elsewhere.

Moreover, reflection on the principled behaviour of vocalic elements in the verb systems of Ethiopian Semitic languages in general makes it possible to suggest an alternative. It has been claimed [Taddese Beyene, forthcoming] that underlyingly the Amharic verb system employs just one vowel, namely, the mid central vowel ä. The significance of this insight, when viewed from the vantage point of a model of phonology utilizing Autosegmental and Underspecification theories is developed in Hayward and Watson [in preparation]. Furthermore, the insight carries over to many aspects of verb morphology in other Semitic languages of Ethiopia. This is not the place to enter into a discussion of how fully Taddese Beyene's claim can be substantiated, but in our forthcoming paper we demonstrate that at all lexical levels the monovocalic melody, ${ }^{31}$ which in the default case comes to be realised as $\ddot{a}$, is associated with any skeletal slot functioning as a syllable head. Moreover, as exemplified by comparison of the Perfect and Imperfect 3ms imperfect forms of the Type A Passive stem in Harari, ä can be associated with a skeletal slot preceding that associated with the first consonant radical.

(75) a. Perfect täk'äbära

'he was buried'

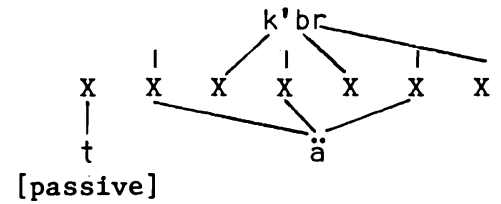

b. Imperfect yitk'äbär

'he will be buried'

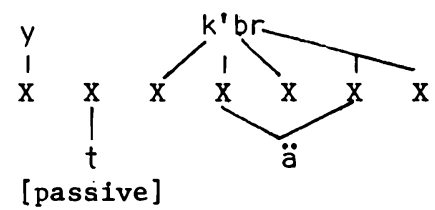

${ }^{31}$ In accordance with the insights of Underspecification Theory, this vowel could be distinguished simply as [-high], though see Hayward and Watson [in preparation]. 
There is some evidence which can be used to argue that $\ddot{a}$ may spread to skeletal slots altogether outside the template itself. In Harari, for example, all the object pronoun suffixes (except the $3 \mathrm{fs}$ form) have alternants with $\ddot{a}$. These alternants occur with those verb forms which do not have a final vowel inflection, viz.

(76)

3ms subject
yigädl -äx 'he kills you(m.)'
yigädl -än̆ 'he kills me'
yägdäl -äs 'may he kill
you(f.)!'

$3 \mathrm{p}$ subject yigädlu-x 'they kill you(m.)' yigädlu-n̆ 'they kill me' yägdälu-š 'may they kill you(f.)!'

If we assumed that these object suffixes are underlyingly consonant-initial, the occurrence of the $\ddot{a}$ could be seen as comparable to that of the epenthetIc (post-1exical) $i$ for Harari, i.e. as supplying prosodic structure. In such a case we would have a morphologically determined creation of a syllable head. ${ }^{32}$ Here, however, phonic substance might become associated with the new slot by assimilation, as in the derivation in (77) of yigädlän̆ 'he kills me'.

(77)

Underlying Representation<smiles>[Y][X]C([X])C([X])O</smiles>

${ }^{32}$ The argument might appear to be weakened by the fact that $\ddot{a}$ appears (with the same distribution) together with the plural forms, e.g.

Imperfect ( $3 \mathrm{~ms}$ subject)

yigädl -äna 'he kills us'

yigädl -äxu 'he kills you(p)

yigädl -äyu 'he kills them'
Jussive ( $3 \mathrm{~ms}$ subject)

yägdäl -äna 'may he kill us!' yägdäl -äxu 'may he kill you(p)!'

yägdäl -äyu 'may he kill them!'

Consideration of the Jussive forms shows that no violation of syllable structure would occur if $\ddot{a}$ were not present. We have probably to reckon with analogical levelling to explain these plural forms. But it has to be recalled that we are considering patterns that should be regarded as lexicalized from a synchronic point of view, i.e. forms where fully phonological explanations are no longer possible. 


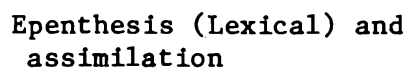

Surface Form

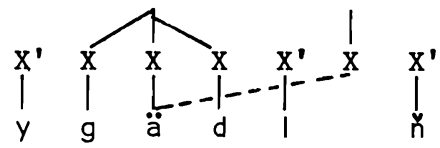

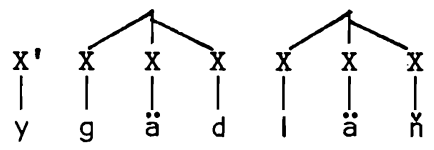

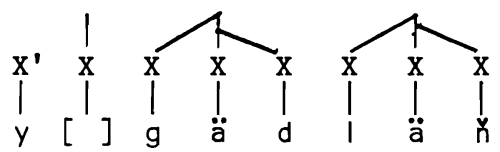

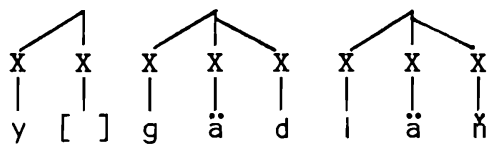

\section{yigädlän}

The view that the vocalic melody may extend its influence beyond its primary and proper domain, i.e. the stem, is in some ways reminiscent of vowel harmony.

Returning to the Harari Type A Jussive it is now possible to suggest that the prethematic ä in näc'mäk', etc. results from just such a lexical attempt to resolve an unsyllabifiable string, as was outlined for the object suffixes. The morphological restrictions on this process are comparable to those governing the rule of Degemination in Tigrinya, for example. Both processes have to be sharply distinguished from fully pervasive post-lexical processes such as $t$-Epenthesis.

\section{Conclusion}

In section 2 of this paper I have proposed a series of analyses for morphological alternations found in several African Semitic languages. In every case the analysis has depended heavily upon a particular theoretical construct, namely, the Skeletal Tier. The analyses would not have been possible without this entity. The analyses themselves then furnish evidence for the value of the Skeletal Tier, and so complement the arguments adduced in Section 1, which attempted to demonstrate that a recent proposal to define morphological templates in strictly prosodic (syllable-based) terms was untenable. 


\section{REFERENCES}

Alemayehu Haile and R.J. Hayward. in preparation. "An autosegmental approach to certain well-known Irregularities in the Amharic Verb." Ms.

Archangeli, D. 1984. "Underspecification in Yawelmant phonology and morpho1ogy." Ph.D. dissertation, MIT.

Clements, G.N. 1986. "Compensatory lengthening and consonant gemination in LuGanda." In L. Wetzels and E. Sezir (eds.), Studies in Compensatory Lengthening. Publications in Language Sciences 23, pp. 37-77. Dordrecht: Foris Publications.

Clements, G.N. and S.J. Keyser. 1983. CV Phonology: a Generative Theory of the Syllable. Linguistic Inquiry Monograph 9. Cambridge, MA: MIT Press.

Cohen, M. 1936. Traitê de langue amharique (Abyssinie). Paris: Institut d'Ethnologie.

Dawkins, C.H. 1960. The Fundamentals of Amharic. Addis Ababa: Sudan Interior Mission.

Halle, M. and J.-R. Vergnaud. 1978. "Metrical structure in phonology." Unpublished paper, MIT.

Halle, M. and J.-R. vergnaud. 1980. "Three dimenstonal phonology." Journal of Linguistic Research 1:83-105.

Hankamer, J. and J. Aissen. 1974. "The sonority hierarchy." In Bruck, A., R.A. Fox and M.W. LaGaly (eds.). Papers from the Parassession on Natural Phonology, pp. 131-145. Chicago Linguistics Society, University of Chicago.

Hayward, D.(R.J.). 1986. "The high central vowel in Amharic: new approaches to an old problem." In J.A. Fishman et al (eds.), The Fergusonian Impact. Vol. I: From Phonology to Society, Pp. 301-325. Berlin: Mouton de Gruyter.

Hayward, R.J. in preparation. "Concerning the interrelationship of templates and melodies in Semitic morphology." Ms.

Hayward, R.J. and J. Watson. in preparation. "Multiple non-specified segments." Ms.

Hetzron, R. 1972. Ethiopian Semitic: Studies in Classification. Journal of Semitic Studies Monograph No. 2. Manchester: Manchester University Press.

Hetzron, R. 1977. The Gunnän-Gurage Languages. Studi di Semitistica e del Vicino Oriente Antica publicati a cura di Giovanni Garbini. Ricerche XII. Napoli: Istituto Orientale di Napoli.

Hooper, J. Bybee. 1976. An Introduction to Natural Generative Phonology. New York: Academic Press. 
Itô, J. 1986. "Syllable theory in prosodic phonology." Ph.D. dissertation, University of Massachusetts, Amherst.

Kaisse, E.M. and P.A. Shaw. 1985. "On the theory of lexical phonology." In C. Ewen and J. Anderson (eds.), Phonology Yearbook 2, pp. 1-30. Cambridge: Cambridge University Press.

Kaye, J. and J. Lowenstamn. 1982. "Syllable structure and markedness theory." In A. Belleti, L. Brandi and L. Rizzi (eds.), Theory of Markedness in Generative Grammar. Proceedings of the 1979 GLOW Conference, pp. 287-316. Pisa: Scuola Normale Superiore.

Kenstowicz, M. 1982. "Gemination and spirantization in Tigrinya." Studies in the Linguistic Sciences 12(1):103-122.

Kenstowicz, M. and C. Kisseberth. 1979. Generative Phonology: Description and Theory. New York: Academic Press, Inc.

Kenstowicz, M. and C. Pyle. 1973. "On the phonological integrity of geminate clusters." In M. Kenstowicz and C.W. Kisseberth (eds.), Issues in Phonological Theory, pp. 27-43. The Hague: Mouton.

Leslau, W. 1941. Documents tigrigna (êthiopien septentrional). Paris: La Société de Linguistique de Paris.

Leslau, W. 1951a. "Archaic features in South-Ethiopic." Journal of the American Oriental Society 71:212-230.

Leslau, W. 1951b. "Le type läbsä en gouraguée." Rassegna di Studi Etiopici $10: 85-98$.

Leslau, w. 1958. The Verb in Harari (South Ethiopic). University of California Publications in Semitic Philology, Vo1. 21. Berkeley and Los Angeles: University of California Press.

Leslau, W. 1964. "The Jussive in Chaha." . Language 40:53-57.

Leslau, W. 1983. Ethiopians Speak. Studies in Cultural Background. Part $V$. Chaha - Ennemor. Athiopistische Forschungen. Herausgegeben von Ernst Hammerschmidt. Wiesbaden: Franz Steiner Verlag GMBH.

Levins, J. 1983. "Reduplication and prosodic structure. Unpublished ms., MIT.

Lowenstamm, J. and J. Kaye. 1986. "Compensatory lengthening in Tiberian Hebrew." In L. Wetzels and E. Sezer (eds.), Studies in Compensatory Lengthening, pp. 97-132. Publications in Language Sciences 23. Dordrecht: Foris Publications.

McCarthy, J. 1979. "Formal problems in Semitic phonology and morphology." Ph.D. dissertation, MIT.

McCarthy, J. 1981. "A prosodic theory of nonconcatenative morphology." Linguistic Inquiry 12:373-418.

McCarthy, J. 1982. "Prosodic organization in morphology." Unpublished ms, University of Texas at Austin. 
Nearthy, J. 1983. "A prosodic account of Arabic broken plurals." In I.R. Dihoff (ed.). Current Approaches to African Linguistics (Vol. 1), pp. 290-320. Publications in African Languages and Linguistics 1. Dordrecht: Foris Publications.

Selkirk, E. 1981. "Epenthesis and degenerate syllables in Cairene Arabic." In $\mathrm{H}$. Borer and $\mathrm{Y}$. Aoun (eds.), Theoretical Issues in the Grammar of Semitic Languages, pp. - MIT Working Papers in Linguistics 3. Cambridge, MA: Department of Linguistics and Philosophy, MIT.

Selkirk, E. 1984. "On the major class features and syllabic theory." In M. Aronoff and R. Oehrle (eds.), Language Sound Structure, pp. 107136. Cambridge, MA: MIT.

Smith, N. 1985. "Spreading, reduplication, and the default option in Miwok nonconcatenative morphology." In H. van der Hulst and N. Smith (eds.), Advances in Nonlinear Phonology, pp. 363-380. Dordrecht: Foris Publications.

Taddese Beyene. forthcoming. "A monovocalic analysis of the Amharic verb." Ms.

van der Hulst, H. and N. Smith. 1985. "The framework of nonlinear generative phonology." In $\mathrm{H}$. van der Hulst and N. Smith (eds.), Advances in Nonlinear Phonology, pp. 3-55. Dordrecht: Foris Publications. 


\title{
DISTINCTIVE NASALITY IN KWAWU:
}

A PROSODIC ACCOUNT

Outi Bat-E1

UCLA

\begin{abstract}
Nasality in Kwawu is distinctive in vowels but predictable in consonants. This uncommon distribution is interpreted here in prosodic terms. It is claimed that the feature [+nasal] is represented on morae rather than on individual segments. The assignment of the feature [+nasal] is integrated with syllabification rules, which explains the prosodic characteristics of nasality. Further evidence is drawn from the distribution of nasality in reduplicated forms; the moraic representation of the feature [+nasal] is crucial for the analysis of reduplicated $\mathrm{CV}$ stems.
\end{abstract}

\section{Introduction}

Kwawu, spoken in the Eastern Region of Ghana, is a dialect of Akan, a member of the Kwa sub-branch of the Niger-Congo Family. ${ }^{1}$ This article is concerned with nasality in Kwawu, in particular the correlation between the syllable structure and the distinctive distribution of the feature [nasal] (where distinctive distribution refers to representations prior to local assimilation rules). Like in other dialects of Akan (see Schachter and Fromkin [1968] and Dolphyne [1987]), nasality in Kwawu is distinctive in vowels only, while predictable in consonants. I will argue that this uncommon distribution of nasality can be best accounted for in prosodic terms, and suggest that the feature [+nasa1] is underlyingly represented on the mora, from where it percolates to the segments dominated by this mora, while [-nasal] is assigned by default. The direct relation between the syllable structure

${ }^{1}$ I wish to thank Mr. Yaw Ntiamoah Agyakwa for his consultant work. Mr. Yaw was born and raised in Obomen, Kwaws, and lived in Kumase, Asante for 4 years. 
and nasality is demonstrated by the incorporation of the assignment of nasality with syllabification rules.

Further evidence for this proposal is given by the distribution of nasality in reduplicated forms. Reduplication in Kwawu is roughly a stem copy, with some modification of the copied vowel in monosyllabic stems. Deviation from this generalization is exhibited by Cã stems, where C is oral; in this case the feature [+nasal] is not copied. I will argue on independent grounds that in Kwawu $a$ is underspecified, thus represented by an empty root node, and assume that [+nasal] cannot percolate to an empty node. Reduplication, which does not copy the moraic tier, applies before the empty node is specified and thus before the feature [+nasal] is 1icenced to percolate. Therefore, the copied segmental material does not include the feature [+nasa1].

The article is organized as follows. In section 1 I present the syllable structure in Kwawu, with particular emphasis on CVN syllables (where $N$ stands for a nasal consonant), whose structure is ambiguous amongst languages. I then propose a set of syllabification rules which derive all permissible syllables. In section 2 I examine the distinctive distribution of nasality, and point out the disadvantages of a linear analysis which assumes that the phonemic inventory of the language consists of oral vowels, nasal vowels, and oral (but not nasal) consonants. I will then offer a representation in which the feature [+nasal] is underlyingly specified on the mora. The benefit of this representation is reflected by the direct relation between the syllable structure and the distinctive distribution of nasality. I will show that the distinctive distribution of nasality can be properly incorporated into syllabification rules, which explains its prosodic characteristics. Further evidence for this proposal is given in section 3 where the behaviour of the feature [tnasal] in reduplicated forms is perused. I will show that the peculiar behaviour of nasality in reduplicated forms can be best accounted for under the assumption that [+nasal] is represented on the mora.

1. The Syllable Structure

The syllable structure in Kwawu is a crucial factor in the analysis of the distinctive distribution of nasality proposed here. In section $1.1 \mathrm{I}$ outline the theoretical concepts relevant to my discussion, pointing out the 
advantages of the moraic theory for the present analysis (the reader is referred to the references mentioned there for more comprehensive exposition). In section 1.2 I examine the syllable structure in Kwawu, in particular the structure of CVN syllables, which are known to be ambiguous with respect to their moraic structure. I then propose a set of syllabification rules which derive all possible syllable structures.

1.1. Theoretical background. Considerable attention has been given in recent work to the study of the syllable structure, where two fundamentally different structures have been proposed to account for various syllable-sensitive phenomena: the more traditional onset-rhyme structure (see Clements and Keyser [1983] for discussion and references) and the moraic structure (Hyman [1985], McCarthy and Prince [1986], and Hayes [1988]). Both views crucially distinguish between light and heavy syllables, as this contrast has been found to play a major role in phonological processes.

(1) a. The onset-rhyme structure

Light

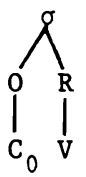

b. The moraic structure

Light

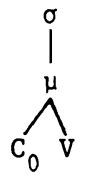

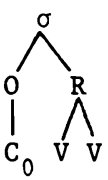

Heavy

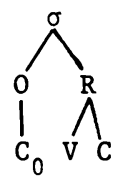

Heavy
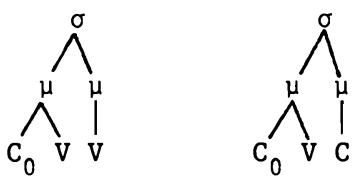

$\mu=$ mora

In the onset-rhyme structure a heavy syllable is characterized by complex rhyme, while in the moraic structure a heavy syllable is characterized by two morae. The distinction between the two types of structure relevant to the present discussion rests on the constituent elements in a heavy $\mathrm{C}_{1} \mathrm{VC}_{2}$ syllable. In the onset-rhyme structure $V$ and $C_{2}$ form a constituent $\left(\left[\mathrm{C}_{1}\left[\mathrm{VC}_{2}\right]\right]\right)$, while in the moraic structure $C_{1}$ and $V$ form a constitutent 
$\left(\left[\left[C_{1} V\right] C_{2}\right]\right)$. Nasality in Kwawu provides strong evidence for the moraic syllable structure, since $C_{1}$ and $V$ must agree in nasality, while $V$ and $C_{2}$ must not. Only in the moraic structure are $C_{2}$ and $V$ exclusively dominated by a mora, and as will be argued later on, the mora is the domain of nasality. ${ }^{2}$

The moraic structure, unlike the onset-rhyme structure, reflects the cross-linguistic distinction between heavy and light CVC syllables. As argued in Hayes [1988], some aspects of the syllable structure are languagespecific. In languages whose phonology does not manipulate any weight distinction or treat CVC and CV syllables alike (as opposed to CVV syllables, if any), a CVC syllable is monomoraic. Alternatively, in languages which provide evidence for weight distinction or treat CVV and CVC syllables alike (as opposed to CV syllables), a CVC syllable is bimoraic. A different type of evidence is given here to show that in Kwawu a CVC syllable is bimoraic, but due to dialect interaction some CVC syllables are interpreted as monomoraic for the purpose of one process only.

A somewhat different syllable structure is assumed in McCarthy and Prince [1986] and Hayes [1988], where it is suggested that the prevocalic consonant is not linked to the mora of the first vowel as in (2a), but rather directly to the syllable node, as in (2b):

(2) $\mathrm{a}$.

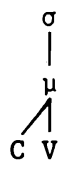

b.

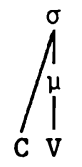

The structure in (2b) is found unsuitable for Kwawu, since the prevocalic consonant and the vowel must form a constituent for the purpose of nasality, therefore both should be dominated by the same mora. I presume that structures (2a) and (2b) are chosen on language-specific grounds, as is the case with postvocalic consonants mentioned earlier, i.e. that in the CVC syllable the final $C$ can be linked to the mora of the vowel, or to an independent mora.

${ }^{2}$ See Hayes [1988] for a discussion presenting arguments for the advantages of the moraic structure. 
The moraic theory neatly accounts for the distinction between short and long vowels and diphthongs. Short vowels and diphthongs are linked to one mora, while long vowels and diphthongs are linked to two morae.

short

vowe1 diphthong

$\left.\right|_{v} ^{\mu}$

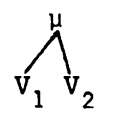

long

vowe1 diphthong

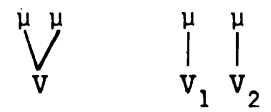

The syllable structure is derived by universal rules subject to language specific constraints. The first rule, as proposed in Hyman [1985], is the Onset Creation rule, which links a consonant to the mora of the following vowe1. Hyman assumes that each segment is underlyingly linked to a mora. Therefore, the mora of the prevocalic consonant is deleted. Hayes [1988] raises the problems posited by the assumption that all segments are underlyingly linked to a mora. This representation does not distinguish between high vowels and their corresponding glides. Since high vowels tend to alternate with glides, it has been assumed that glides and vowels have the same melodic features. But if both are underlyingly linked to morae there is no way to distinguish between $u$ and $w$ or $i$ and $y$. Therefore Hayes suggests, following Guersse1 [1986], that only vowels are lexically linked to morae, while consonants are free.

(4) high vowels<smiles>I[Tl]</smiles>

glides

i u

The assumption that vowels are underlyingly linked to morae is crucial to the analysis proposed here, since the mora must be given underlyingly in order to host the feature [+nasal].

Assuming that vowels are underlyingly linked to morae we must then abandon the claim that underlying representations are subject to the obligatory Contour Principle (OCP), which prohibits identical adjacent (auto) segments. As shown in Janeway [1987], Luganda permits sequences of glides and high vowels, as in kuwummula 'rest' and kusilyiika 'scorch'. Three possible 
structures can be assumed for these forms, but only one seems appropriate:

(a) If we assume that onsets are linked to the syllable node and that the OCP is in force, the resulting representation (5a) is rather odd. As noted by Janeway [1987:28],

"The oddness of this representation is no argument against 1 , but it does have implications. First, prosodic well-formedness conditions must be revised to allow ambisyllabic vocalic melodies... Second, this predicts that in a language which has such forms, and also some rule that alters the featural specification of vowels (e.g. $i \rightarrow e / \ldots$ ), then the entire melody will undergo this rule."

(b) If we assume that a prevocalic consonant is linked to the mora and the OCP is in force (5b), the underlying representation, would not reflect the correct surface form.

(c) Therefore it is assumed that the prevocalic consonant is 1inked to the mora and that the OCP is not in force $(5 c)$.

(5) a.
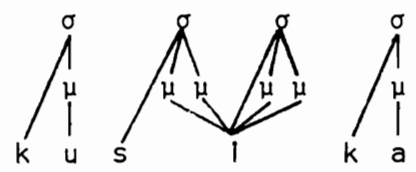

b.
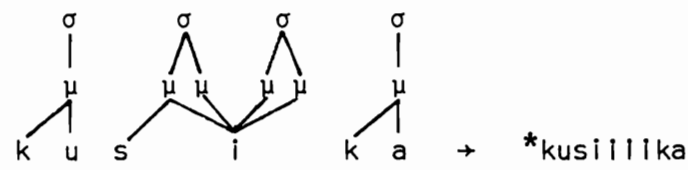

c.

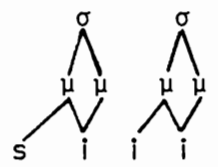<smiles>[Y][C@@H]([CH])O</smiles>

As shown in Odden [1986] OCP violation is not a rare phenomenon, therefore the structure in (5c) is not far-fetched.

The structure of the syllable is mainly rule driven, where partial underlying prosodic structure is often required. The resulting representations consist of three tiers: the syllabic tier, the moraic tier (which is redundant in languages with light syllables only), and the segmental/melodic tier (where segments are short hand for a feature matrix). The advantage of this 
representation is that each tier can be independently manipulated by phonological or morphological processes. In addition, as proposed in Clements [1985], Sagey [1986] and others, the feature matrix has an internal hierarchical structure, with an intermediate root node which links the hierarchically organized features to the mora. The exact organization of the features is still controversial. As argued in Archangel1 [1984] and Christdas [1988], not all features are underlyingly specified, but here again, the authors do not agree on the degree of underspecification.

1.2. The syllable structure in Kwawu. The following are the surface syllables permitted in Kwawu:

\begin{tabular}{|c|c|c|c|c|}
\hline (6) $\mathrm{CV}$ & ká & 'bite' & pìnî & 'agree' \\
\hline V & j̀á & 'he bites' & slé & 'hide' \\
\hline$\underset{i}{N}$ & p̀ká & 'not bite' & pàmm & 'sewed' \\
\hline i & fir & 'go out' & pr̀á & 'sweep' \\
\hline VN & j̀nká & 'he doesn't bite' & tiém & 'cry out' \\
\hline CVN & bám & 'embrace' & tintám & 'wrestle' \\
\hline
\end{tabular}

A VN syllable results from morpheme concatenation $(/ \mathrm{J}+\mathrm{N}+\mathrm{ko} / \rightarrow$ jokj́ 'he should go', /tı $\ell+m u / \rightarrow$ tiém 'cry out'), and it behaves exactly like a cVN syllable. Syllabic $r$ results from vowel deletion before $r(/ \mathrm{fir} /)_{\rightarrow}$ frí 'go out'), and stems of the surface shape $\mathrm{CrV}$ behave 1ike disyllabic stems. No special consideration will be given to these surface syllables.

The syllabic structure of a stem can be determined on the basis of the verbal tone pattern. Monosyllabic verb stems, typically $\mathrm{CV}$, have high tone (H), while disyllabic verb stems, typically CVCV, have low high tone (LH). CVV stems are disyllabic, since their tone pattern is LH, like that of CVCV stems. CVN stems are monosyllabic since their tone pattern is $\mathrm{H}$, like that of $\mathrm{CV}$ stems. The following Verbal Tone rule assigns the $\mathrm{H}$ tone, while $\mathrm{L}$ is assigned by default: 
(7) Verbal Tone

$[(\sigma) \quad \vdots$

It would be incorrect to state the environment of Verbal Tone as the first syllable from the end since in reduplicated disyllabic verbs, where the copied stem is prefixed, the $\mathrm{H}$ tone is also on the second syllable, kàsákàsà 'speak'. The L tone at the end of the form is assigned by default. Similar$1 y$, in careful speech a $L$ tone is assigned by default to the final consonant in CVN stems.

What is crucial for the ensuing discussion is the structure of the CVN syllable. As noted in section 1.1, the structure of CVC syllables is determined on language-specific grounds, as it can be monomoraic in some languages, and bimoraic in others. In Kwawu a CVN syllable is bimoraic. The argument is based on a vocalization rule, by which a word final nasal velar becomes a high nasal vowel agreeing in rounding and ATR with the preceding vowel.

(8) Nasal Velar Vocalization

$$
\left[\begin{array}{l}
\text { tcons } \\
\text { +nasal } \\
\text {-labial }
\end{array}\right] \rightarrow\left[\begin{array}{l}
\text {-cons } \\
\text { around } \\
\text { BATR } \\
+ \text { high }
\end{array}\right] \quad / \quad\left[\begin{array}{l}
\text { around } \\
\text { BATR }
\end{array}\right]-\#
$$

Since Kwawu permits only velar and bilabial nasals in word final position, the featuer [-labial] is sufficient to make sure that the rule would not turn final $m$ into a vowel. The output of Nasal Velar Vocalization undergoes a Vowel-to-Vowel Nasalization rule, by which a vowel is nasalized when followed by a nasal vowel. Some examples are given below: ${ }^{3}$

${ }^{3}$ (i) The evidence for underlying final nasal velar comes from the past tense forms, where the nasal velar surfaces. Past tense is formed by suffixing an empty mora, to which the final segment spreads:

$\begin{array}{lll}\text { Present } & \text { Past } & \\ \text { ká } & \text { kàà } & \text { 'bite' } \\ \text { tón } & \text { tònì } & \text { 'sell' }\end{array}$

The first $\mathrm{L}$ tone is derived by a Past Lowering rule, which simply lowers the 
(9)

\begin{tabular}{|c|c|c|}
\hline & $\begin{array}{l}\text { Nasal Velar } \\
\text { Vocalization }\end{array}$ & $\begin{array}{l}\text { Vowe1-to-Vowé1 } \\
\text { Nasa1ization }\end{array}$ \\
\hline$d s o$ & $\rightarrow$ doõ & $\rightarrow$ dóò \\
\hline ton & $\rightarrow \quad$ ton & $\rightarrow$ tốة \\
\hline odan & $\rightarrow \quad$ oda $\tilde{\imath}$ & $\rightarrow \quad j d a \tilde{a} \tilde{\imath}$ \\
\hline san & $\rightarrow$ sa $\tilde{~}$ & $\rightarrow$ sấ \\
\hline 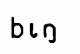 & $\rightarrow b_{l} \tau$ & $\rightarrow b \dot{i} \tilde{\imath}$ \\
\hline$s \in \eta$ & $\rightarrow s \varepsilon \tilde{\imath}$ & $+s \tilde{\varepsilon} \tilde{\tilde{\imath}}$ \\
\hline en & $\rightarrow$ de $\tilde{~}$ & $\rightarrow$ dễ் \\
\hline
\end{tabular}

$$
\begin{aligned}
& \text { 'to soak' } \\
& \text { 'to sell' } \\
& \text { 'room' } \\
& \text { 'to return' } \\
& \text { 'to be hot' } \\
& \text { 'to hang on' } \\
& \text { 'strength' }
\end{aligned}
$$

As mentioned earlier, CVN stems are monosyllabic as their tone pattern is $\mathrm{H}$, like that of CV stems (additional evidence for the monosyllabicity of CVN syllables is drawn from reduplicated forms; see section 3 ). Now, the question is whether the CVN syllable is monomoraic or bimoraic. If CVN is monomoraic, the output of Nasal Velar Vocalization must be monomoraic as we11, and hence $\mathrm{CV}$, where $\mathrm{V}$ is a short vowel (in case the vowel in the CVN syllable is high) or a short diphthong (see the structural distinction between short and long vowels and diphthongs in (3) above). Phonetically it is clear that Nasal Velar Vocalization results in a long vowel or a long diphthong, which must be represented by two morae. Therefore, it is concluded that CVN syllables are bimoraic, as it is implausible that Nasal Velar Vocalization would have an effect on the syllable structure, changing monomoraic structure to bimoraic. The process of Nasal Velar Vocalization and Vowe1-to-Vowel Nasa1ization is illustrated below:

$$
\begin{array}{ll}
\text { Nasal Velar } & \text { Vowel-to-Vowel } \\
\text { Vocalization } & \text { Nasalization }
\end{array}
$$
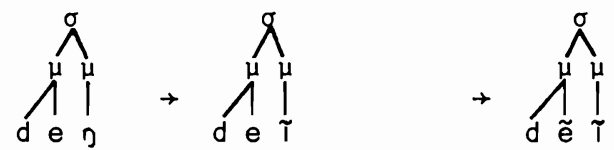

tone of the leftmost syllable in the past tense. The last $\mathrm{L}$ tone is assigned by default.

(ii) Vowel-to-Vowel Nasalization is presumably a general rule. There are po vocalic sequences [-nasal] [+nasal], but there arre [+nasal][-nasal], e.g. mõá 'gather', as well as [+nasal][+nasal], e.g. mữa 'crumple'. 
As will be shown in section 3, due to dialectal variation CãN stems are realized as monomoraic for the purpose of reduplication.

Establishing that the CVN syllable is bimoraic, the following are the possible underlying syllable structures in Kwawu:

$$
\text { CV } \quad \mathrm{V} \text { or } \mathrm{N} \quad \mathrm{CVN}
$$<smiles>CC(C)C1CC1</smiles><smiles>[O][V]=[W]</smiles>

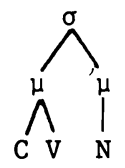

$$
\begin{aligned}
& \text { syllabic tier } \\
& \text { moraic tier } \\
& \text { segmental tier }
\end{aligned}
$$

Notice that, as pointed out in Hyman [1985], syllable final nasal and syllabic nasal, which are each the sole element dominated by the mora, contrast only on the syllabic tier. Syllabic nasals are not specified for place features since they always agree in place of articulation with the adjacent consonant. Therefore, in order to distinguish between a syllabic (nasal) consonant and a nasal vowel which constitute syllables, I assume that consonants are specified for the feature [tconsonantal].

Given the above underlying syllable structures, the following set of rules is proposed for deriving these structures:

(12) a. Underlyingly each vowel is linked to a mora, while consonants are free (C stands for unspecified consonant)
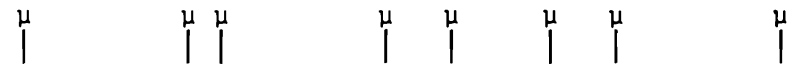
d u b
d u a
C k $\circ \mathrm{ko}$
o d i
$c p a b c$

b. Link a free segment to the adjacent mora to the right (non iterative)

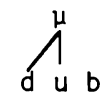<smiles>Cl[Hg][Hg]</smiles><smiles>CC(C)OC1CO1</smiles><smiles>O[Hg]I</smiles><smiles>CCP</smiles>

c. Build a syllable on every mora

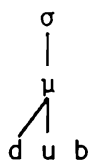

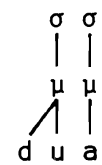

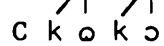<smiles>OC(O)[C@H](O)I</smiles><smiles>[10BH][10BH]C</smiles> 
d. Assign a mora to a free segment

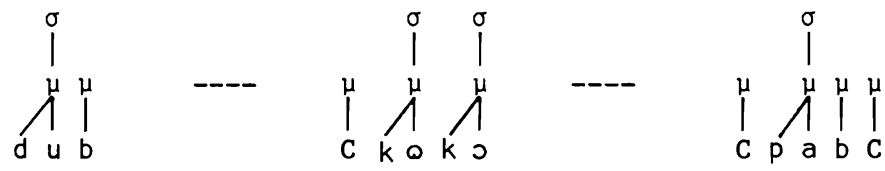

e. Link a free mora to the adjacent syllable on the left (non iterative)

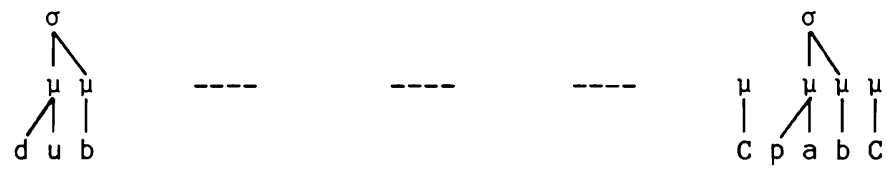

f. Build a syllable on each remaining free mora

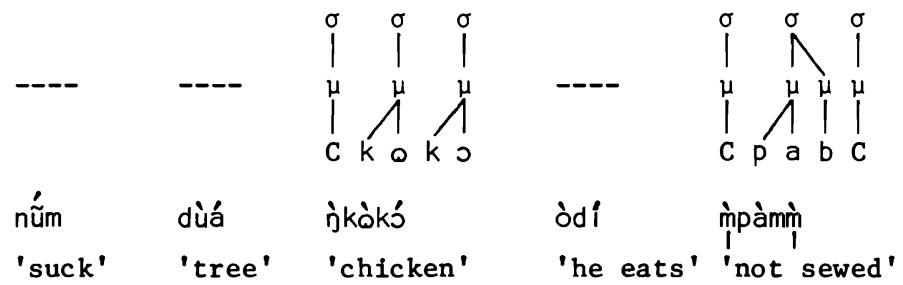

The syllabification rules provided above do not account for the nasal segments. This will be elaborated in the ensuing section, where the assignment of nasality is incorporated in the syllabification rules.

2. The Assignment of the Feature [Nasal]

The distinctive distribution of the feature [nasal] given in section 2.1 below could in principle be analyzed in linear terms, as presented in section 2.2., but this analysis is found inappropriate on universal and language specific grounds. I thus provide in section 2.3 a prosodic account, where it is argued that the feature [+nasal] is represented on the mora. The prosodic characteristic of the feature [nasal] is manifested by a revised version of the syllabification rules proposed in (12) above, with which the assignment of nasality is integrated.

2.1. Descriptive background. The following is the distinctive distribution of nasality in Kwawu: 
(13) a. A nasal consonant must be followed by a nasal vowel

\begin{tabular}{|c|c|c|}
\hline \multicolumn{2}{|c|}{$\underset{[+ \text { nasal }]}{\mathrm{C}} \underset{[+ \text { nasal }}{\mathrm{V}}$} & $\stackrel{\text { [+nasal] }}{\text { C }} \underset{[- \text { nasal }]}{\mathrm{C}}$ \\
\hline & 'give' & $\star_{\mathrm{ma}}$ \\
\hline$n \dot{\tilde{\imath}}$ & 'his/her' & $*_{n}$ \\
\hline
\end{tabular}

b. An oral voiced consonant must be followed by an oral vowel

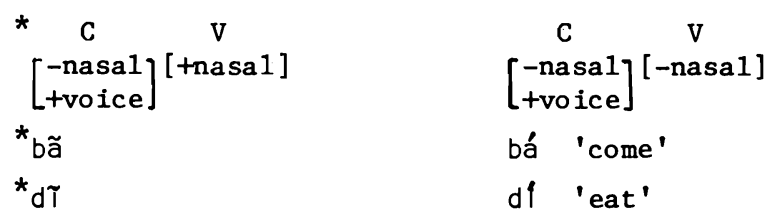

c. A voiceless consonant can be followed by an oral or nasal vowel

\begin{tabular}{|c|c|c|}
\hline 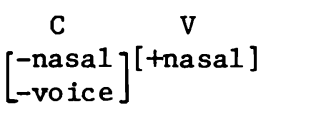 & {$\left[\begin{array}{c}\text { C } \\
- \text { nas } \\
- \text { voi }\end{array}\right.$} & $\left.\begin{array}{c}\mathrm{V} \\
\mathrm{a}\end{array}\right]\left[\begin{array}{c}\text {-nasa1] } \\
\text { [-nas }\end{array}\right.$ \\
\hline på 'palm branch' & pàpá & 'father' \\
\hline 'it scratches' & èt $f$ & 'head' \\
\hline
\end{tabular}

d. Syllable final consonants must be nasal regardless of the preceding vowe1

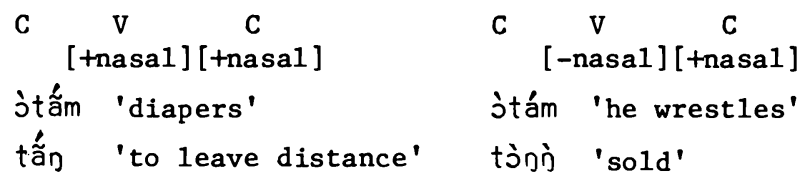

e. Kwawu has syllabic nasals, which are confined to the edge of the word

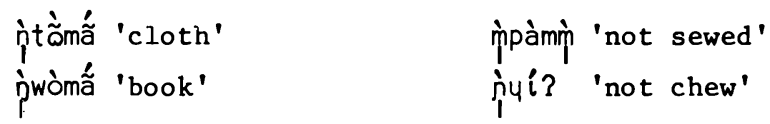

Only the distinctive distribution of nasality is given above. Due to various nasal assimilation rules these facts are not always surface true. For instance, the rule of Vowel-to-Vowel Nasalization mentioned in section 1.2 yields a sequence of a voiced consonant followed by a nasal vowel, e.g. dej $\rightarrow$ deî (Nasal Velar Vocalization) $\rightarrow$ déî̀ (Vowe1-to-Vowel Nasalization) 'strength', in violation of (13b). Simflarly, surface violation of (13a) is created by a rule of Nasal Assimilation by which a voiced consonant 
is nasalized when preceded by a nasal consonant, yielding a nasal consonant followed by an oral vowel (/N+bá/ $\rightarrow$ ịmá 'not give'). Notice that nasal consonants agree in place of articulation with the adjacent consonant on the right. ${ }^{4}$

The facts given above show dependency in nasality within the mora; a voiced consonant and a vowel dominated by the same mora must agree in nasality. Thus, in a CVN syllable $C$ and $V$ must agree in nasality (if $C$ is volced), but $\mathrm{V}$ and $\mathrm{N}$ must not, since $\mathrm{N}$ is dominated by an independent mora.

2.2. A linear account. Within a linear account it must be assumed that in Kwawu nasality is distinctive in vowels only, while all consonants are phonemically oral. This line has been taken in Schachter and Fromkin [1968] with respect to other dialects of Akan, and Capo [1983] with respect to Gbe dialects. The following rules are then required for Kwawu under this assumption:

(14) a. Prevocalic Consonant Nasalization

$$
\mathrm{C} \rightarrow\left[\begin{array}{l}
\text { +nasa1 } \\
+ \text { voice }
\end{array}\right] /-\underset{[+ \text { nasal }]}{\mathrm{V}}
$$

b. Syllable Final Nasalization ${ }^{5}$

$$
\mathrm{C} \rightarrow[+\mathrm{nasa1}] /-\sigma^{]}
$$

Rule (14a) accounts for nasal consonants which precede a nasal vowel, e.g. /bã/ $\rightarrow$ mã 'give', and rule (14b) accounts for syllabic nasals and syllable final nasals, both in syllable final position, e.g. /Cpáb/ $\rightarrow$ mpám 'not sew').

\footnotetext{
${ }^{4}$ But if the nasal consonant is followed by $h$, the former agrees in place of articulation with the vowel which follows the $h$; it becomes $D$ whęn the vowel is back (hïnhăm 'wave') and $\Omega$ when the vowel is front (hĩnhĩm 'wave'). As argued in Hayes [1986] and Steriade [1987], h (as well as ?) does not have place features, thus allowing long-distance assimilation.

${ }^{5}$ Rule ( $\left.14 \mathrm{~b}\right)$ could be stated as the following morpheme structure constraint: *[+consonantal -nasal] $\sigma]$, i.e. an oral consonant cannot appear at the end of a syllable. This would require the assumption that Kwawu has phonemic nasal consonants, since a constraint does not assign a feature but rather limits its distribution.
} 
This analysis is found undesirable on both universal and language-specific grounds. Universally, there are just a few languages in which nasality is distinctive in vowels only. According to a survey conducted by Cohn [1987], at most 10 out of 164 languages fall into this category. Cohn herself wonders whether "these cases are prosodic in nature, but were described or interpreted by someone who did not consider the possibility of [nasal] playing a role in a domain larger than the segment" [Cohn 1987:17]. This state of affairs is indeed strange, since the generalization about the phonetic distribution of nasality in languages is very different. If a language has nasal vowels it must have nasal consonants, but if a language has nasal consonants it does not necessarily have nasal vowels. Therefore, the assumption that the phonemic inventory of a language consists of nasal vowels but not nasal consonants is unfeasible considering this universal distribution.

From a language-specific point of view, the linear analysis derives the low level nasality on consonants in a rather diverse manner. Prevocalic consonants get their nasal specification on the basis of segmental structure on$1 y$, while post vocalic and syllabic consonants get their nasality specification on the basis of syllable structure.

2.3. A prosodic analysis. The prosodic analysis advocated here eliminates this undesirable situation. First, neither vowels nor consonants are phonemically distinguished for nasality, it is rather the mora which exhibits this distinction. The claim is that the feature [+nasal] is represented on the mora, while [-nasal] is assigned by default at a later stage in the derivation. Second, all segments get their nasality specification in a unified way, on the basis of the syllable structure. The feature [+nasal] percolates to all nasal bearing segments dominated by the mora it specifies; the nasal bearing units in Kwawu are voiced consonants and vowels.

It has already been established in the literature that in some languages the feature [nasal] has prosodic characteristics, as it tends to spread over domains larger than the segment, e.g. Guarani [Goldsmith 1976] and Gokana [Hyman 1982]. Like tone, which in some languages is represented on the mora and in others on the syllable, nasality is represented in some language on 
the consonant and in others on the mora or a larger unit. 6

It is thus natural that nasality, being a prosodic feature, is interrelated with other prosodic phenomena, which in this case is the syllable structure. This relation is neatly accounted for by incorporating the assignment of nasality with syllabification rules. As shown below, two of the syllabification rules given in (12) above need to be modified in order to derive the appropriate distribution of the feature [nasal].

(15) a. (modified) Underlyingly each vowel is linked either to a [+nasal] mora (marked $N$ ) or to an unspecified mora, while consonants are free
$\left.\right|_{u} ^{\mu N} b$
$\left.\left.\right|_{u} ^{\mu}\right|_{a} ^{\mu}$
c k $\left.\left.\right|_{0 k} ^{\mu}\right|_{0} ^{\mu}$
$\left.\left.\right|_{0} ^{\mu}\right|_{i} ^{\mu}$
c p a b c

b. Link a free segment to the adjacent mora on the right (non iterative)
$\bigwedge_{\mathrm{d}}^{\mathrm{N}} \mathrm{b}$
$\left.\bigwedge_{\mathrm{d}}^{\mu}\right|_{a} ^{\mu}$
c $\bigwedge_{\mathrm{k}}^{\mu} \bigwedge_{\mathrm{k}}^{\mu}$
$\left.\right|_{0} ^{\mu} \eta_{i}^{\mu}$
c $\bigwedge_{\mathrm{p} a \mathrm{~b}}^{\mu}$

c. Build a syllable on overy mora
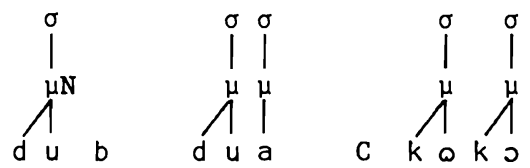

$\left.\left.\right|_{0} ^{\alpha}\right|_{0} ^{\alpha}$<smiles>[2H][13C]([10BH2])[18OH]</smiles>

d. (modified) Assign a [tnasal] mora to a free segment

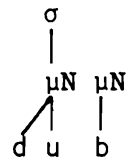<smiles>[Y]C(O)C(O)C(O)NC</smiles>

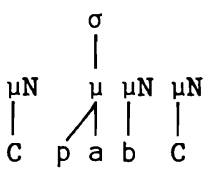

${ }^{6}$ Another way to account for nasal vowels is to assume an abstract representation of monomoraic $\mathrm{VN}$, where $\mathrm{V}$ becomes nasal and $\mathrm{N}$ is later deleted (see Stahlke [1971] for this view with respect to nasal vowels in Ewe). If this is the case diachronically, it is not implausible that the feature [+nasal] is represented on the mora at a later stage of the language. A similar diachronic process is exhibited by tonogenesis, whereby a segmental distinction at one stage becomes a tonal distinction at a later stage (see Gil [1986] and references there). Thus the syllables $\mathrm{CVC}_{1}$ and $\mathrm{CVC}_{2}$ (where $\mathrm{C}_{1} \neq \mathrm{C}_{2}$ ) become $\mathrm{CV}^{\mathrm{T} 1}$ and $\mathrm{CV}^{\mathrm{T} 2}$ (where $\mathrm{T}=$ tone and $\mathrm{T} 1 \neq \mathrm{T} 2$ ). Here, as well, the earlier segmental distinction is manifested on a prosodic domain. 
e. Link a free mora to the adjacent syllable on the left (non iterative)

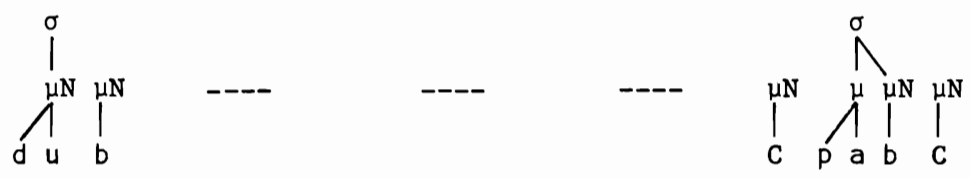

f. Build a syllable on each remaining free mora

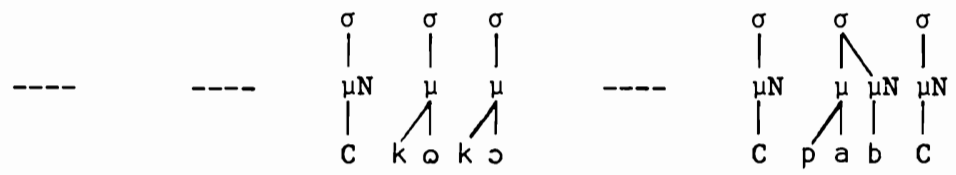

g. Feature percolation

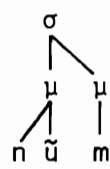
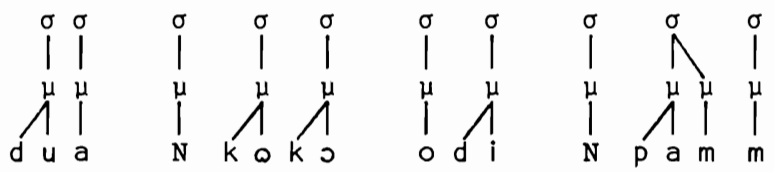

$\begin{array}{lll}\text { nũm } & \text { dua } & \text { Dkoko } \\ \text { 'suck' } & \text { 'tree' } & \text { 'chicken' }\end{array}$

od $\mathrm{i}$

mpamp

'he eats' 'not sewed'

As mentioned earlier, the unspecified nasal consonant (N) agrees in place of articulation with the adjacent consonant.

One may argue that since vowels are lexically linked to morae, the proposal that [+nasal] is lexically specified on the mora is a notational variant to phonemic nasal vowels. An analogical example would be a language with phonemic stress and only monomoraic syllables. Assuming that vowels are lexically linked to a mora, stress would be then lexically specified on the mora. But I doubt that the phonemic inventory of this language could be argued to consist of stressed and stressless vowels, as it is by now well established that stress is a prosodic feature. Nasality in Kwawu is similar to to stress in this hypothetical language. Therefore, morae specified for the feature nasal are not notational variants of nasal vowels.

3. Nasality in Reduplicated Forms

Verbs in Kwawu are reduplicated to indicate distributive meaning or multiple object or subject, as in ká 'bite' kiká 'keep biting', tón 
'se11' tòntón 'sell to many people'. Disyllabic stems are reduplicated by copying the whole stem as it is; kàsá kàsákàsà 'speak', bìsá bisábisà 'ask', tàá tàátàà 'run after', sié siéslè 'hide'. Monosyllabic stems are reduplicated by stem copying as well, but here the copied vowel surfaces as high, agreeing in rounding and ATR with the stem vowe1. 7

\begin{tabular}{|c|c|c|}
\hline (16) ká & kiká & 'bite' \\
\hline pé & pipé & 'search' \\
\hline hú & hùhú & 'sieve' \\
\hline bó & bàbó & 'break' \\
\hline fém & fimfém & '1end' \\
\hline tám & tintám & 'wrestle' \\
\hline kán & kinkán & 'read' \\
\hline tón & tòntón & 'sel1' \\
\hline
\end{tabular}

Two cases deviate from this generalization:

a. The copied vowel does not agree in rounding with the stem vowel when the stem vowel is $a$ and the stem initial consonant is /b, $p, f, m, k^{w}$, or $s^{4 /}$. Then, the copied vowel is [tround] as in (17a).

b. The copied vowel does not agree in ATR with the stem vowel when the stem vowel is $a$ and the stem initial consonant is what is termed in Clements [1981] a high consonant (Cy). Then, the copied vowe1 is $[+A T R]$ as in $(17 \mathrm{~b})$.

\begin{tabular}{|c|c|c|c|c|c|c|}
\hline \multirow[t]{6}{*}{ (17) a. } & fá & fòfá & 'take' & & & \\
\hline & mã & mãmã & 'give' & & & \\
\hline & pá & pòpá & 'strike' & & & \\
\hline & kwá & kwòkwá & 'polish' & & & \\
\hline & pám & pòmpám & 'sew' & (cf. $f \hat{\varepsilon} m$ & fimf ém & 'lend') \\
\hline & bám & bòmbám & 'embrace' & & & \\
\hline b. & $\varsigma^{4} a ́$ & 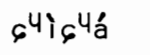 & 'pee1' & (cf. $\varsigma^{4} \varepsilon$ & $\varsigma^{4} i \varsigma^{4} \varepsilon$ & 'look') \\
\hline & tç4á & $t_{c^{4}} i t_{q^{4}} a^{\prime}$ & 'cut' & & & \\
\hline
\end{tabular}

${ }^{7}$ Reduplication may reapply to its own output (rarely in disyllabic stems). Reduplicated monosyllabic stems are reduplicated like disyllabic stems, as in (bá $\rightarrow$ ) bàbá $\sim$ bòbábòbà 'come'. 


$$
\begin{array}{lll}
\text { c4ắm } & \text { Gपį̀4ăm } & \text { 'pull away' } \\
\text { syá } & \text { syisyá } & \text { 'be smal1' }
\end{array}
$$

The contrast between mono- and disyllabic stems is manifested by the copied vowel. The question is then what information is to be specified in the reduplication rule to account for this distinction. In the spirit of Marantz [1982], reduplication is viewed here as affixation of a prosodic unit unspecified for segmental material. I uphold however McCarthy and Prince's [1986] idea that the affixed unit is not composed of timing units (C- and V-slots) as proposed by Marantz, but rather of prosodic units (mora, syllable, etc.). The segmental material is later copied from the base stem and associated with the affixed prosodic unit. The distinction between mono- and disyllabic reduplication 1 ies on the copied prosodic unit; only monosyllabic prefixes are prespecified for the feature [+high], which takes precedence over any contradicting feature contributed by the stem.

The first stage of reduplication is copying the syllabic tier of the stem and placing it on the left of the base.

Syllabic tier copying

$\sigma$
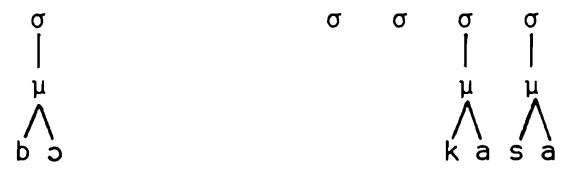

The difference between mono- and disyllabic reduplicated stems falls at the succeeding stage, where the feature [thigh] is linked to a monosyllabic prefix only. By convention, the intermediate prosodic structure (in this case the mora) is automatically set, to link between the feature and the syllable. (19) Prespecification of [thigh] to monosyllabic prefix<smiles>O=C(O)C(=O)Cl</smiles>

The next stage is to copy the stem and to link it to the prefixed syllable(s): 
(20)

Stem copying
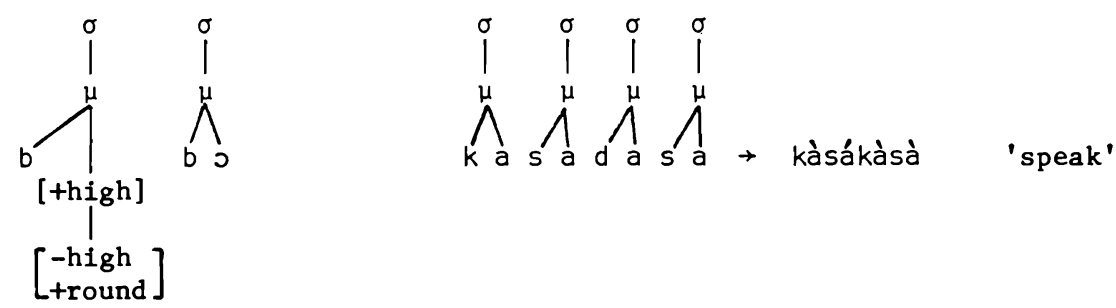

Since the features [+high] and [-high] contradict each other, the feature [-high] is deleted, giving precedence to the prespecified feature. [-ATR] is assigned by default.

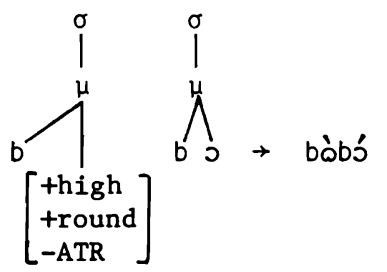

Reduplication in Kwawu is basically stem copying, but it applies in two stages: (1) copy the syllabic tier, and (ii) copy the segmental tier. A specific rule which applies between the two stages, linking the feature [+high] to monosyllabic prefixes, is responsible for the surface distinction between mono- and disyllabic reduplicated stems. Notice that CVN stems, being monosyllabic, are reduplicated like $\mathrm{CV}$ stems, regardless of the number of morae.

underspecification: Relevant to the present discussion is the behavior of monosyllabic stems with a (hereafter a-stems) with respect to rounding. As mentioned earlier, in reduplicated a-stems the copied vowel is [+round] if the stem initial consonant is a nonpalatal labial or is labialised ( $b$, $p$, $f, m, s^{4}, k^{w}$ ) and [-round] elsewhere (also in the environment of labialised palatals like $t_{q^{4}}$ and $8^{4}$ ). This situation can be well accounted for assuming that $a$ is underspecified and is thus represented by a mora 1 inked to an empty root node. The notion of underspecification is discussed in length in Archangeli [1984] and Christdas [1988] where it has been argued that seg- 
ments are not fully specified in the underlying representation. In Kwawu, as I will show below, there is strong evidence for underspecifying $a$, which yields the following feature matrix of vowels ([ATR] is omitted):

$$
\begin{aligned}
& \text { i u e o a } \\
& \text { high }++- \\
& \text { round - - - }
\end{aligned}
$$

The feature [round] must be specified for its two values in order to distinguish between reduplicated a-stems, where the vowel does not contribute a value for [round] to the copied material, and e/i-stems, where the copied vowel is always [-round] (cf. pám pòmpám 'sew' vs. fém fimfém 'lend'). As for [high], McCarthy and Prince [1986] argue that this feature is specified for its negative value only. I find this representation inappropriate since there are consonants in Kwawu which must be underlyingly specified for secondary articulation [+high], and it is implausible that [+high] in consonants is different from [+high] in vowels ( $I$ will return to the analysis of McCarthy and Prince at the end of this section).

After reduplication, the feature [+labial] spreads from a [+labial] nonpalatal consonant to the following vowel, as formulated below ( $\odot$ stands for a root node):

Labial Spreading

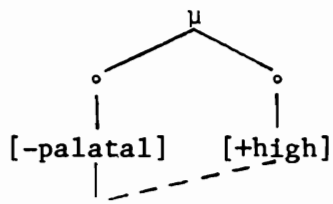

$$
\text { [+labial] }
$$

I assume that the feature [+1abial] is realized as [+round] when linked to vowels. Labial Spreading applies after the segmental material is copied, such that it does not affect the stem a ; the feature [+high] is thus crucial in the structural description. Notice that Labial Spreading is a fillin rule, rather than feature-changing rule and therefore does not affect high vowels which are already specified for the feature round. Thus, $f i ́ \sim f i f i$ 


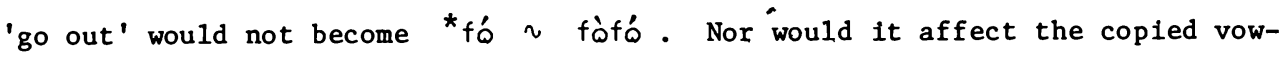
el in e-stems since e contributes its [-round] feature to the copied vowel. Thus, fém fimfém 'lend' would not become *fòmfém.

The following default rules then apply to fill in the missing features:

(24) a. [aback $] \rightarrow /\left[\begin{array}{c}--- \\ \alpha \text { round }\end{array}\right]$

b. $\left.\right|_{0} ^{\mu} \rightarrow\left[\begin{array}{l}+ \text { low } \\ + \text { back } \\ \text {-round } \\ \text {-ATR }\end{array}\right]$

Rule (24a) fills in the value for [back], which is later required for the Nasal Assimilation rule across $h$ (see footnote 4). Rule (24b) fully specifies the features for $a .{ }^{8}$

It is worth mentioning the advantage of a complete underspecified a regarding [ATR]. As argued in Clements [1981] [+ATR] is specified on stems while [-ATR] is assigned by default, with the exception of $a$, which is underlyingly specified for [-ATR]. That is, not only is a the single vowel specified for this feature, it is also specified for the default value. A complete underspecification of a eliminates this cumbersome representation, assuming that vowel harmony applies after a gets its features via rule (24b). This is not a remote assumption since vowel harmony affects the verbal clitics, which indicates its late application.

Recall also that in cases where the stem vowel is a and the stem in $1-$ tial consonant is $\mathrm{CY}$, the copied vowel is always [+ATR], regardless of the stem vowel. We must therefore assume a minor rule which links the feature [+ATR] to a root node specified for [thigh] only when preceded by this particular class of consonants. Notice that here again, in order to distinguish

${ }^{8}$ These rules are not crucially ordered. If (24a) applies first, it falls to assign a value for [back] to the empty root node in the absence of the feature [round]. If (24a) applies second, it does not affect the feature matrix of $a$, filled in by rule $(24 b)$, since it is a feature-filling rule and not a feature-changing rule. 


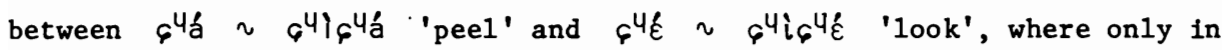
the former the copied vowel is [+ATR], we must assume that a is underspecified. Otherwise the copied vowel would be [thigh -round] in both cases, and there would be no way to account for the fact that [+ATR] is Iinked only when the stem vowel is $a$.

The process of reduplication of a-stems is illustrated below for bá bàbá 'come' (irrelevant features of $b$ are omitted for simplicity):

(25) a. Reduplication (syllabic tier copying, high specification, segmental tier copying)

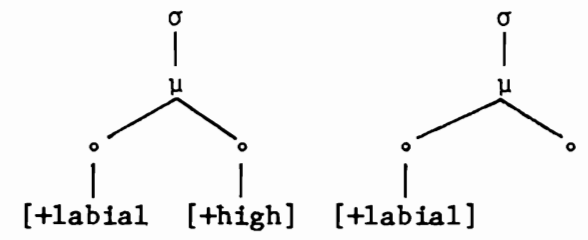

b. Labial Spreading (23)
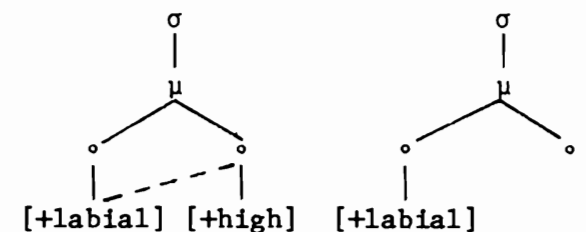

interpreted as

[+labial] [+high] [+labial]

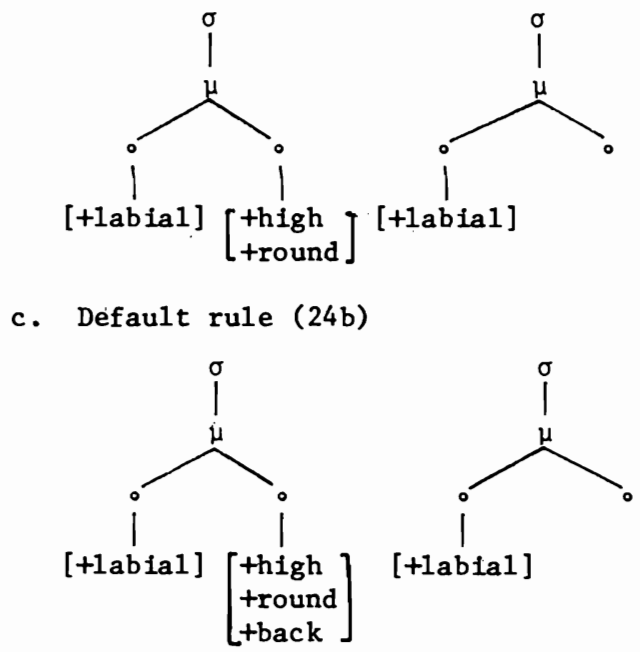


d. Default rule (24b)

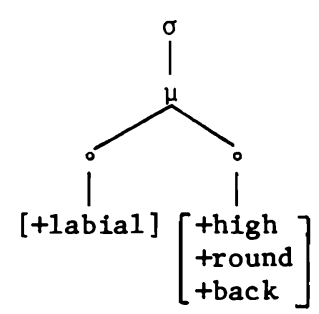

b

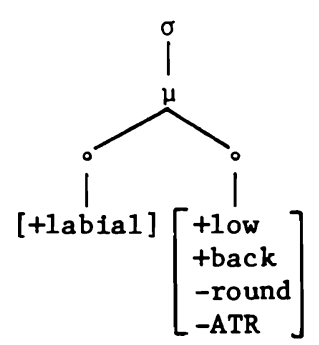

b

a

([-ATR] is assigned to 0 by default)

In stems where Lablal Spreading does not apply, e.g. ká kiká 'bite', the negative value for [round] is assigned by default.

Thus, in order to account for the peculiar behaviour of a-stems it has been assumed that $a$ is underspecified. Labial Spreading, which spreads the feature [+labial] from the stem initial non-palatal labial or labialized consonant to the following [thigh] vowel is responsible for the feature [+round] (and consequently [+back]).

reduplication and nasality: The underspecification of $a$ is a crucial factor in the distribution of nasality in reduplicated a-stems. In disyllabic stems nasality is copied along with the other features, e.g. kisã́ ? kisấkisầ 'turn over'. In monosyllabic stems the situation is more complicated as can be seen from the data below:
a. kâ $\begin{array}{ll}\text { sí } & \text { sisá }\end{array}$
'say'
b. $t^{2} \quad t i t+\hat{~}$
'change'
hứ hừhú
'scratch'
'see'
c. mấ mà̀má
'give'
nấ nìnâ
'find'
d. fắm fồmfắm
'embrace'
'worship'

The generalizations to be drawn from the above data are as follows: 
a. In a C $\tilde{V}$ stem ( $C$ is oral) where $\tilde{V}$ is [-high] (thus must be a ), 9 the copied vowel is oral:

b. In a $C \tilde{V}$ stem where $\tilde{V}$ is [thigh], the copled vowel is nasal.

c. In a $N \tilde{V}(N)$ stem, the copied vowel is always nasal (regardless of vowel height).

d. In a CṼN stem, the copied vowel is always nasal (regardless of vowel height).

Following the assumption that $a$ is underspecified (thus represented by an empty root node 1 inked to a mora), my claim is that the feature [+nasal] fails to percolate from the mora to the empty root node. That is, [+nasal] cannot be the sole feature dominated by a node (recall that syllabic nasals are specifled for [+ consonantal], thus they license percolation). When reduplication applies, the feature [+nasal] is still located on the mora, therefore not copied along with the segmental tier. Later on, when the empty root node receives the features for a via rule (24b), the feature [+nasal] percolates, as it must eventually end up on the segmental tier. Recall that reduplication involves copying of the syllabic and the segmental tiers, but not the moraic tier. Therefore, the feature [+nasal] cannot be copied if it is still located on the mora. This explains why in reduplicated $C \tilde{V}$ stems, which consist of an oral consonant and a low nasal vowel, the copied vowel is oral.

In Nã stems the feature [+nasal] does percolate, as there is a specified nasal bearing unit dominated by the mora, 1.e. the consonant. It is thus assumed that [+nasal] can be the sole feature dominated by a root node only if it is doubly-linked, and the second root node is specified for other features. ${ }^{10}$ That is, the representation in (27a) is ill-formed while that in (27b) is acceptable:

${ }^{9}$ There are no phonemic mid nasal vowels in Kwawu. The only source of mid nasal vowels is the rule of Vowel-to-Vowel Nasalization mentioned in section 1.2, whereby a vowel is nasalized when followed by a nasal vowel. ${ }^{10}$ Similar restrictions are discussed in Itô [1986]. In Italian, for example, obstruents (other than $s$ ) can appear in coda position only if they are doubly-1inked, e.g. labbro '1ip' but *aptro. The syllable structure is ( $C$ ) CVC. 
(27) a.

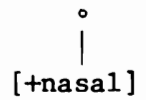

b.

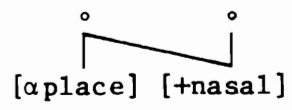

I assume that the representation is exhaustive, that is, features which are not specified are not there. Thus in (27a) the root node is specified for [+nasal] only, and therefore the representation is 111 -formed. In (27b) the feature [+nasal] is doubly-1inked, which licenses one empty root node.

The behavior of CãN stems does not conform with the above analysis, I believe for historical reasons. On the basis of the analysis provided above the prediction is that the copied vowel in CãN stems is oral, as it is the case with Cã stems; but this is wrong (see data in (26d). The problem is that CãN stems are reduplicated as if they were monomoraic, i.e. ä and $N$ are dominated by the same mora, as in Nã stems. This is evident from the copied nasal vowel.

As described in Dolphyne [1987] for other dialects of Akan, many CVN stems are historically derived from CVNV stems. This actually explains the bimoraic structure of CVN stems at the current stage of the language: a disyllabic bimoraic stem became monosyllabic without effect on the moraic structure. The relevant details are as follows:
(i) $\underset{[+h i g h]}{\mathrm{V}} \mathrm{N} \quad \mathrm{V}>\mathrm{C} \underset{[+\mathrm{high}]}{\tilde{\mathrm{V}}} \mathrm{N}$
(ii) $\mathrm{C} \underset{[-\mathrm{high}]}{\mathrm{V}} \mathrm{N}$
$\mathrm{V}>\mathrm{C} \underset{[-\mathrm{high}]}{\mathrm{V}} \mathrm{N}$

The nasalization of a high vowel preceding a nasal consonant is a synchronic rule in Kwawu (as well as in some other dialects of Akan). The evidence comes from surface forms like bũm 'bark' whose underlying forms must be bum in accordance with the generalization given in (13b) that an oral voiced consonant must be followed by an oral vowel.

These are the cases which do not cause any problems. CVN stems, where V is oral, are underlyingly represented as bimoraic, as has been argued earlier and also in accordance with the historical facts. CṼN stems, where $\tilde{V}$ is high, are underlyingly bimoraic CVN stems. High Vowel Nasalization precedes reduplication, as is evident from pairs like (kúm $\rightarrow$ ) kứm $\sim$ kừnkứm 'kil1', tón (tố) $\sim$ tòntón (tòntóồ) 'sell'. If High Vowel Nasalization followed reduplication, we would expect *tõntón. 
The problem is then limited to CãN stems, which are historically monomoraic. Otherwise we would not expect the vowel to be nasal (recall that CaNV > CaN and not CãN). In general, historical considerations cannot provide evidence for synchronic analysis, since native speakers (at least infants and uneducated adults) do not have knowledge of the history of their language. But in this particular case the historical evidence is reflected in the neighboring dialects, and all dialects of Akan are mutually intelligible. The dialects which optionally preserve the final vowel are Asante and Akuapem, and surprisingly enough Mr. Yaw, who provided the data for this paper, is a fluent speaker of Asante (but a native speaker of Kwawu-see footnote 1). It is very possible then that in order to solve some surface irregularities, speakers search for a clue in another dialect.

My claim is that CaN stems are interpreted as bimoraic since they correspond to disyllabic stems in other dialects (and those which do not correspond to bisyllabic stems are regularized). CãN cannot correspond to disyllabic stems since the vowel is nasal and is therefore interpreted as monomoraic with respect to reduplication. This explains why the copied vowel in reduplicated CãN stems is nasal. As in Nã stems, [tnasal] is 1icensed to percolate since there is at least one specified root node which can dominate it, i.e. the syllable final consonant.

Notice, however, that this interpretation does not hold for Nasal Velar Vocalization (8), where all CVN syllables behave alike, 1.e. as bimoraic. This is clearly reflected by the minimal pair tintán (tán) 'dislike' tĩntắn (tấn) 'leave distance', which after Nasal Velar Vocalization becomes tintã $\sim$ tĩntã . The distinction between tán and tãn is lost after Nasal Velar Vocalization, resulting in tấ bimoraic. But for the purpose of reduplication tấn is interpreted as monomoraic.

The cumbersome solution I suggest reflects the inconsistency of the language, which results from historical change. It is possible that there is an additional syllabification rule which merges two [+nasal] morae dominated by the same syllable: 
(28)

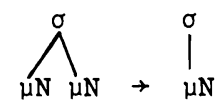

This representation is appropriate for feature percolation and reduplication. High Vowel Nasalization applies after reduplication. Therefore, we must assume that (28) is undone before this rule. Informally, all CVN stems are treated alike, 1.e. as bimoraic, for the purpose of High Vowel Nasalization. Another problem arises with disyllabic stems, where $\tilde{a}$ is copied as $1 t$ is, e.g. kisã kisãkisã 'turn over' (*kisakisã). To reconcile this discrepancy I assume that reduplicated disyllabic stems are subject to the Identity Constraint proposed in Wilbur [1973], which accounts for the tendency to preserve the Identity between the stem and the copied material. In Taga$10 g$ for example, there is a Nasal Assimilation rule (maptbigay $\rightarrow$ mamigay 'give (Moda1)') and a reduplication rule which copies the first CV of the stem (sulat $\sim$ susulat 'write (Future)'). Since reduplication applies before the prefix man- is attached, the expected prefixed reduplicated form of man+bitbigay is *mamibigay, where only the first b, i.e. the copied one, is affected by Nasal Assimilation. The actual form is however mamimigay 'give (Future)', where both b's are nasalized (although only the first one is preceded by a nasal consonant) in accordance with the Identity Constraint. Similarly in Kwawu, since in most disyllabic reduplicated stems the copied material is identical to the base, disyllabic stems with $\tilde{a}$ are regularized.

I turn now to the analysis of reduplication of other dialects of Akan presented in McCarthy and Prince [1986]. I abstract away from irrelevant disagreements which are due to dialectal variation. 11 Prespecification has

${ }^{1}$ McCarthy and Prince argue that the mora is the relevant unit for reduplication. In their data CVN stems are either monomoraic or bimoraic, as some are reduplicated as monomoraic, 1.e. monosyllabic, and others as bimoraic, i.e. disyllabic. In Kwawu all CVN stems are reduplicated as monosyllabic. So the minimal pair pam pampam (bimoraic) 'drive out' vs. pam pimpam (monomoraic) 'sew' does not appear in Kwawu. The reduplicated form of both is pòmpám. Similarly, dan $\sim$ dandan (bimoraic) 'turn' appears in Kwawu as a disyllabic stem danĩ , thus reduplicated danídani . 
been rejected by McCarthy and Prince mainly because it allows a wide range of possibilities which are not attesţed. For instance, McCarthy and Prince note that $r$, or probably consonants in general, are never found as the prespecified element. I believe that the absence of prespecified consonants (or consonantal features) lies in the 111 -formedness of a structure in which a prosodic unit, mora or syllable, is linked to a consonant. Since the affixed material in reduplication is prosodic in nature, and does not consist of segmental positions ( $C$ - and $V$ - slots), the prespecified element must be a potential syllabic nucleus. Indeed, languages which permit syllabic consonants should in principle allow reduplicated affixes with prespecified consonants (only those which participate as syllabic in the language). But this situation does not arise since consonants are not topical syllabic nucleis, as they gain this property via the prosodic structure, and may lose it when prespecified at the stage which the rest of the stem is copied.

The alternative solution proposed by McCarthy and Prince, which abolishes prespecification, is that in monosyllabic stems only part of the segmental material is copied. Assuming that vowels are specified for [ \pm round], [-1ow], and [-high], only [round] and [low] are copied; [thigh] is assigned later by default to the copied vowel.

The major problem with the assumption that [thigh] is a default feature lies in consonants which must be underlying specified for the secondary articulation [thigh]. Consider Kwawu's phonemic inventory:

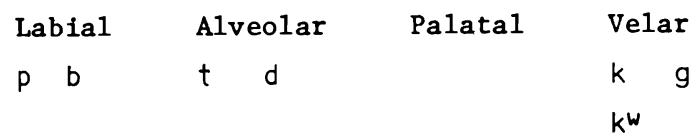

\section{Affricates}

labialized

Fricatives

palatalized

f

labialized

labiopalatalized

Liquids \& Glides

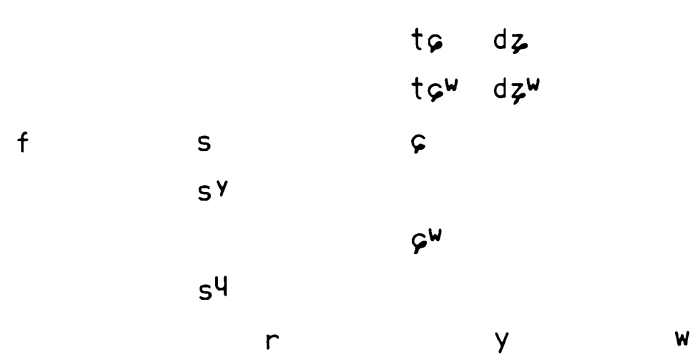


As argued in Keating [1988], palatals are complex segments, 1.e. they involve double articulation, one of which is [+high]. In addition, in order to distinguish between $s$ and $s^{y}$ the feature [+high] must be available. It is not to claim that vowels and consonants share the same features, but rather that consonants may have a secondary articulator, which is a vocalic feature. It would be far-fetched to believe that a secondary articulator [F] on consonants is not the same as the primary articulator [F] in vowels, especially in the presence of consonant - vowel assimilation rules, as Labial Spreading (23) and Nasal Assimilation (footnote 4). Therefore [thigh] cannot be underspecified in Kwawu, which subsequently requires that monosyllabic reduplicated prefixes must be assigned a [+high] feature prior to copying the melodic material.

Another argument against the analysis presented by McCarthy and Prince is the feature geometry they assume. Given the underlying features [round], [low], and [high], they propose that only [round] and [1ow] are copied in monomoraic reduplication (while all the features are copied in bimoraic reduplication). Therefore they suggest that [round] and [low] are grouped together separate from [high]. This classification is rather odd since one would expect height features, i.e. [low] and [high], to be grouped together.

Empirical evidence against this proposal for Kwawu rests on the behavior of a with respect to rounding. Under this account there would be no explanation why Labial spreading affects the copied vowel of pám 'sew' (pòmpám) but not of fém 'lend' (fimfém), if it applies after [thigh] is assigned by default. If Labial spreading applies before [thigh] is assigned, there is no explanation why the $a$ of the stem is not affected. I thus conclude that McCarthy and Prince's analysis is not compatible with Kwawu data.

4. Conclusion

The account of distribution of nasality suggested here centers on the view that features are not necessarily represented on the segmental node in the underlying representation. This view is adopted from several studies which propose units larger than the segment as feature bearers, in order to account for the surface distribution of this feature within a domain larger 
than the segment.

This, indeed, is not the immediate conclusion which comes to mind when observing the distribution of nasality in Kwawu, since its domain is a small prosodic unit. But I believe that the arguments set forth do demand the proposed conclusion. It has been shown that the alternative linear analysis does not coincide with universal observations, and it seems rather odd from a language specific point of view.

In addition, the behavior of nasality in reduplicated forms provides a strong support for the representation of the feature [+nasal] on the mora. Since the mora is not involved in reduplication, the feature [+nasal] is not copied when it fails to percolate.

\section{REFERENCES}

Archangeli, Diana B. 1984. "Underspecification in Yawelmani phonology and morphology." Ph.D. dissertation, MIT.

Capo, Hounkpatin C. 1983. "Nasal vowels and nasalized consonants in Gbe." In I.R. Dihoff (ed.), Current Approaches to African Linguistics v.1., pp. 127-143. Dordrecht: Foris Publications.

Clements, George N. 1981. "Akan vowel harmony: a nonlinear analysis." In G.N. Clements (ed.), Harvard Studies in Phonology, v. 2, pp. 108-177. Bloomington, IN: Indiana University Linguistics Club.

Clements, George N. 1985. "The geometry of phonological features." In G. Ewen and J. Anderson (eds.), Phonology Yearbook 2, pp. 225-252. Cambridge: Cambridge University Press.

Clements, George N. and Samuel J. Keyser. 1983. CV Phonology: a Generative Theory of the Syllable. Cambridge, MA: MIT Press.

Christdas, Prathima. 1988. "The phonology and morphology of Tamil." Ph.D. dissertation, Cornell University.

Cohn, Abigail C. 1987. "A survey of the phonology of the feature [ \pm nasal]." Ms ., UCLA.

Dolphyne, Florence A. 1987. The Akan Twi-Fante Languages: its Sound System and Tonal Structure. Legon: University of Ghana Press.

Gil, David. 1986. "A prosodic typology of language." Folia Linguistica 20: 165-231. 
Goldsmith, John A. 1976. "Autosegmental phonology." Ph.D. dissertation, MIT .

Guerssel, Mohamed. 1986. "Glides in Berber and syllabicity." Linguistic Inquiry 17:1-12.

Hayes, Bruce. 1986. "Assimilation as spreading in Toba Batak." Linguistic Inquiry $17: 467-500$.

Hayes, Bruce. 1988. "Compensatory lengthening in Moraic Theory." Ms., UCLA.

Hyman, Larry M. 1982. "The representation of nasality in Gokana." In H. van der Hulst and N. Smith (eds.), The Structure of Phonological Representation (part I), pp. 111-130. Dordrecht: Foris Publications.

Hyman, Larry M. 1985. A Theory of Phonological Weight. Dordrecht: Foris Publications.

Itô, Junko. 1986. "Syllable theory in prosodic phonology." Ph.D. dissertation, University of Massachusetts, Amherst.

Janeway, Roger. 1987. "Luganda in Moraic Theory." Ms., UCLA.

Keating, Patricia A. 1988. "Palatals and complex segments: X-ray evidence." In UCLA Working Papers in Phonetics v. 69, pp. 77-91. Los Angeles: UCLA Department of Linguistics.

Marantz, Alec. 1982. "Rereduplication." Linguistic Inquiry 13:435-482.

McCarthy, John J. and Alan S. Prince. 1986. "Prosodic morphology." Ms., University of Massachusetts, Amherst, and Brandeis University.

Odden, David. 1986. "The role of the obligatory contour principle in phonological theory." Language 62:353-383.

Sagey, Elizabeth C. 1986. "The representation of features and relations in non-linear phonology." Ph.D. dissertation, MIT.

Schachter, Paul and Victoria Fromkin. 1968. A Phonology of Akan: Akuapem, Asante \& Fante. Working Papers in Phonetics, 9. Los Angeles: UCLA Department of Linguistics.

Stahlke, Herbert F.W. 1971. "Topics in Ewe phonology." Ph.D. dissertation, UCLA.

Steriade, Donca. 1987. "Locality conditions and feature geometry." In J. McDonough and B. Plunkett (eds.), Proceedings of NELS, 17, pp. 595-617. Amherst: University of Massachusetts.

Wilbur, Ronnie B. 1973. "The phonology of reduplication." Bloomington, IN: Indiana University Linguistics Club. 



\title{
VERBAL INFLECTION IN KWAWU AKAN*
}

\author{
Richard Campbel1
}

UCLA

\begin{abstract}
Morphological processes in Kwawu are argued to be governed by a condition which states that words are morphologically analyzable only in terms of properties of the head of the word. The head of an affixed word is the most external affix. Certain rules apply only to bare stems and not to words with affixes. A verb formed by reanalyzing adjacent verbs as a single morphological word is accessible to these rules if its head is a stem; non-head roots in the reanalyzed verb are inaccessible to all morphological rules, as predicted.
\end{abstract}

\section{Introduction}

In this paper I discuss some aspects of the verb inflection system of Kwawu (Akan), a Kwa language of Ghana. I shall be particularly concerned with the conditions under which a given rule may apply to a word to attach an affix to it. I believe that the correct analysis of much of these phenomena can shed light on the theory of morphology, especially regarding constraints on morphological rules.

In section 1, the theoretical assumptions that will serve as the starting point of the discussion are set forth; in section 2, most of the inflectional categories, and the rules that derive them, are discussed; section 3 discusses a set of inflectional phenomena which arise in serial verb constructions; and section 4 discusses some aspects of the derivational morphology of nouns, adjectives, and verbs in Kwawu.

\footnotetext{
*Akan is a Kwa language spoken in Ghana. The current work is based on the speech of Mr. Yaw Agyakwa of Los Angeles. I am especially indebted to Paul Schachter and my fellow students in his Field Methods course given at UCLA in Winter and Spring, 1987, which gave rise to the work reported on here.
} 


\section{Theoretical Background}

1.1. Word-headedness. I assume a particular theory of morphology that relies crucially on the notion "head of a word" in the following sense: the head of a morphologically complex word is the morpheme, or formative, that carries all of the information about that word that is accessible to rules. In other words, at any point in the derivation, a word is a pair consisting of its phonological form and its head. The statement of a rule can make reference only to features of heads of words, never to features contained exclusively in formatives that are not heads. We refer to this constraint as the Head Convention (HC):

Head Convention $(H C)$ : Morphological analysis refers only to properties of words [Grimshaw 1986:747], and properties of a word are just the properties of the head of that word.

It is necessary to have an explicit way of determing what the head of the word is. I assume, following Williams [1981] and Grimshaw [1986], that the head of a word at a given point in the derivation is the affix or formative which was most recently applied to the word.

For example, the morphological properties of the Kwawu word nkyérel 'not catch' are just those of its head, which in this case is the negative prefix $\mathrm{N}-$. If a subsequent rule attaches another prefix to this word, that prefix will become the head. For example, the progressive prefix réis the head of rénkyére 'isn't catching'.

of course, properties of stems or affixes can be inherited from previous heads by affixes applied subsequently. In the preceding example, the word $n$-kyére is still a verb, for example, with all of the lexical properties of kyére 'catch'.

However, as will be seen below, reference to certain aspects of the

${ }^{1}$ Kwawu data is given in standard (Akan) orthography. Where necessary, they are accompanied by a broad phonetic transcription. In addition, tones are transcribed as follows:,$=$ high, $=$ low; sentence initial syllables that have no mark are low; otherwise unmarked syllables indicate no change from the immediately preceding syllable; downstep is marked as a high tone following a high tone. 
structure of words is excluded in principle from morphological analysis. These fall into two basic types: first, properties of parts of a word which are never heads, and could never be inherited, since they are never properties of the word. This will be relevant to a rule that combines whole words to make a complex word.

The second type of property that cannot be inherited by affixes are merely stipulated as such. The analysis of Kwawu verb inflection, for example, requires us to postulate that "stemhood" is such a property: a word that contains an affix is never a stem. ${ }^{2}$

In fact, the notion "stem" is an interesting one in this 1ight. In this paper, it is suggested (although not thoroughly argued) that the property of being a stem is relevant only for inflectional morphology and not for derivational operations. This is proposed as a solution to a paradox concerning reduplication.

It is worth noting how the HC differs from similar theories, e.g. Lieber's [1980] theory of feature percolation. In that theory, features of affixes take precedence over features of roots when determining which features percolate to the combined form. In most cases, the HC has the same result, since we are assuming that affixes are the head of affix + root combinations. However, by separating the notion "head" from that of "affix", we are able to make predictions for cases where a complex word contains no affixes, e.g. where it consists of two roots. Indeed, this is crucial to our analysis of adjacent verb series in section 3 .

1.2. Rule ordering. Two other theoretical assumptions should be mentioned. The first is that morphological rules are explicitly ordered. It may be the case that certain rules are disjunctively ordered, following work such as Anderson [1982]. This will turn out to be of little consequence for the analysis proposed here, in part because much of the work that might have been done by disjunctively ordering rules has been taken up by the HC.

${ }^{2}$ Ideally, this should follow from the definition of stem; however, this goes beyond the scope of this paper. 
The second assumption concerns the distinction between derivational and inflectional processes. Following Anderson [1982], I assume that derivational processes operate in the lexicon and are not sensitive to syntactic information. Inflectional processes are post-lexical and are (or at least can be) sensitive to syntactic environment. This distinction will be crucial in the discussion of the relation between stemhood and reduplication, which I take to be a derivational process in Kwawu.

\section{Verbal Affixation in Kwawu}

In this section I will present the basic facts about verbal inflection in Kwawu, along with their analysis in terms of the word-headedness theory. 2.1. Basic tone. Verbs in Kwawu all have a basic lexical tone pattern which is predictable from the phonological structure of the word. The tone pattern that we refer to as basic is the pattern that shows up in the present (habitual) tense in non-negative sentences. This is one of the forms that have no (apparent) affixes; the others are the imperative and the stative. As we shall see, however, these (which have low tone) are best described as deriving from an underlying form with high tone.

Monosyllabic verb stems have as their basic pattern a high (H) tone, and most disyllabic stems have LH. For ease of exposition, I will refer to these two classes of verbs as Class 1 and Class 2, respectively. I will assume that the basic tone is assigned to verbs in the lexicon, according to the following rule:

(1) $\emptyset \rightarrow$

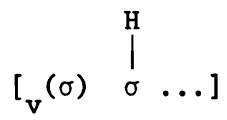

That is, $\mathrm{H}$ is associated with the second syllable of the stem, if there are more than one, otherwise with the first. This rule applies in the lexicon to all verbs, ${ }^{3}$ whether active or stative. Furthermore, assume that $\mathrm{L}$ is

${ }^{3}$ Possible exceptions are irregular verbs, especially verbs that never inflect, e.g. de (usually glossed as 'take'), which always has low tone, except in certain embedded environments, in which case all verbs get high tone on the first syllable. 
assigned (in the lexicon) to syllables that are not specified as $H$. Thus, Class 2 verb stems are $\mathrm{LH}$, and monosyllabic stems are $\mathrm{H}$.

There is, however, a class of disyllabic verb stems which have a basic tone pattern of $\mathrm{HH}$, which I will call Class 3 verbs. Clearly, rule (1) is not sufficient. These verbs can be accommodated by (1) with some additional assumptions. First of $a 11$, it is significant that all such verbs are of the form $\mathrm{CV}_{1} r V_{1}$ or $\mathrm{CV}_{1} \mathrm{nv}_{1}:{ }^{4}$ the vowel of the second syllable is always identical to the vowel of the first, and the second consonant is always [+sonorant,tcoronal]. Therefore, we can assume that rule (2) applies in the lexicon after ( 1 ), with the result that (1) correctly assigns $H$ to the first syllable of Class 3 verbs:

(2) $\emptyset \rightarrow \mathrm{V} /\left[\begin{array}{l}+ \text { son } \\ +\operatorname{cor}\end{array}\right] \longrightarrow$ \#

For this analysis, it is also necessary to assume that the (high) tone of the syllable copied by (2) is copied along with the vowel. A sample derivation of the Class 3 verb stem hóro 'wash' is given in (3):

(3)

$$
\left.\right|_{\text {hor }} \rightarrow \overbrace{\text { horo }}^{\text {hor }} \rightarrow \text { by rule (1) }
$$

The basic tone of a verb is assigned in the lexicon completely independent of any lexical features (such as active or stative), based only on sy1lable count. Morphological rules that change the tone of verbs (discussed in section 2.2) do just that: they alter the previously existing tone pattern, usually by deleting tones. The alternative would be for these rules to assign tones to unspecified forms and then to assign the basic pattern to the remaining unspecified forms at the end of the derivation. This alterna-

${ }^{4}$ Stems of the form CVN may also be in this class. For discussion of the disyllabic status of CVN forms in Kwawr, see Dolphyne [1987] and Bat-E1 [1988]. 
tive is unworkable, as will be shown at the end of section 2 .

2.2. Verb inflection. I will assume, following Anderson [1982], that inflectional formatives, or morphemes, are introduced by rule rather than being drawn from the lexicon and inserted in a phrase-marker. Nothing crucial in this analysis depends on this assumption, but I believe it makes it easier to describe the distribution of certain formatives.

2.2.1. Affixes. Negative: All verbs, whether active or stative, inflect for negation in the same way, with a low tone nasal prefix. The rule for this is given in (4):

(4) $[+V,+$ negative $] \rightarrow \dot{N}+V$

Optative: The rule that introduces the optative prefix is given in (5). Optative is taken to be [-indicative,-imperative].

(5) $[+V$, -indicative,-imperative, -negative $] \rightarrow \hat{N}+V$

The optative rule cannot apply to verbs that are inflected for negation; negative optative verbs in Kwawu have only one nasal prefix, which has low tone, indicating that it is the negative prefix.

Future and Progressive: In non-negative simple sentences, future tense is marked by a verbal prefix bé-, and progressive aspect by the prefix re- . In negative contexts, this distinction is neutralized. This is illustrated in (6):

(6) kofi re- ì- kó kùmáse 'Kofi will not go to Kumase' or K. FUT/PR-NEG-go Kumase 'Kofi is not going to Kumase'

In non-negative serial constructions, the prefixes b́- and re- show up only on the main (first) ${ }^{5}$ verb of the construction. The following verb(s) have a different prefix a-, called the consecutive prefix. We can write a set of disjunctively ordered rules to introduce these formatives as in (7), 6

${ }^{5}$ These prefixes appear on the first verb of a verb series unless that verb is uninflectable de 'take', in which case they appear on the second verb.

${ }^{6}$ This is only for the sake of exposition. I do not wish to rule out a syntactic analysis for the distribution of these affixes, for example. 
where [+FUT/PR] is the feature shared by future and progressive forms:

$$
\begin{aligned}
\text { (7) i. }[+\mathrm{V},+\mathrm{FUT} / \mathrm{PR},-\mathrm{NEG},-\mathrm{PROG}] & \rightarrow \mathrm{b} \varepsilon+\mathrm{V} / \text { main verb } \\
\text { ii. }[+\mathrm{V},+\mathrm{FUT} / \mathrm{PR},-\mathrm{NEG}] & \rightarrow \mathrm{re}+\mathrm{v} / \mathrm{main} \text { ver } \\
\text { iif. }[+\mathrm{V},+\mathrm{FUT} / \mathrm{PR}] & \rightarrow r e ́+\mathrm{V} / \mathrm{main} \text { verb } \\
\text { iv. }[+\mathrm{V},+\mathrm{FUT} / \mathrm{PR},-\mathrm{NEG}] & \rightarrow \mathrm{a}+\mathrm{v}
\end{aligned}
$$

In negative contexts, the consecutive prefix does not show up, either, as

(8) demonstrates:

(8) a. kofí be- ye àdwúma a- má yàw K. FUT-do work CONS-give $Y$.

'Kof 1 will work for Yaw'

b. kofí re- h̀- yé àdwúma (*a-) ì- má yàw K. FUT/PR-NEG-do work (CONS-) NEG-give Y.

'Kofi will not work for Yaw'

Thus the consecutive prefix, like the optative prefix, cannot cooccur with the negative prefix.

Note that other inflectional affixes (such as the negative prefix in (8b)) usually show up on all verbs in a serial construction. Indeed, it is a property of serial constructions in Kwawu that the verbs in a construction share all features for tense/aspect, mood, and negation.

Other affixes: The perfect prefix is a-, which is homophonous with the consecutive prefix. However, it is clearly a distinct affix, since it does cooccur with the negative prefix, as shown in (9):

(9) a. kofl a- ǹ- kó kùmáse

K. PERF-NEG-go Kumase

'Kofi didn't go to Kumase'7

${ }^{7}$ The negative perfect in Kwawu is semantically simple past, whereas the negative past is semantically perfective. I have no explanation for this "switching" effect, but I do not think that it is a morphological effect per se. In other words, the forms given in (9) are formally perfect rather than past, and since we are concerned with the formal properties of inflection, we will ignore the strange semantic effect. 
b. kofí a- ̀̀- yé àdwúma *(a-) ìm- má yàw

K. PERF-NEG-do work (PERF-) NEG-give Y.

'Kofi didn't work for Yaw'

Past tense: The simple past tense in Kwawu is marked by three different things, only two of which will concern us here. When a verb in the past tense is S-final, it has an extra suffix, $-\varepsilon$, in addition to the other affixes, which are described below. This suffix will be of no concern to us here, although it will show up in some examples.

of the two that will be discussed, one is a tone-changing rule and will be discussed in section 2.2.2. The other is a suffix consisting of a lengthening of the final segment of the verb stem, e.g. k' 'go' becomes kos 'went', furá 'put on' becomes furáà 'put on (past)', hóro 'wash' becomes horoo 'washed', etc. The added segment has low tone. We can write a rule for this as in (10):

$$
\begin{array}{ll}
{[+V,+ \text { past }] \rightarrow V+\grave{x} \quad \begin{array}{l}
\text { where } x \text { is a slot on } \\
\text { the } C V \text { tier }
\end{array}} &
\end{array}
$$

This suffix is crucial to the discussion in section 3 .

2.2.2. Tone changing rules. There are three morphological rules in Kwawu whose sole effect is to make the tone of the verb stem low. These apply to stative, imperative, and past tense forms. Since we are assuming that the basic tone of a verb is assigned in the lexicon, these rules must delete high tones associated with verb stems.

The past tense tone rule applies only to class 1 and 3 verbs, 1.e. to verbs whose initial tone is $\mathrm{H}$. This rule is given in (11):

$$
{ }_{\left[v^{\sigma} \ldots\right]}^{H} \rightarrow \emptyset /[+v,+ \text { past }]
$$

Rule (11) deletes $\mathrm{H}$ only if it is linked to the first syllable of the verb. This provision correctly excludes Class 2 (basic disyllabic) verb stems from undergoing this rule. The correct past tense form of blsá 'ask' is bisáà, not *bisaa.

The tone-changing rules for stative and imperative verbs are given in 
(12) :

(12) a. $\mathrm{H} \rightarrow \emptyset /[+\mathrm{V}$, +imperative $]$

b. $\mathrm{H} \rightarrow \emptyset /[+\mathrm{V}$, -active $]$

In each case, any $\mathrm{H}$ linked to the verb stem is deleted regardless of which syllable it is linked to. These rules differ in this respect from the past tense tone changing rule (11). It is necessary to state the rules in this way because the stative and imperative forms of all verbs are all low, whereas the past tense tone change does not apply to Class 2 verbs.

Nor can it be the case that the rules in (12) delete highs that are linked to final syllables. The reduplicated form of a class 2 verb such as kyeré 'show' has a basic tone pattern of LHLL, i.e. kyerékyère 'teach'. This follows from rule (1), which assigns basic tone to all verbs, along with one additional assumption, viz. that reduplication applies before (1). The reduplicated verb, kyerckyere, is assigned $H$ linked to the second syllable, as in (13):

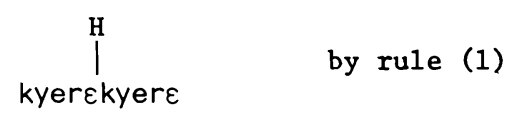

A11 remaining unspecified syllables get linked to $\mathrm{L}$. This must occur in the lexicon and before the application of (2) (since (2) was assumed to copy tones). This derives the correct tone pattern:

(14)

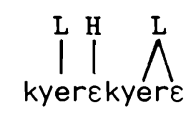

This class of verbs (reduplicated dissyllabic verbs) is not exempt from $(12 a)$, as demonstrated in (15):
(15)
a. bisabisa
ask: a round-IMP
b. *bisábisa
c. kyerckyere no
teach-IMP him
'ask around!'
'teach him!' 


\section{d. *kyerékyère no}

Thus it appears that rule (12a), and probably (12b) as well, are correct as given.

The interesting thing about rules (11) and $(12 a, b)$ is that they do not apply to verbs which have the negative prefix. Example (16) shows this for the past tense, (17) for the stative, and (18) for the imperative:
a. yaw hu $-u$ no
Y. see-PAST him
'Yaw saw him'
b. yaw n- hú -ì no
'Yaw hasn't seen him' (see fn. 7)
Y. NEG-see-PAST him
a. kofî hyè atadée
$K$. wear-STAT
'Kof $i$ is wearing an atade'
b. kofi h̀- hyé àtadée 'Kofi is not wearing an atade' K. NEG-wear-STAT

(18)
a. twa dúa no
cut-IMP wood DEF
'cut the wood!'
b. n-twá dúa no
NEG-cut-IMP wood DEF
'don't cut the wood!'
kyekyere no
tie:up-IMP him
'tie him up!'
d. n-kyekyérè no NEG-tie:up-IMP him
'don't tie him up!'

These "affixes" join the consecutive and prefixes in the class of formatives that cannot cooccur with the negative prefix. However, unlike the consecutive and optative prefixation rules, the inability of the tone changing rules to cooccur with the negative affix will be attributed to the HC.

\subsection{Stemhood.}

2.3.1. The analysis. As indicated above, the analysis of rules which cannot cooccur with the negative prefix involves the HC. In order to appeal to the HC to derive these facts, it must be the case either that the words these rules cannot apply to lack some property which is necessary for the application of the rules or that they have some property which is incompatible with 
the application of these rules. In order for a word to have or lack a property, its head must have or lack that property by the HC. Since the rules in question do apply to bare stems, but not to verbs which have the negative prefix, the problem must be with the prefix, which is the head of the words at the point in the derivation where the rule tries to apply.

It could be, for example, that these rules all have the property of not being able to apply to words that are [+negative]. As it turns out, however, the solution has nothing to do with negation per se. It so happens that the negative affix is usually the one that prevents these rules from applying because it is one of the few affixes that is attached before these rules apply. But other affixes also block the application of these rules.

For example, the aspectual prefixes be- (not to be confused with the future tense prefix $b \varepsilon ́-)$ and $k^{-}$, referred to by Christaller [1875] as the "ingressive" prefixes, also block the application of the imperative rule, as (19) demonstrates:

\begin{tabular}{|c|c|c|c|}
\hline (19) a. & $\begin{array}{l}\text { to } \\
\text { buy-IMP }\end{array}$ & $\begin{array}{l}\text { okráman } \\
\text { dog }\end{array}$ & 'buy a dog!' \\
\hline b. & $\begin{array}{l}b \varepsilon-t j \\
B E-b u y\end{array}$ & $\begin{array}{l}\text { okráman } \\
\text { dog }\end{array}$ & 'come buy a dog!' \\
\hline c. & $\begin{array}{l}\text { ton } \\
\text { sel1-IMP }\end{array}$ & $\begin{array}{l}\text { okráman } \\
\text { Pog }\end{array}$ & 'sell a dog!' \\
\hline d. & $\begin{array}{l}\text { ko-tóǹ } \\
\text { Ko-sel1 }\end{array}$ & $\begin{array}{l}\text { okráman } \\
\text { dog }\end{array}$ & 'go se11 a dog!' \\
\hline
\end{tabular}

We have already seen (in (15) and the accompanying discussion) that the rule that changes the tone of the imperative does not care what syllable the $H$ that it deletes is linked to. Therefore, there must be something morphological that blocks the application of rule (12a) in (19).

The ingressive affixes look a great deal like the verbs bá 'come' and k' 'go' and are translated into English as these, but these cannot be analyzed as independent stems, since verbs with an ingressive prefix behave morphologically like one verb, taking only one affix between them. Observe the contrast in (20), where (a) has a verb with the prefix kJ- and one nega- 
tive prefix, and (b) has a true serial construction and two negative prefixes:

(20) a. kofí n-kذ̀- dá

K. NEG-KO-sleep-STAT

'Kofi should 8 not go to sleep'

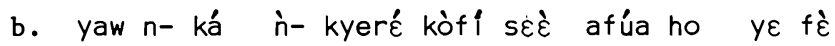

Y. NEG-say NEG-show K. that A. body do beauty

'Yaw doesn't tell Kofi that Afua is beautiful'

Moreover, as Paul Schachter [p.c.] has pointed out, there are genuine serial constructions with ingressive meaning using bá and $k j$ as the first verb. These often cooccur with verbs with ingressive prefixes, as in (21):

(21) kofí ko kj̀- dá

K. go KO-sleep

'Kofi goes to sleep'

Therefore, these must be genuine affixes. I conclude that in (19) the imperative tone change is blocked because of the affix on the verb.

Similarly, the tone change of the stative is blocked if there are any other affixes on the verb. Consider, for example, the sentences in (22), which contain examples of stative verbs which are inflected for future tense or optative mood:

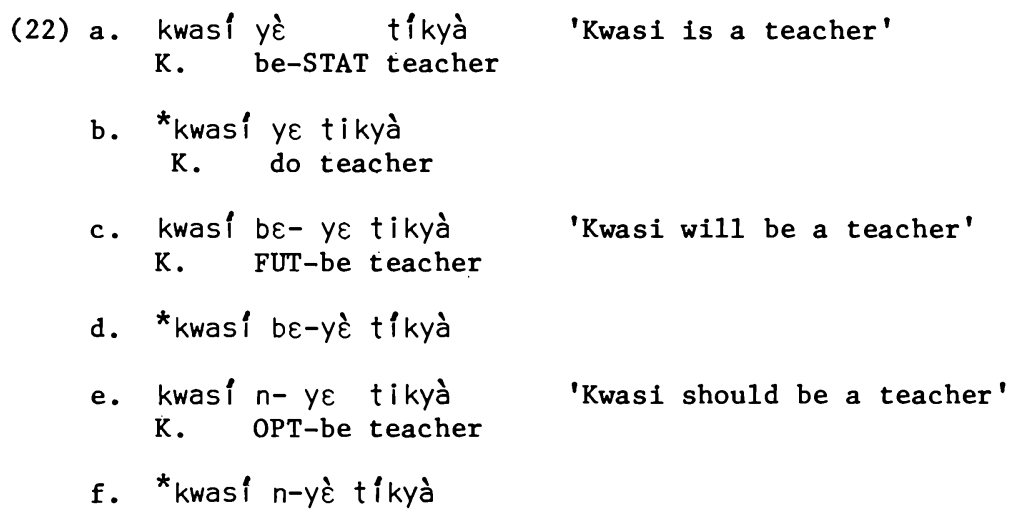

${ }^{8}$ This sentence was actually elicited as negative optative, but as noted above, this form is syncretic with the simple present negative. 
Examples (22a) and (22b) show that only the stative form of the verb is acceptable in this configuration. Nevertheless, in (22c) and (22e), the verb stem has high tone rather than the low tone usually associated with the stative. Apparently this rule, too, is blocked by the presence of an affix.

Why should the presence of an affix prevent these rules from applying? It seems that they can only apply to bare stems, i.e. verbs that have no affixes. I assume, then, that this is indeed the case: the rules must be stated so as to apply only if the (head of the) word is a stem. ${ }^{9}$ We can rewrite (11) as $\left(11^{\prime}\right)$, and (12) as $\left(12^{\prime}\right)$ :

$$
\left.\prod_{\mathrm{v}}^{\mathrm{H}} \rightarrow \ldots\right][+\mathrm{V}, \text { +past. +stem }]
$$

$\left(12^{\prime}\right)$ a. $\mathrm{H} \rightarrow \emptyset /[+\mathrm{V},+$ imperative, +stem $]$

b. $\mathrm{H} \rightarrow \emptyset /[+\mathrm{V}$, -active, +stem $]$

If the word has an affix at the point in the derivation when these rules apply, then the affix, rather than the stem, is the head of the word, and the rules cannot apply. This follows from the HC. It is no doubt not a coincidence that all of the rules in Kwawu that have this property are rules that delete tones rather than add an affix. I have no explanation as to why that should be the case, however.

2.3.2. A remark on basic tone insertion. This analysis also provides an argument for the assumption made at the beginning of section 2, viz. that the basic tone pattern of verbs is assigned in the lexicon and the tone-changing rules alter the existing tone pattern. The alternative would be for these rules to insert $L$ in the appropriate place on a stem which is unspecified for tone. At the end of the derivation, the basic tone is assigned (by inserting $H$ and linking it to the appropriate syllable) to stems that have not yet been specified for tone. It turns out that the domain of this rule would be (a) the verbs which have remained bare stems, 1.e. present habitual forms, and (b) just those verb stems which are not heads of words. (a) and

\footnotetext{
${ }^{9}$ But see note 2 .
} 
(b) form a rather unnatural class, I think.

In contrast, the assumption that basic tone is inserted lexically and then changed in some environments allows us to state all the rules affecting the tones of verbs in uniform ways, so that they apply to natural classes, as it were.

\section{Adjacent Verb Series (AVS)}

In this section I will discuss a problem in the inflectional system of Kwawu and propose a solution which makes use of the HC. I believe that the theory of word-headedness provides an elegant solution to the problem, whereas other analyses seem ad hoc and unsatisfying. I will discuss what I think is the best alternative analysis at the end of this section and demonstrate Its shortcomings.

3.1. The problem. In most cases, except where noted, serialization does not directly affect verbal inflection. Verbs in a series apparently always share all tense/aspect and mood features, with a few alternations specific to main verbs (usually the first member of the series), and they always agree in polarity. This is true, for example, in (23):

(23) kofî kà- a asém kyèré-દ̀ yaw K. say-PAST thing show-PAST $Y$.

'Kofi told Yaw something'

Each verb shows the expected past tense marking. Ka 'say' is a Class 1 verb, so it has a lengthened final segment and low tone throughout the stem in this tense; kyeré 'show' is a class 2 verb, so it gets only the final lengthening. However, if the two verbs in (23) were adjacent, as in (24), then only the second one would get past tense marking. The first one gets neither the final lengthening nor the low tone on the stem. This I will refer to as the . Adjacency effect.

(24) kofí ka kyèré-غ̀ yaw séż... K. say- $\emptyset$ show-PAST Y. that ...

'Kofi told Yaw that ...'

This contrast only appears in the past tense. In (25), the same two 
verbs are in the perfect. In (25a) they are adjacent, in (25b) they are not:

(25) a. kofí a-ká a-kyèré yàw séc̀...

K. PERF-say PERF-show $Y$. that ...

'Kof $i$ has told Yaw that ...'

b. kofí a-ká asém a-kyèré yàw

K. PERF-say thing PERF-show $Y$.

'Kofi has told Yaw something'

The explanation of the Adjacency effect is the subject of section 3.2.

3.2. The analysis. The basic form of the analysis of the Adjacency effect described in the preceding section is to assume that at some level of the derivation adjacent serial verbs combine to form a single complex verb, so that affixation rules apply to the combination as a whole, rather than to each part. First, however, it will be instructive to see how a more straightforward analysis might handle these facts.

The observable differences between the past tense form in (24) and what is expected, i.e. the form in (23), are two: (1) the past tense suffix (lengthening) is missing from the first verb ká, and (ii) ká has high tone, even though it is monosyllabic and should get low tone in the past tense. The most straightforward account of this is to write rules that (i) delete the final vowel of ká, and (ii) insert a high tone. These rules would have to be stated so as to apply just to the past tense, which could be handled by assuming that suffixes are deleted or long segments shortened, and they must also apply only if the following word is a verb. Thus, it must take into account both morphological and phonologocial information.

The most unattractive aspect of this approach, however, is that it does not explain anything. If it turns out that there are other effects associated with this structure, the approach outlined above would have to say that this is a coincidence, i.e. that the two effects are independent and unrelated. In fact, it says just that about the two parts of the effect noted: the loss of the lengthened segment and the high tone on the first verb. It leaves unexplained why these two things cooccur.

Instead we will seek an explanation that ties these facts together and al- 
lows for the possibility that other observable effects will follow from the same explanation. Suppose, then, there is a rule that reanalyzes members of an adjacent verb series as a single complex word, as in (26):

(26) AVS Reanalysis

$$
v_{1}-v_{2} \rightarrow\left[v_{1}+v_{2}\right]
$$

This rule applies to verbs that are string adjacent without reference to, or effect on, the syntax. The output is a single verb made up of the adjacent verbs of a serial construction. Since the effect of this rule only shows up in the past tense, it is necessary to assume either that it applies only to verbs in the past tense or that it applies before the past tense inflection rules but after the other inflectional rules.

The latter is definitely preferable, since it does not require the mention of a particular feature in the statement of the rule. In fact, we can find evidence that this approach is correct. In the past negative, the effect of rule (26) is apparent, in that the past tense inflection is missing from the first verb of the combination, but each verb has a negative prefix, as in (27):

$$
\begin{aligned}
& \text { yaw } n \text { - ká } n \text {-kyèré-z̀ kofí séc̀ ... } \\
& \text { Y. NEG-say- } \emptyset \text { NEG-show-PAST K. that } \\
& \text { 'Yaw has not told Kofi that ...' }
\end{aligned}
$$

This is explained by the assumption that (26) applies after certain inflectional affixation rules, but before the past tense rules. The rule that attaches the negative prefix applies first, affecting both verbs; then AVS REANALYSIS applies, making the sequence n-ká n-kyèré a single word to which the past tense inflection rules apply just once.

In fact, (26) follows all of the inflectional rules discussed so far except for the two rules for past tense inflection $\left(10,11^{\prime}\right)$.

Since the reanalyzed verbs are a single word when the past tense rules apply, they can only apply to the whole construction once. For rule (10), which adds a segment to the end of the word, this is straightforward: a single segmental slot is added to the right edge of the complex word, as in (28): 
(28)

$$
[\mathbf{v} k a+k y e r \varepsilon]+\varepsilon
$$

For rule ( $\left.11^{\prime}\right)$, which deletes a high tone on the stem of a verb in the past tense, matters are slightly more complex. In AVS constructions, this happens only on the rightmost member of the series if that verb is Class 1 or 3 (initial high tone):

$$
\begin{array}{lll}
\text { kofi pu gù- uE } & \text { pu } \\
\text { K. } & \text { spit- } \emptyset \text { drip-PAST }
\end{array}
$$

The initial verb of this series, pú, not only lacks the additional segment of the past tense suffix, but it has high tone rather than low. To account for this, we need a way of referring to the rightmost verb in the reanalyzed construction.

Here is where the HC comes in. I propose (the head of) $v_{2}$ is the head of the reanalyzed verb in (26). Thus, in (29), the head of [ $\mathrm{pu} g u$ ] is gu after rule (26) has applied. This word ([pu+gu]) now has the property that its head (gu) is a stem. Consequently, rule (11), which applies only to stems, can apply to it. Rule (11') cannot apply to pu, however, since it is not the head of anything.

3.3. Another post-reanalysis rule. There is a morphological rule that applies to Class 3 verbs (the underlyingly monosyllabic verbs that become dissyllabic) and to reduplicated class 3 verbs, but to no other class of verb. That rule is the subject of this section.

Consider the sentences in (30):
a. o- bé- kyerè kofí
3sg.-FUT-catch K.
'he will catch Kof 1 '
b. ว-bع́-kyerè twúm
'he will catch Twum'
c. っ-bé-kyere da biara
'he will catch everyday'
d. ว-bé-kyerè dá biara
'he will catch it everyday'

${ }^{10}$ The extra $-\varepsilon$ in this case shows up on all verbs in the past tense that are clause $f$ inal. It is in addition to the final segment lengthening that always shows up. See section 2.2.1. 
In sentences $(30 a),(30 b)$, and $(30 d)$, the final tone on the verb ts low whereas in sentence (30c) the final tone is high. The verb is the same in each case and in the same tense, the only difference being that in (30a), $(30 b)$, and (30d), but not in (30c), the verb is followed by a noun phrase object, whether overt or empty. The pair (30a) and (30b) shows that the presence of the final $L$ is not sensitive to the initial tone of the NP; pair (30b) and (30c) shows that it is sensitive to whether or not the verb has an NP object; and the pair (30c) and (30d) shows that this holds even if the object is null (inanimate, unemphatic object pronouns are almost always null in Kwawu).

This alternation only appears in Class 3 verbs (and their reduplicated forms) in non-suffixed tenses where the basic tone is preserved, i.e. present, future, progressive, and perfect tenses of active verbs. In all other tenses, Class 3 verbs end in low tone anyway.

Now suppose, for concreteness, that this alternation is triggered by a morphological feature related to the verb's ability to assign Case to an NP. ${ }^{11}$ Let us call this feature [+Case]. The rule accounting for the alternation is given in (31):

$$
[+\mathrm{V},+ \text { Case }] \rightarrow \mathrm{V}+\mathrm{L} \text { (low tone) }
$$

Class 3 verbs (and their reduplicated forms) have the unique property that their basic tone pattern consists of $\mathrm{H}$ linked to two syllables. We can assume, then, that the floating $L$ inserted by (31) is allowed to 1 ink up to the syllable to its left only if that syllable is linked to an $H$ that is also linked to another syllable. In this way, the fact that this alternation shows up only on Class 3 verbs is accounted for in terms of the phonological representation of the verb.

Recall that in section 3.2, AVS Reanalysis was claimed to apply to adjacent verbs in all tenses, even though the overt alternation usually only showed up in the past tense. If this is the case, then it ought to apply to

${ }^{1}$ In fact, nothing depends on this assumption. I choose this feature merely because it relates the rule to the presence of NP. 
the adjacent verbs in (32a), where the verbs are in the present tense. Furthermore, the first verb in the sequence is a (reduplicated form of a) Class 3 verb and hence should show the alternation described by (31). The expected final low tone is present in (32b) and (32c) but absent in (32a), where the verbs are adjacent:

(32) a. yaw kyekyére bo duá ho

Y. tie:up hit tree outside

'Yaw ties it up to a tree'

b. yaw kyekyérè no bó duá ho

Y. tie:up him hit tree outside

'Yaw ties him up to a tree'

c. yaw kyekyérè

Y. tie:up

'Yaw ties it up'

The absence of the expected low tone on the final syllable of kyekyére in (32a) is explained by the Head Convention under the analysis proposed here, assuming that rule (31) applies after AVS Reanalysis. Since kyekyere and bo are adjacent, they are subject to AVS Reanalysis and are a single complex verb at the point where rule (31) applies. But only properties of heads of words are visible to morphological rules, and kyekyere is not the head of this construction, bo is. Hence, the feature [+Case] is not visible to the rule, since they are not features of the head, therefore the rule cannot apply.

Since this rule also seems to be sensitive to whether serial verbs are adjacent or not and can be explained in terms of the analysis proposed in section 3.2, it provides independent evidence in favor of that analysis and hence in favor of the theory of word-headedness adopted here.

3.4. An alternative analysis. In this section I will discuss a plausible alternative analysis of the Adfacency effect, and then present arguments against it.

3.4.1. The analysis. In section 3.2, we tried to account for the fact, among others, that when serial verbs in the past tense are adjacent, only the right- 
most member of the sequence gets inflected, while all the other members showed their basic tone pattern, e.g. the pattern associated with the present tense. But it is conceivable that the unexpected high tone on $k a$ in (24), repeated below, is due not to a lack of inflection, but rather to a high tone inserted between the verbs:

(24) kofl ka kyèrt̂-દ̀ yaw séc̀ ...

K. say- $\emptyset$ show-PAST Y. that ...

'Kofi told Yaw that ...'

If this is the case, then all that needs to be accounted for in (24) is the absence of the final lengthening on $k a$. Suppose, then, that this is also triggered by the inserted floating $\mathrm{H}$ in the following manner: assume that the added segment (the past tense suffix), which is always associated with low tone, deletes when followed by a floating $\mathrm{H}$, allowing the $\mathrm{H}$ to associate with the preceding syllable, i.e. the final syllable of the stem.

Where does the floating high tone come from? Suppose that in any serial construction, no matter whether the verbs are adjacent or what the tense is, a floating $H$ is inserted before the second verb as a sort of connective morpheme. Some independent evidence for this position is taken from sentences like (33):

(33) a. yaw de nó kyèrદ́ kòfí 'Yaw shows him to Kofi' $\mathrm{Y}$. take him show $\mathrm{K}$.

b. me- to- ó́ tòn- ne 'I bought and sold it' 1sg-buy-PAST se11-PAST

In (33a), the object pronoun nó has high tone whereas object pronouns in general have low tone, as in (34):

(34) yaw fá nò Y. take him

'Yaw takes him'

Similarly, in (33b), the final $-\varepsilon$ of too' 'bought' is high, though this form is usually low, as it is in tonne 'sold'. This hypothesis proposes that since pronouns have no lexical tone ( $L$ being a default tone), a floating $\mathrm{H}$ before kyeré associates with the pronoun, making it high. The reason it does not happen in (34) is because this is not a serial construc- 
tion, and hence there is no connective floating $H$. The presence of this floating $\mathrm{H}$ could also be used to account for the lack of final syllable lowering illustrated in (32a) above.

In summary, the presence of a floating high tone before any non-initial member of a verb series is responsible for (i) the deletion of the past tense suffix and (ii) the presence of a high tone on the final syllable of a preceding adjacent verb. These phenomena are handled, it is claimed, without recourse to a rule that combines adjacent verbs into a complex verb.

3.4.2. Problems with the analysis. The problems with this analysis are basically two: ( 1 ) when a broader range of data is considered, the analysis of the association of the floating $H$ needs to be complicated; (ii) it is unable to account for exceptional cases.

First, consider the case of Class 3 verbs in non-final position in a sequence of adjacent verbs, illustrated in (32a), repeated here:

(32) a. yaw kyekyére bo duá ho

Y. tie:up- $\emptyset$ hit tree outside

'Yaw ties it up to a tree'

In this case, the last two syllables of the first verb have high tone, not just the last one. Hence, there is a single high tone 1 inked to two sy1lables. There is now a problem, and that concerns the tone lowering rule discussed in section 3.3. If this rule applies to any tense in which these verbs normally end in high tone, as suggested above, then what prevents it from applying in (32a)? On the other hand, if the rule of final syllable lowering specifies that it cannot apply in the past tense, then that would entail a complication of that rule.

I think that the problem with Class 3 verbs is actually a relatively minor problem, since these verbs have been argued to derive from underlying monosyllabic forms.

Far more troublesome is the exceptional behavior of the serializing verb de, often glossed as 'take'. When this verb is the initial member of a sequence of adjacent verbs in whatever tense, it has low tone, which is its ba- 
sic tone pattern. ${ }^{12}$ This is illustrated in (35):

(35) a. yaw de ma- a kofí

Y. take give-PAST $\mathrm{K}$.

'Yaw gave it to Kof $i$ '

b. kofí dè kyekyére bj̀- o dúa no ho

K. take tie:up- $\emptyset$ hit-PAST tree DEF outside

'Kofi tied it up to the tree with it'

According to the hypothesis under consideration, de should have high tone in this environment, since it precedes a floating high tone, which precedes the following verb. One way to handle this would be to say that for whatever reason, de is an exception: verbs following de do not have a floating $H$ connective immediately preceding them. However, it was precise$1 y$ in this environment, i.e. after de, that the evidence for the high tone was claimed to have been found, as in (33). Either de is not an exception, in which case (35) is unexplained, or a high tone on an object pronoun occurring between serial verbs is not related to the tone changes associated with the Adjacency effect.

The first alternative is unacceptable: if there is independent evidence at all for the connective high tone, it comes from constructions with de (recall (33)). The second alternative, as we shall see, is arguably the correct conclusion.

The distribution of object pronouns with high tone is not entirely traceable to serialization and is quite clearly a fact about pronouns to the exclusion of lexical NP's. Consider the sentences in (36) and (37):

(36) a. Yaw de nó kyèré kòfî 'Yaw shows him to Kof $i$ ' Y. take him show $\mathrm{K}$.

b. yaw de ago má kòfí 'Yaw gives velvet to Kofi' Y. take velvet give $K$.

(37) a. kofí pu nò gú 'Kofi spits him out' K. spit him drip

b. kofî pù- u nó gù- ue 'Kofi spat him out' K. spit-PAST him drip-PAST

${ }^{12}$ The so-called secondary tone environment is an exception to this: de, like all other verbs, has high tone on the first or only syllable in certain' 
In (36a), an object pronoun gets high tone, but in (36b), a noun with lexical low tone retains its normal tone pattern in the same position. In (37a) the object pronoun gets low tone after pú 'spit', which has high tone, even though it is a serial construction. This contrasts with (37b), where the pronoun again gets high tone after low tone puu 'spat'. This suggests that, at the very least, whether an object pronoun gets high tone depends on the form of the verb that precedes it.

Although the precise distribution of high tone object pronouns is not clear, it is apparent that it is not part of the same phenomenon as the Adjacency effect. The presence of a floating high tone connective may ultimate1y be the explanation of the fugitive high tone pronouns and the high tone suffix $-\varepsilon$, but this cannot explain the behavior of adjacent verb series. 3.5. Rule order. We have argued that a rule of AVS Reanalysis is necessary to account for certain alternations in past tense inflection, as well as for other alternations. It was claimed that this rule preceded the rules of past tense inflection but followed most other inflectional rules. The order of the rules described here, insofar as this is not stated explicitly in the text, is given in (38). Rules mentioned in the same line indicate that there is no evidence to suggest that one is ordered before another.

(38) 1. Ingressive prefixation

11. Negative pref. (4); Optative pref. (5)

iii. Imperative tone change (12'a); FUT/PR rules (7); Perfect pref.

Iv. Stative tone change $\left(12^{\prime} \mathrm{b}\right)$

v. AVS Reanalysis

vi. Past tense tone change (11')

vii. Past tense suff. (10)

viii. Class 3 transitivity rule (31)

It is assumed that all the rules mentioned in (38) are inflectional, 1.e. post-lexical. Some of the consequences of this are discussed in the next section.

subordinate clauses. It is of course an interesting question as to why de, which never shows any inflection, apparently does show this alternation. Nevertheless, this is arguably an independent issue. 


\section{Related Areas}

In this section, I discuss two related areas of Kwawu morphology that are of interest to the theory adopted here. One is the status of the Head Convention with respect to derivational morphology in nominal elements, and the other concerns a particular problem posed for the analysis by reduplicated verbs, which I also take to be derivationally complex.

4.1. Nominal suffixes. Words of category [+N] can take certain prefixes, which often distinguish between singular and plural. There are four such prefixes: $\varepsilon_{-}, \nu^{-}, a-$, and $N_{-}$. The first two are always singular and alternate with one of the other two in the plural. The last two can be singular or plural; if a noun takes a- in the singular, it could take either a- or $\mathrm{N}$ - in the plural; if it takes $\mathrm{N}$ - in the singular, it takes $\mathrm{N}-$ in the plural. Which prefixes a noun takes is a lexical (and largely idiosyncratic) property of the noun.

Often, when a noun is formed by attaching the [thuman] suffixes -ni (sg.) or - fo (p1.) to a noun, the resulting word takes $0-$ as its singular

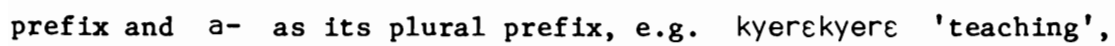
o-kyerદkyeréni 'teacher', a-kyerદkyerદ́fo 'teachers'.

This holds even if the noun root that the suffix attaches to takes different prefixes. For example, a-buro (sg.) m-buro (p1.) 'corn', becomes o-buro-ni (sg.) a-buro-fo (p1.), literally 'corn person(s)', but used to mean 'European(s)'. This fact follows from the Head Convention, since the suffix is the head of the word and consequently the properties of the suffix are the properties of the word. The relevant properties of $-n i /-f o$ are that they take the prefixes $\mathrm{o}^{-}$and $a-$. That is, whatever feature(s) of nominal elements are associated with this set of prefixes is an inherent property of the $-n i /-f o$ suffix and therefore a property of a word that has one of these suffixes as its head.

There are some apparent exceptions to this generalization. Specifically, many place names that take a- as their prefix in both the singular and plural forms do so also when they appear with the derivational suffixes $-n i$ or -fo, e.g. asánte 'Asante (adj; sg. or pl.)', asante-nl, asante-fó 'Asan- 
te person(s)'. The expected singular form ssante-ni also occurs, but the existence of the forms with a- poses a problem for the Head Convention.

I suggest that the form asante has become reanalyzed in these cases as a single morpheme without a prefix. One might wonder, then, why other prefixes have not become reanalyzed as well. There are two possible explanations for this. First, the prefixes $\supset$ - and $\varepsilon$ - are always singular; any noun or adjective that takes either of these in the singular takes either aor $\mathrm{N}$ - in the plural. Therefore, these are more transparently prefixes since they always show alternation for number.

The second possible explanation has to do with the morpheme structure constraints of Kwawu. Root morphemes cannot have either $/ \supset /$ or $/ \varepsilon /$ as their first segment. Arguably, /a/ can be root-initial. There are function words in Kwawu that begin with /a/, where it is apparently not a prefix, e.g. àa (relative clause complementizer). There are also other words where initial /a/ looks like a prefix but behaves in a way that is unexpected of prefixes, e.g. asé 'under (N)'. Although this looks like a prefix, it can occur internal to compounds, for example in kumáse (name of a city, but lit. 'under the kum tree'). This is unexpected if these prefixes are inflectional and therefore not attached in the lexicon. Therefore it is not surprising that /a/ has been reanalyzed in some cases, but $/ \supset /$ and $/ \varepsilon /$ have not.

4.2. Reduplication. Verb reduplication in Kwawu is a productive process. Class 1 and 3 verbs reduplicate by copying the initial syllable to the left of the root. The vowel in the copied syllable is always [+high], but agrees in roundness with the original vowel. For example, twá 'cut' reduplicates as twitwá 'cut to pieces'; bóro [boro] 'get drunk' becomes bobóro [boboro] 'get drunk (dist.)'.

Class 2 verbs reduplicate by total reduplication, with no change in the vowels. For example, bisá 'ask' becomes bisábisa 'ask around'; kyeré 'show' becomes kyerékyère 'teach'.

For all verbs, the reduplicated forms are subject to the tone assignment rule (1): all reduplicated verbs have low tone on the first syllable and high on the second syllable; reduplicated forms of class 3 verbs have high on 
the third syllable, as expected (see section 2.1). Since this rule was argued to apply in the lexicon and since it must follow reduplication, it follows that reduplication applies in the lexicon, as well. By the division adopted in section 1 , this means that it is a derivational process.

This makes sense, since the meaning of the reduplicated form, though related, is not entirely predictable from the meaning of the root form. The most usual case, however, is for the reduplicated verb to have a distributive sense, while maintaining the basic sense of the root verb.

It is apparent that reduplication, at least in the case of class 3 verbs (which is clearly partial reduplication), involves some sort of affixation. More specifically, it is clearly not a case of concatenating two stems.

Recall from section 2 that some rules of verb inflection are sensitfve to whether or not the (head of the) word they apply to is a stem. One of these rules changes the tone on verbs in the imperative mood, making them all low. Since reduplication involves affixation, the imperative rule ought not to be applicable to reduplicated forms since reduplication (which is a lexical rule) applies before the inflectional rule of imperative.

However, this is not the case, as shown by (39):
(39) a. kyekyere no
'tie him up!'
tie:up-IMP him
b. bisabisa
ask: around-IMP
'ask around!'
$(=15 \mathrm{a})$

Assuming that the analysis of the imperative rule is correct, (39) poses a serious problem for the Head Convention. Indeed, it appears to be a straightforward counterexample to it.

Notice that it cannot be the case that derivational affixes are not subject to the HC since the derivational suffixes discussed in section 4.1 were shown to act as heads of the nouns they appeared in. Therefore, something else must be at work here. Reduplication has been argued to be a derivational, i.e. lexical, process of word formation. All of the other morphological rules affecting verbs that have been discussed are of the type that are typically thought to be inflectional. 
I suggest, then, that the solution to the problem illustrated in (39) is that the notion of stem is undefined for lexical processes. In other words, a derivationally complex word is still a stem so long as it has no inflectional affixes. This corresponds rather neatly with the lexical/post-lexical distinction that is assumed to underly the derivational/inflectional distinction. A stem in this conception is a form that can be inserted into a phrase marker by Lexical Insertion. Derivational rules form words before Lexical Insertion, whereas inflectional rules operate on words that have been inserted into a syntactic representation.

One apparent problem with this approach to which I have no solution to offer is that it makes the rule that accounts for stative morphology inflectional. It follows the rules that attach the negative affix, the future prefix, and the optative prefix. These rules clearly apply to forms bearing features that are taken from the syntactic environment, i.e. tense and aspect features, which are properties of sentences or of verb phrases, and are therefore post-1exical.

One would think, however, that the feature [ \pm active] is a lexical property of verbs, and independent of syntactic configuration. It is therefore odd that the one morphological rule that makes reference to that feature is a post-lexical rule.

\section{Conclusion}

We have discussed several morphological processes in Kwawu, especially in the domain of verbs, in the light of a theory of word-headedness, in particular that of Williams [1981] and Grimshaw [1986]. Whereas a variety of theories incorporating the notion "head of a word" could be envisioned, a theory that incorporates what we have termed the Head Convention has allowed us to make sense of a range of phenomena in Kwawu morphology that would otherwise be mysterious. To the extent that the particular analyses proposed here are valid, they provide evidence in favor of such a theory.

In particular, it was seen that there is a class of inflectional rules in Kwawu that can apply only to bare verb stems or, more precisely, only to verbs whose head is a bare stem. The analysis of verb reduplication leads us to 
adopt a particular conception of what a stem is, which relies on the distinction between derivational and inflectional processes being based on a lexical/post-lexical division: a stem is a formative or morpheme that is inserted in a phrase-marker, and to which inflectional rules apply.

\section{REFERENCES}

Anderson, Stephen R. 1982. "Where's morphology?" Linguistic Inquiry 13: 571-612.

Bat-E1, Out1. 1988. "Distinctive nasality in Kwawu: a prosodic account." Studies in African Linguistics 19:173-203.

Christaller, J.G. 1875. A Grammar of the Asante and Fante Language Called Tshi (Chwee, Twi). Basel: Basel Evangelical Missionary Society.

Dolphyne, Florence. 1987. "The Akan language: its sound system and tonal structure." Ms., UCLA.

Grimshaw, Jane. 1986. "A morphosyntactic explanation for the mirror principle." Linguistic Inquiry 17:745-749.

Lieber, R. 1980. "On the organization of the lexicon." Ph.D. dissertation, MIT .

Williams, Edwin. 1981. "On the notions 'Lexically Related' and 'Head of a Word'." Linguistic Inquiry 12:245-274. 


\title{
THE BONDEI OBJECT PRONOUN IN \\ CLEFTS AND PSEUDO-CLEFTS*
}

\author{
Elizabeth G. Weber \\ UCLA
}

\begin{abstract}
Verbs in Bondei, a Bantu language spoken in East Africa, have crossreferencing pronouns which agree in noun class with the subject and object of the clause. This paper will examine the distribution of the syntactic category object pronoun in four grammatical constructions: (a) basic affirmative declarative clauses; (b) relative clauses; (c) clefts; and (d) pseudo-clefts. In declarative and relative clauses, the presence of the object pronoun does not require a definite interpretation of the object noun; the absence of the object pronoun does not preclude a definite interpretation of the object noun. In both cleft and pseudo-cleft constructions, however, the object pronoun obligatorily functions to grammatically mark clefted and pseudo-clefted objects as definite. In the cleft constructions, the definiteness of the clefted NP forces a contrastive interpretation. Thus, a judgement concerning the function of this grammatical construction with regard to contrastive function will be made on the basis of the distribution of the syntactic category object pronoun. In the pseudo-cleft constructions, it is not possible to make the same judgment. Contrastive function is unambiguously signaled by the relative morphology on the verb of the pseudo-cleft. In this constuction, the object pronoun serves only to force a definite interpretation of the NP.
\end{abstract}

\section{0 . Introduction}

This paper will examine the relation of the syntactic category object pronoun and cleft and pseudo-cleft constructions in Bondei, a Bantu language spoken in East Africa. Bondei, classified G24 by Guthrie [1948], is

\footnotetext{
*I would like to thank Vicky Carstens, Tom Hinnebusch, Russ Schuh,
} Sandy Thompson, and Benfi Wald for their comments. 
a member of the Seuta sub-group of northeast coastal Bantu [Nurse and Philippson 1980; Hinnebusch, Nurse and Mold 1981]. In addition to Bondei, this sub-group includes Seuta, Shambala, Zigula, and Ngulu. There are approximately thirty to thirty-five thousand Bondei speakers in Tanzania in an area southwest of the northwest coastal town of Tonga, north of the Pangani River. In Bondei, subject and object pronouns appear as quasi-agreement affixes on the verb, i.e. these pronouns agree in noun class with the lexical subject and object of the clause. Subject pronouns exhibit more variation in form than object pronouns because they interact with other morphemes which appear as prefixes on the verb, e.g. morphemes coding tense/aspect and polarity. The form of the subject pronoun also depends upon whether the verb exhibits main clause or relative clause morphology. (See the appendix for the forms of subject pronouns.)

In this paper, I will examine the distribution of the syntactic category object pronoun in four grammatical constructions: (a) basic affirmative declarative clauses; (b) relative clauses; (c) clefts; and (d) pseudo-clefts. It has been noted that, in the languages of the world, cleft and pseudocleft constructions show structural similarities to relative clauses [Takizala 1972, Schachter 1973]. All three constructions are highly presuppositiona1. 1 Clefts and pseudo-clefts, as opposed to relative clauses, however, are focusing constructions, i.e. they present new or previously inactive information in conjunction with a presupposed clause which presents given or already activated information. ${ }^{2}$

I will show that in Bondei the object pronoun in cleft and pseudo-cleft constructions obligatorily functions grammmatically to mark clefted NP's as definite. An NP which is marked as definite is coded by the speaker as identifiable by the recipient. In the cleft constructions, the definite-

${ }^{1}$ The terms "presupposition" and "assertion" are relevant on a logicosemantic level of analysis, while the terms "new" and "given" or "identifiable" refer to the information status of NP's and are relevant on a discourse level of analysis.

${ }^{2}$ See Chafe [1984] for a discussion of previously inactive, already activated, and semi-activated information. 
ness of the clefted NP forces a contrastive interpretation. In short, I will show that the syntactic category object pronoun in the environment of cleft constructions correlates indirectly with contrastive function through the mediation of the definiteness of the clefted NP. In pseudo-cleft constructions, the same correlation does not obtain. Contrastive function does not correlate through the mediation of the definiteness of the NP with the presence of the syntactic category object pronoun in pseudo-cleft constructions. Contrastive function is unambiguously signaled by the relative morphology on the verb of the pseudo-cleft. In other words, pseudo-clefts without the object pronoun may be contrastive.

The task of demonstrating the correlation between object pronouns, definiteness, and constrastive function in clefts and pseudo-clefts must be distinguished from an examination of the functional distribution of the object pronoun in discourse, i.e. the way Bondei speakers actually use the object pronoun. In conversation, speakers make communicative choices with regard to the appearance of the object pronoun on the basis of discourse factors [Wald 1979]. In order to discover which discourse factors are relevant for speakers' decisions and what functions the object pronoun serves, it is necessary to look at conversational data. Since this paper is based upon elicited data from a single Bondei speaker, no claims can be made as to how the object pronoun functions in discourse. ${ }^{3}$ In contrast, this paper involves an examination of the syntactic environments in which the grammar allows or disallows the presence of the object pronoun. A speaker's choice to use or not use the object pronoun in a clause is conditioned by discourse factors. Such a choice, however, is only relevant in some environments. This paper will examine the syntactic environments in which such speaker choice is relevant and the relation of these environments to definiteness and contrast.

${ }^{3}$ I am grateful to Rose Lugembe not only for her patience with my ignorance and her acute linguistic insights, but for many hours of good company. 


\section{The Origin and Development of the Bantu Object Pronoun}

Givón [1976] has suggested that the Bantu object pronoun originated in a preverbal pronoun in left-dislocation constructions, i.e. in referent-proposition constructions. This hypothesis is supported by the function of the object pronoun as an anaphor of an NP previously mentioned in the discourse. As an anaphor, the object pronoun, like any pronoun, is interpretable as identifying the referents of given NP's or identiflable NP's. Givón further suggests that right-dislocations, i.e. afterthought-topic constructions, played an important intermediate step in the development of the object pronoun. It is suggested that right-dislocations gave rise to the pattern of an object pronoun appearing with a post-verbal lexical object. Wald [1979: 511] suggests an alternative hypothesis, namely, that this distributive pattern of the object pronoun most plausibly originated in the use of the object pronoun to agree with given postverbal object NP's. He suggests that it was the object pronoun, and not the lexical object, which was the original unusual element in discourse productions. In any case, 1ike Swahili [Wald 1979:512], Bondei has further innovated in its use of the object pronoun to include indefinite, nonreferential, and generic objects.

2. The Object Pronoun in Declarative Clauses

2.1. The object pronoun as an anaphor. The object pronoun can serve as an anaphor of an NP previously mentioned in the discourse.

(1) a. mumangu pengine enda eze, $\ldots$ my husband maybe 3Ps FUT comc ${ }^{4}$

'my husband might be coming, ...'

${ }^{4}$ The following abbreviations are used in the exampies.

$\begin{array}{lll}\text { 1Ps } & \text { first person singular } & \text { subject person/number } \\ \text { 2Ps } & \text { second person singular } & \text { pronoun person/number } \\ \text { 3Ps } & \text { third person singular } & \\ \text { 1Pp } & \text { first person plural } & \\ \text { 2Pp } & \text { second person plural } & \\ 3 \mathrm{Pp} & \text { third person plural }\end{array}$


b. nenda ni-mw-one

1 Ps FUT 1Ps-OP-see

'I will see him'

(2) a. Jessie, wa-manya vigano vyovyose?

Jessie 2Ps PRES-know stories any

'Jessie, do you know any stories?'

b. $n k i-v i-j a a$

1Ps PERF-OP-forget

'I have forgotten them'

The object pronoun can serve as an anaphor of a left-dislocated NP. It is obligatory in this construction.

(3) wana na- $\left\{\begin{array}{c}w a- \\ * \emptyset\end{array}\right\}$ kunda

children 1Ps PRES-OP-love

'the children I love them'

(4) vikombe nki- $\left\{\begin{array}{c}v i- \\ * \emptyset\end{array}\right\}$ tua

cups 1Ps PERF-OP-break

'those cups I broke them'

\begin{tabular}{|c|c|c|}
\hline $\begin{array}{l}\text { PRES } \\
\text { PAST } \\
\text { PERF } \\
\text { FUT }\end{array}$ & $\begin{array}{l}\text { present } \\
\text { past } \\
\text { perfect } \\
\text { future }\end{array}$ & verb tense/aspect \\
\hline $\begin{array}{l}\text { IND } \\
\text { INF } \\
\text { SUBJUNC } \\
\text { PART }\end{array}$ & $\begin{array}{l}\text { indicative } \\
\text { infinitive } \\
\text { subjunctive } \\
\text { participle }\end{array}$ & verb mood \\
\hline $\begin{array}{l}\text { COP } \\
\text { APPLIC }\end{array}$ & $\begin{array}{l}\text { copula } \\
\text { applicative }\end{array}$ & verb type \\
\hline NEG & negative & verb polarity \\
\hline $\begin{array}{l}\text { OP } \\
\text { EMP } \\
\text { REL } \\
\text { \#1, \#2, etc. } \\
\text { DEM } \\
\text { PL AN } \\
\text { SG AN }\end{array}$ & $\begin{array}{l}\text { object pronoun } \\
\text { emphatic } \\
\text { relative } \\
\text { noun class } \\
\text { demonstrative } \\
\text { plural animate } \\
\text { singular animate }\end{array}$ & \\
\hline
\end{tabular}


No intonation break is noticeable between the left-dislocated NP and the rest of the clause.

2.2. The object pronoun and postverbal objects. Example (5) demonstrates that a defintte human object can appear with or without the object pronoun.

(5) $k a-\left\{\begin{array}{l}w a- \\ \emptyset\end{array}\right\}$ ona wana wada

3Ps PERF-OP-see children those

'he saw those children'

Example (6) demonstrates that a definite inanimate object can appear with or without the object pronoun.

(6) baadae nki- $\left\{\begin{array}{l}i- \\ \emptyset\end{array}\right\}$ pata kae ida tiket $i$

at last 1Ps PERF-OP-get already DEM ticket

'at last, I finally got the ticket'

Examples (7) through (10) demonstrate that the object pronoun can serve to definitize an NP.

(7) ka-ø-ona wana

3ps PERF-OP-see children

'he saw some children'

(8) ka-wa-ona wana

3Ps PERF-OP-see children

'he saw the children'

(9) a-ka- $\emptyset$-kunda kitabu,...

3Ps-PART-OP-want book

'when she wants a book, ...'

(10) a-ka-ki-kunda kitabu,...

3Ps-PART-OP-want book

'when she wants the book, ...'

Example (11) demonstrates that an indefinite human object can appear with or without the object pronoun.

(11) wa- $\left\{\begin{array}{l}\text { wa- } \\ \emptyset\end{array}\right\}$ ona wanafunzi washano

3Pp PERF-OP-see students five

'they saw five students' 
Example (12) demonstrates that an indefinite inanimate object can appear with or without the object pronoun.

(12) wa- $\left\{\begin{array}{l}\text { ya- } \\ \emptyset\end{array}\right\}$ gua machunga mashano 3Pp PERF-OP-buy oranges five

'they bought five oranges'

Examples (13) through (15) demonstrate that nonreferential objects can appear with or without the object pronoun.

$$
\text { ka-onda } \quad k u-\left\{\begin{array}{c}
m- \\
\emptyset
\end{array}\right\} \text { toa mtu }
$$

3Ps PERF-want INF-OP-hit person

'he wanted to hit somebody'

(14) nke-ku\{ $\left\{\begin{array}{l}v i- \\ \emptyset\end{array}\right\}$ ona viti vyovyose

NEG 3Ps PAST-INF-OP-see chairs any

'he didn't see any chairs'

$$
\begin{aligned}
& \text { nke-ku- }\left\{\begin{array}{l}
\text { wa- } \\
\emptyset
\end{array}\right\} \text { ona wana wowose } \\
& \text { NEG 3Ps PAST-INF-OP-see children any } \\
& \text { 'he didn't see any children' }
\end{aligned}
$$

When there is no lexical object, the object pronoun precludes any indefinite or nonreferential interpretation. It must be interpreted as a definite NP.

(16) nke-ku-wa-ona

NEG 3Ps PAST-INF-OP-see

'he $\operatorname{didn}$ 't see $\left\{\begin{array}{l}\text { them } \\ \dot{x} \text { any }\end{array}\right\}$ '

Exampie (17) demonstrates that a generic object can appear with or without the object pronoun.

(17) wantu wa- $\left\{\begin{array}{l}m w- \\ \emptyset\end{array}\right\}$ ogoha simba

people 3Ps PRES-OP-fear 1ion

'people fear the lion' 


\section{The Object Pronoun and Pronominal Objects}

The object pronoun is obligatory for pronominal human objects, which, of course, are both human and definite. Animate nonhumans and inanimates do not require the object pronoun.

(18) ka- $\left\{\begin{array}{c}n i- \\ * \emptyset\end{array}\right\}$ toa mie 'he hit me'

3Ps PERF-OP-hit 1Ps

(19) na- $\left\{\begin{array}{l}k u- \\ \star \emptyset\end{array}\right\}$ toa wewe

'I am hitting you'

$1 P s$ PRES-OP-hit you

(20) $n k i-\left\{\begin{array}{c}m- \\ \star \emptyset\end{array}\right\}$ toa yuda

'I hit him'

1Ps PERF-OP-hit 3Ps DEM

(21) $k a-\left\{\begin{array}{l}d^{i}- \\ \emptyset\end{array}\right\}$ toa dida

'he hit it' (dog)

3Ps PERF-OP-hit 非 5 DEM

(22) $k a-\left\{\begin{array}{l}k i- \\ \emptyset\end{array}\right\}$ toa kida

'he hit it' (chair)

3Ps PERF-OP-hit 非 DEM

4. Multiple Objects

Bondei allows multiple objects and multiple object pronouns for three argument verbs.
nki-ki-mw-enka
mdee
kitabu
1Ps PERF-OP \#7-OP \#1-give gir1 (非1) book (\#7)
'I gave the gir1 a book'

Only a single object pronoun can appear for compound direct objects of two argument verbs. If direct objects can take different concord, the object pronoun agrees with the first NP.

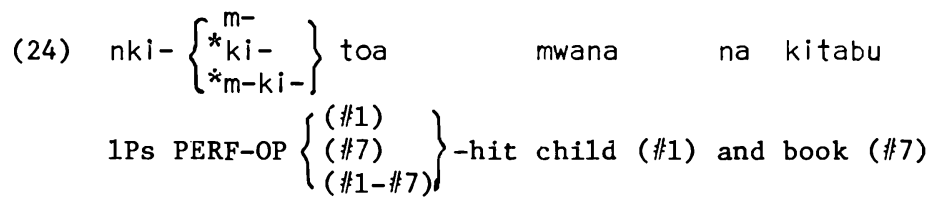

'I hit the child and the book' 
$n k i-\left\{\begin{array}{l}k i- \\ *_{m}- \\ *_{k i-m-}\end{array}\right\}$ toa kitabu na mwana

1PS PERF-OP $\left\{\begin{array}{l}\left(\begin{array}{l}(k) \\ (\# 1) \\ (\# 7-\# 1)\end{array}\right.\end{array}\right\}$-hit book and child

'I hit the book and the child'

Compound objects which take the same concord can be marked by a plural object pronoun. In example (26), where the objects both take animate concord, the object pronoun which agrees with plural animate objects can appear.

(26) nki-wa-wisha mdee na mbwanga

1Ps PERF-OP-feed girl and boy

'I fed the girl and the boy'

In example (27) the object pronoun di agrees. with the first lexical object kul 'dog', and the object pronoun wa is the plural animate object pronoun which agrees with both lexical objects. The sequence of object pronouns di-m which are the agreement markers for kui 'dog' and mbwanga 'boy', respectively, can only be interpreted as the direct and indirect objects, giving the interpretation 'I fed the dog to the boy'.

(27) $n k i-\left\{\begin{array}{l}d i- \\ \text { wa- } \\ \star d i-w a-\end{array}\right\}$ wisha kui na mbwanga

1Ps PERF-OP-feed dog and boy

'I fed the dog and the boy'

Applicative or prepositional verb forms are restricted as to which lexical object can be crossreferenced by the object pronoun. Only the object of the prepositional meaning can be marked by the object pronoun, as demonstrated in examples (28) and (29).

$$
\begin{aligned}
& n k i-\left\{\begin{array}{c}
w a- \\
* i-
\end{array}\right\} \text { do-e-a nkande mdee na mbwanga } \\
& \text { 1Ps PERF- }\left\{\begin{array}{l}
\text { OP (PL AN) } \\
* \text { OP (SG }
\end{array}\right\} \text {-take-APPLIC-IND food(非9) gir1 and boy }
\end{aligned}
$$


(29) $n k i-\left\{\begin{array}{l}m- \\ { }^{*} \text { wa- }\end{array}\right\}$ gus-i-a

1Ps PERF- $\left\{\begin{array}{l}\text { OP (SG AN) } \\ *_{\text {OP }}(\text { PL AN) }\end{array}\right\}$-sing-APPLIC-IND

'I made the children sing for the teacher'

In summary, I have shown that the object pronoun in Bondei can crossreference a wide range of $\mathrm{NP}^{\prime}$ 's in simple declarative clauses. It can serve as an anaphor for previously mentioned NP's. It can mark topicalized NP's. It can also mark given and new postverbal NP's, including nonreferential and generic NP's. In the absence of a lexical object, however, the object pronoun must be interpreted anaphorically. The object pronoun is obligatory when the object is a pronoun which refers to a human referent. In the case of two argument verbs, only a single object pronoun can appear. The object pronoun must agree with the first NP when direct objects take different concord. When direct objects take the same concord, a plural object pronoun may appear. In the case of three argument verbs, two object pronouns appear; the first must be interpreted as the direct object, and the second as the indirect object. In the case of applicative verbs, the object pronoun must be interpreted as the object of the prepositional meaning.

\section{The Object Pronoun in Relative Clauses}

Relative clauses are formed (1) by relative morphology on the verb of the embedded clause or (2) by the use of the relativizing word amba 'to say' with the verb retaining main clause morphology. When relative verbal morphology is used, the relative can be inflected for tense, as in example (30), or be realized as a tenseless construction, as in example (31).

5.1. Subject relatives. The following are examples of subject relatives. Verb Coding

(30) mvyie e-ku-gwa-e woman 3Ps PAST-INF-fall down-REL

(31) mvyie mwe-ku-gwa-e woman 3Ps REL-INF-fa11 down-REL 'the woman who fell down'

'the woman who $\left\{\begin{array}{l}\text { is falling down } \\ \text { fell down } \\ \text { will fall down }\end{array}\right\}$ ' 


\section{amba Coding}

(32) mvyie amba-e ka-gwa

woman say-REL 3Ps PERF-fall down

'the woman who fell down'

5.2. Object relatives. Although object relatives can be formed without an object pronoun, the consultant consistently included them in elicited relatives of definite NP's. No meaning difference was noted for constructions with and without the object pronoun. The head of the relative which the object pronoun crossreferences is in preverbal position.

\subsubsection{Inanimate objects.}

\section{Verb Coding}

(33) kiti n-e-ku- $\left\{\begin{array}{l}k i- \\ \emptyset\end{array}\right\}$ gua-cho 'the chair which I bought'
chair 1Ps-PAST-INF-OP-buy-REL (34) tonte $n i-\left\{\begin{array}{l}d i- \\ \emptyset\end{array}\right\}$ da-do 'the banana which I am eating'
banana 1Ps PRES-OP-eat-REL

amba Coding

(35) kiti amba-cho nki- $\left\{\begin{array}{l}k i- \\ \emptyset\end{array}\right\}$ gua 'the chair which I bought'

(36) tonte amba-do $n-a-\left\{\begin{array}{l}d i- \\ \emptyset\end{array}\right\}$ da 'the banana which I am eating' banana say-REL 1Ps-PRES-OP-eat

\subsubsection{Animate objects.}

Verb Coding
(37) mwana n-e-ku- $\left\{\begin{array}{l}m- \\ \emptyset\end{array}\right\}$ toa-e
'the child whom I hit'
child 1Ps-PAST-INF-OP-hit-REL
(38) mwana $n i-\left\{\begin{array}{l}m- \\ 0\end{array}\right\}$ toa-e
child 1Ps PRES-OP-hit-REL
'the child whom I am hitting'
amba Coding
(39) mwana amba-e nki- $\left\{\begin{array}{l}m- \\ \emptyset\end{array}\right\}$ toa 'the child whom I hit'
child say-REL 1Ps PERF-OP-hit 
(40) mwana amba-e $n-a-\left\{\begin{array}{l}m- \\ \emptyset\end{array}\right\}$ toa 'the child whom I am hitting' child say-REL 1Ps-PRES-OP-hit

5.3. Ambiguity in relative clauses. Because the object pronoun can appear in a relative construction but is not obligatory, some relatives are ambiguous. The following examples without the object pronoun can be interpreted as subject or object relatives.

(41) mwana mwe-ku-ona-e child $\left\{\begin{array}{l}3 P s \\ 2 P s\end{array}\right\}$ REL-INF-see-REL

'the child who saw' (SUBJECT RELATIVE)

'the child whom you saw' (OBJECT RELATIVE)

(42) mwana e-ku-ona-e child 3Ps PAST-INF-see-REL

'the child who saw' (SUBJECT RELATIVE)

'the child whom he saw' (OBJECT RELATIVE)

The following examples with the object pronoun can be interpreted as subject or object relatives.

(43) mwana mwe-ku-mw-ona-e child 3Ps REL-INF-OP-see-REL

'the child who saw him' (SUBJECT RELATIVE)

'the child whom he saw' (OBJECT RELATIVE)

(44) mwana e-ku-mw-ona-e child 3Ps PAST-INF-OP-see-REL

'the child who saw him' (SUBJECT RELATIVE)

'the child whom he saw' (OBJECT RELATIVE)

Although the grammar permits these interpretations, some are more felicitous than others in context. The choice of the subject marker (e vs. mwe) and the presence or absence of the object pronoun are both relevant factors for the contextual interpretation of the clause.

\section{Clefts}

Givón [1979] states that it is well known that in cleft constructions of the world's languages, one element, usually a nominal, is the asserted 
focus, while the rest of the material, which often resembles a relative clause, is presupposed ( .217 ). These constructions are strong disruptions of the neutral syntax in terms of the presence of the focused constituent at the beginning of the clause as well as the presence of a focus-marking morpheme and relative clause morphology and syntax (p. 78).

Hetzron [1971] classifies clefts as emphatic constructions. He calls emphasis "the phenomenon where all but one (of the) components of a sentence are known to be combined together within the proposition in terms of a presupposition, and the emphasized element is filling the only slot left open in the previous knowledge" (p. 84).

It should be noted that the description of cleft constructions as being composed of an asserted NP and a presupposed relative clause is not based on any specific discourse studies of conversational or written data. Rather, it is the result of typological observations which capture the logico-semantic structure of the cleft construction as it exists in the languages of the world. When Prince [1978] examined clefts in spoken and written English, she found instances of clefts in which the focused NP represents new information and the that-clause represents old or known information, i.e. information which can be described as presupposed given the prior discourse. In addition, however, she found clefts in which the information in the logical1y presupposed that-clause constitutes new information in the discourse. She labeled these clefts "informative-presupposition clefts". These informative-presupposition clefts have a general function of presenting statements as facts, as well as a number of various sub-functions. In conversation, then, the NP which is asserted on the logico-semantic level may be given in the discourse, and the information represented in the relative clause, which is presupposed on the logico-semantic level, may be new information in the discourse. During the elicitation of the following cleft examples, however, the consultant was always given a context in which the asserted NP would constitute new information and the presupposed relative clause would represent given or known information.

In Bonde1, clefts are formed with the general copula $\mathrm{ni}$ and the em- 
phatic particle ne. A relative clause serves to restrict the clefted NP, which is new or previously inactive information. The relative clause presents given or already activated information. The NP is in preverbal position with regard to the verb of the relative clause.

6.1. Subject clefts. In examples (45) and (46) the already activated information is that someone or something fell or is falling. The new information consists of the identity of the entity which fell or is falling. There are, of course, no object pronouns in these examples.

(45) ni mvyie ne mwe-ku-gwa

COP woman EMP 3Ps REL-INF-fa11 down

'it's a woman who fell down'

(46) ni kiti ne ki-gwa-cho

COP chair EMP \#7-fall down-REL

'it's a chair that is falling down'

6.2. Object clefts. In example (47), the already activated information is that the speaker wants something, and the new information is that what she wants is a child. In example (48), the already activated information is that something was eaten, and the new information is that what was eaten was a banana. There is no object pronoun in these examples.

(47) ni mwana ne ni-kunda-e

COP child EMP 1Ps-want-REL

'it's a child that I want'

(48) $\mathrm{ni}$ tonte ne $\mathrm{n}-\mathrm{e}-\mathrm{ku}-\mathrm{da}-\mathrm{do}$

COP banana EMP 1Ps-PAST-INF-eat-REL

'it's a banana that I ate'

The object pronoun cannot appear without changing the interpretation of the cleft. When the object pronoun appears, the NP must be interpreted as definite. The definiteness of the NP forces a contrastive interpretation, as in example (49).

(49) ni tonte ne $n-e-k u-d i-d a-d o$

COP banana EMP 1Ps-PAST-INF-OP-eat-REL

'it's the banana that I ate' 
Hetzron [1971] calls contrast

"another type of stressing element, with a primarily corrective function: to replace an element wrongly used in a previous utterance, or to show additional elements which may appear in exactly the same slot, surrounded by the same elements. Thus, a contrastive element always replaces another concrete one, or several of them,-which is not the case for emphasis" ( $p .34)$.

Chafe [1976] discusses three factors which are involved in contrastiveness: shared background knowledge, a set of possible candidates, and the assertion of the correct candidate. He calls the asserted alternative the focus of contrast. In this paper, it is assumed that simple focus and contrastive focus are distinct functions.

In example (49), the banana is understood as being one member of a set of possible edibles which was, in fact, eaten, while the others were not eaten. Thus, the already activated information is that something was eaten. The cleft conveys the new information that "what was eaten was the banana as opposed to the other possible edibles, e.g. the mango and the papaya." The new information is not the identity of the banana per se, but the relation "the banana and not the other possibilities." The assertion of the banana is serving a corrective function.

Note that the object pronoun cannot serve as an anaphor in clefts, as demonstrated in example (50).

(50) * ni ne n-e-ku-di-da-do

COP EMP IPs-PAST-INF-OM-eat-REL

'it's it which I ate'

Pronouns can be focused, but not with the cleft construction, as in examples (51) and (52). In these examples, the pronoun is focused with the emphatic particle ne.

(51) mie ne mwe-ku-da-e tonte

1Ps Pro EMP 1Ps REL-INF-eat-REL banana

'I'm the one who $\left\{\begin{array}{l}\text { is eating } \\ \text { ate } \\ \text { will eat }\end{array}\right\}$ the banana' 
(52) mie ne amba-e nkina-n-id-e

1Ps PRO EMP say-REL NEG 1Ps FUT-1Ps-eat-SUBJUNC

'I'm the one who won't eat'

The emphatic particle ne can also focus lexical NP's in other than cleft constructions. Example (54), with the particle ne, is the focused counterpart of example (53).

wana we-se-o-ku-da

children 3P.p-NEG-REL-INF-eat

'the children who are not eating'

(54) wana ne we-se-o-ku-da

children EMP 3Ps-NEG-REL-INF-eat

'those are the children who are not eating'

While these ne examples resemble clefts in that the verb must take relative morphology, they differ in that there is no copula. It is not clear how ne constructions and clefts differ with regard to their meaning or discourse function. A satisfactory answer to this question would require an examination of both clefts and ne constructions in Bondel discourse.

In cleft constructions, the relativizing morphology must agree with the clefted NP, as demonstrated in example (47) repeated here as (55). This is not the case for pseudo-clefts, as will be seen below (p. 13). In the case of pseudo-clefts, the relative morphology can agree either with the noun class of the focused NP or with the general concept "the thing".

(55) ni mwana ne ni-kunda- $\left\{\begin{array}{l}e \\ \star c h o\end{array}\right\}$ 'it's a child that I want'

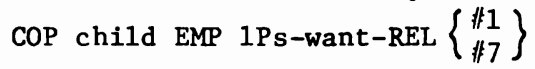

6.3. The relation of the object pronoun, definiteness, and contrastive focus in clefts. In summary, I have shown that the appearance of the object pronoun in clefts forces a definite interpretation of the focused NP. The definiteness of the NP precludes a simple focus interpretation of the cleft, since the definiteness of the NP forces a contrastive interpretation. When no object pronoun appears, however, the focused NP is interpretable as indefinite. A contrastive focus is not forced; the cleft can receive a simple 
focus interpretation. Because of these relations between the presence or absence of the object pronoun and the definite or indefinite interpretation of the clefted NP, there exists a correlation between the presence of the object pronoun and contrastive function in clefts. This is not to say that the object pronoun marks contrastive function. The relation between the presence of the object pronoun and contrastive function is mediated by the definiteness of the NP.

7. Pseudo-clefts. Pseudo-cleft constructions are formed by a relative clause, the general copula $\mathrm{ni}$, and an NP. The relative clause constitutes the given or already activated information, while the NP which follows the copula constitutes the new information. The NP is in postverbal position with regard to the verb of the relative clause.

Hetzron [1971] classifies the pseudo-cleft as a presentative construction. He says,

"... at issue is not the novelty of the element, but what the speaker intends to build up in the discourse. ... The element which is meant to represent a special contrast to all possible other elements susceptible to appear in the same slot, i.e., the element whose individual and specific presence is the most important in the sentence, comes last" (p. 79).

Presentative constructions serve a cataphoric function. The element they present will be relevant in the subsequent discourse.

7.1. Subject pseudo-clefts. In Bondei, pseudo-clefts differ from clefts in that the relative morphology can agree either with the noun class of the pseudo-clefted NP or with the general concept "the thing". Examples (56) and (57) exhibit the two possible agreements for pseudo-clefted subject NP's.

che-ku-bonda-cho tindi ni mpeho

\#7 PAST-INF-break-REL \#7 banana plant COP wind

'what broke the banana plant is the wind'

(57) ye-ku-bonda-yo tinde ni mpeho

\#9 PAST-INF-break-REL \# 9 banana plant COP wind

'what broke the banana plant is the wind' (not the rain, not the hail) 
In example (56), the subject pronoun and the relative suffix agree with the noun class of the "what", i.e. the concept of "the thing". This agreement gives no information about the pseudo-clefted NP. In example (57), the subject pronoun and the relative suffix agree with the noun class of mpeho 'wind'. This agreement, therefore, is cataphoric and points ahead to the specific pseudo-clefted NP by identifying its noun class.

The use of the specific noun class agreement morphology necessitates a different interpretation of the pseudo-cleft from the more general class \#7 agreement. The pseudo-cleft with specific noun class morphology signals a contrastive meaning. In example (56), the presupposition is that something broke the banana plant, and the new information is that it was the wind. In example (57), the presupposition is that it was one of a set of known possibilitites which broke the banana plant. The new information is that "it was the wind and not the other possibilitites (the rain, the hail) which broke the banana plant."

7.2. Object pseudo-clefts. Object pseudo-clefts can also take two different kinds of relative agreement morphology, as demonstrated in examples (58) and (59). There is no object pronoun in these examples.
mvyie a-kunda-cho
ni tonte
woman 3Ps PRES-want-REL \#7 COP banana
'what the woman wants is a banana'

These two forms force different interpretations. In example (58), the presupposition is that the woman wants something, and the new information is that what she wants is a banana. In example (59), the presupposition is that the woman wants one of a set of known possibilitles. The new information is that "it is the banana and not the other possibilities which, in fact, the woman wants."

In examples (60) and (61), a pronoun which refers to a human referent is clefted. 
(60) ni-onda-cho $\mathrm{ni}$ wewe

1Ps-want-REL \#7 COP 2Ps

'what I want is you'

(61) ni-onda-ye ni wewe

1Ps-want-REL \#1 COP 2Ps

'what I want is you', 'the one I want is you' (not him, not her)

The presence of a human referent in these examples clearly demonstrates the difference in the information activated by the different morphology on the verbs. In (60) the cho gives no information about what is wanted, since it agrees with the general concept 'the thing'. In (61) the ye signals that what is wanted belongs to noun class 1 , which consists of nouns that are human or divine. Thus, the set of possibilities has been delineated by the relative morphology, and a contrastive interpretation is forced.

7.3. The object pronoun in pseudo-clefts. The object pronoun cannot appear in a pseudo-cleft which has only class $\$ 7$ concord, as demonstrated in example (62).

(62) mvyie a- $\left\{\begin{array}{l}\emptyset- \\ \star_{m}-\end{array}\right\}$ kunda-cho ni mwana woman 3Ps PRES-want-REL \#7 COP child

'what the woman wants is a child'

When this class $\$$; 7 agreement is used, no information is given by the relative morphology about the identity of the NP which follows the relative clause. This type of pseudo-cleft cannot have a contrastive interpretation Hence, it cannot focus an NP which is interpreted as definite, since definite NP's require a contrastive interpretation.

In contrast, the object pronoun can appear in pseudo-clefts which have the specific noun class morphology of the focused NP. The morphology of the specific noun class agreement provides some information about the noun. The NP is, in some sense, semi-active in this type of pseudo-cleft. The relative morphology serves as a cataphoric reference, invoking the semantic associations which accrue to the noun class to which the NP belongs. The following example with specific noun class morphology does not have an ob- 
ject pronoun.

$$
\begin{array}{ll}
\text { mvyie a- } \emptyset-k \text { unda-e } & n i \text { mwana } \\
\text { woman 3Ps PRES-OP-want-REL \#1 COP child }
\end{array}
$$

a. 'what the woman wants is (to have) a child' (as opposed to a career)

b. 'what the woman wants is the child' (as opposed to the house, In the context of a divorce)'

Example (63) demonstrates that the specific noun class morphology forces a contrastive interpretation independently of the presence of the object pronoun. The NP need not be interpreted as definite, as in (a), as long as the contrastive sense can be maintained.

When the object pronoun appears with the specific noun class morphology, however, the NP must be interpreted as definite, as demonstrated in the following example.

$$
\begin{aligned}
& \text { mvyie a-m-kunda-e } \\
& \text { woman 3Ps PRES-OP-want-REL \#1 COP child } \\
& \text { 'what the woman wants is }\left\{\begin{array}{l}
\text { the child } \\
\star_{a} \text { child }
\end{array}\right\} \text { ' }
\end{aligned}
$$

In summary, the two possibilities for marking the noun class of focused $\mathrm{NP}^{\prime} \mathrm{s}$ in the relative clause of pseudo-clefts correlate with the function of contrastiveness. Pseudo-clefts which take the general class \# 7 agreement morphology cannot function to contrast the focused NP. Consequently, the object pronoun is restricted from appearing in this syntactic environment since the appearance of the object pronoun in clefts or pseudo-clefts correlates with definiteness, and focusing a definite NP forces a contrastive interpretation. Pseudo-clefts which take the specific noun class morphology must be interpreted as contrastive (ex. 63). The object pronoun can appear in this syntactic environment, but when it does the NP must be interpreted as definite. The object pronoun in this construction correlates with definiteness, and definiteness requires a contrastive interpretation. The correlation, however, is not symmetrical. A contrastive interpretation of pseudo-clefts is possible without the presence of the object pronoun. The NP may be interpreted as definite or indefinite. 


\section{Conclusion}

In this paper I have shown that the object pronoun in Bondei can appear in a wide range of syntactic environments. It can serve as an anaphor for previously mentioned NP's. It can mark left-dislocated NP's. It can appear with given and new postverbal NP's. It appears freely in relative clauses. It can appear in declarative and relative clauses without necessarily changing their meaning, i.e. without necessarily definitizing their objects.

When the object pronoun appears in the relative clause of a cleft, however, it definitizes the clefted NP. In other words, the presence of the object pronoun precludes an indefinite interpretation of the clefted NP. Thus, depending upon whether or not the object pronoun is present or absent In the cleft, the NP will be interpreted as definite or indefinite.

The definiteness of the clefted NP forces a contrastive meaning of the cleft. Thus, on the basis of the meaning change which the presence of the object pronoun effects (definite vs. indefinite), we can say that while new, indefinite NP's can be focused by cleft constructions without the syntactic category object pronoun, definite NP's can only be given contrastive focus. Focus and contrastive focus are distinct functions. In cleft constructions, the presence of the object pronoun signals a definite interpretation of the NP which, in turn, forces a contrastive function. In both the case of simple focus and contrastive focus, however, some new information is being communicated, either the identity of the referent or the contrastive relation.

The object pronoun can only appear in one of two possible pseudo-cleft constructions. It can appear in the relative clause of a pseudo-cleft which takes specific noun class concord. This morphology itself serves to require a contrastive interpretation for the NP which is being focused. The object pronoun in this construction forces a definite interpretation of the NP. The definiteness of the NP does not force a contrastive interpretation; it is, however, compatible with the contrastive interpretation signaled by the verb morphology.

In contrast to these two constructions, the object pronoun cannot appear in the relative clause of a pseudo-cleft which takes general class \#7 concord. This construction cannot have a contrastive meaning. Thus, definite 
pseudo-clefted NP's are not compatible with this construction, since definiteness forces a contrastive interpretation. Since it is the presence of the object pronoun which forces a definite interpretation of the pseudoclefted NP, the object pronoun cannot appear in this type of pseudo-cleft. The two types of pseudo-clefts differ with regard to their interpretations, noncontrastive vs. contrastive. On the basis of this meaning difference, we can say that new, indefinite NP's are presented in class \#7 pseudo-clefts which appear without the object pronoun.

The following facts may be stated for the interpretation of contrast in clefts :

(1) the presence of the object pronoun in clefts requires a definite interpretation of the NP;

(2) the presence of a definite NP in a cleft construction forces a contrastive interpretation.

It is also possible that a cleft with an indefinite NP can receive a contrastive interpretation, given the appropriate context. This question must be left open, however, because a satisfactory answer can only be given after an examination of actual examples from Bondei discourse. That, however, is beyond the scope of this paper.

The following facts may be stated with respect to the interpretation of contrast in pseudo-clefts:

(1) specific noun class pseudo-clefts force a contrastive interpretation independently of the presence or absence of the object pronoun; moreover, this contrastive interpretation is possible with an indefinite interpretation of the NP;

(2) the presence of the object pronoun in specific noun class pseudoclefts requires a definite interpretation of the NP;

(3) class \#7 pseudo-clefts do not permit a contrastive interpretation. The relation between focus, contrastive focus, and definiteness may be represented as in the diagram opposite. In clefts, the object pronoun correlates with definiteness which, in turn, correlates with contrastive function. The relation between the object pronoun and contrastive function is mediated by definiteness. 

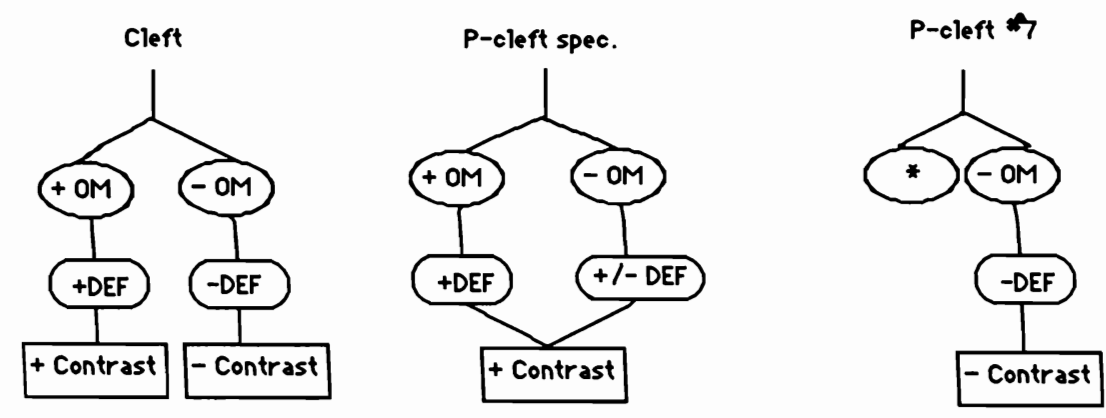

In pseudo clefts, a different relation exists. Noun class morphology correlates with contrastive function. Class $\$ 7$ pseudo-clefts correlate with noncontrast, while specific noun class pseudo-clefts correlate with contrast for both definite and indefinite NP's. In specific noun class pseudo-clefts, the object pronoun correlates with definiteness. The contrastive interpretation which the definiteness of the NP forces is compatible with the contrastive interpretation signaled by the verb morphology. 
Appendix

The following surface forms are examples of the possible forms the subject pronoun can take in combination with tense/aspect and polarity morphemes.

$\begin{array}{lll} & \text { Singular } & \text { Plural } \\ \text { 1P Pres } & \text { na } & \text { ta } \\ \text { 1P Pres-Neg } & n k i & \text { nka } \\ \text { 1P Past/Perf } & n k i & t i \\ \text { 1P Continuous Past } & n i & t i \\ \text { 1P Past-Neg } & \text { nce } & \text { nkate } \\ \text { 1P Re1 } & \text { mwe } & \\ \text { 2P Pres } & & \text { we } \\ \text { 2P Pres-Neg } & \text { wa } & \\ \text { 2P Past/Perf } & \text { nku } & \text { mwa } \\ \text { 2P Continuous Past } & \text { ku } & \text { nka } \\ \text { 2P Past-Neg } & u & m \\ \text { 3P Pres } & \text { nkwe } & \text { m } \\ \text { 3P Pres-Neg } & & \text { nkamwe } \\ \text { 3P Past/Perf } & a & \text { wa } \\ \text { 3P 1Ps Continuous Past } & \text { nka } & \text { nka } \\ \text { 3P Past-Neg } & \text { ka } & \text { wa } \\ \text { 3P Re1 } & \text { nke } & \text { wa } \\ & & \text { nkawe } \\ & \text { mwe } & \text { we }\end{array}$

Noun classes take secondary concord. 


\section{REFERENCES}

Chafe, W. 1976. "Givenness, contrastiveness, definiteness, subjects, topics, and point of view." In Charles Li (ed.), subject and Topic, pp. 25-55. New York: Academic Press.

Chafe, W. 1984. Cognitive Constraints on Information Flow. Berkeley Cognitive Science Report No. 26.

Givoon, T. 1976. "Topic, pronoun, and agreement." In Charles Li (ed.), Subject and Topic, Pp. 149-188. New York: Academic Press.

Givón, T. 1979. On Understanding Grammar. New York: Academic Press.

Guthrie, M. 1948. Classification of the Bantu Languages. London: Dawsons of Pall Mal1. Reprinted 1967.

Hetzron, R. 1971. Presentative Function and Presentative Movement. In Papers from the Second Conference on African Linguistics, pp. 79-105. Studies in African Linguisitics, Supplement 2.

Hinnebusch, T.J., D. Nurse, and M. Mold. 1981. Studies in the Classification of Eastern Bantu Languages. Hamburg: Helmut Buske.

Nurse, D. and G. Philippson. 1980. "Bantu languages of eastern Africa: a lexico-statistical survey." In E. Polomé and C.P. Hill (eds.), Languages in Tanzania, pp. 26-66. London: Oxford University Press.

Prince, E. 1978. "A comparison of WH-clefts and it-clefts in discourse." Language 54:883-906.

Schachter, P. 1973. "Focus and relativization." Language49:19-46.

Takizala, A. 1972. "Focus and relativization: the case of Kihung'an." Studies in African Linguistics 3:259-287.

Wald, B. 1979. "The development of the Swahili object marker." In Talmy Givôn (ed.), Discourse and Syntax, pp. 505-524. New York: Academic Press. 


\section{BEATRICE AND WILLIAM E. WELMERS}

IGBO :

\section{A LEARNER'S DICTIONARY}

AND

\section{IGBO: A LEARNER०S MANUAL}

The Welmere and Welmere Igbo booke, orlglnally publlahed in 1968. were written ae pedagogical texte for learnere of Igbo, but eerve e. general refarence worke on "Centrel Igbo" as well. The dictlonary has both Igbo-Englieh and Englieh-Igbo ectione. Entrles in the Igbo eection are elphabetized by initlal root consonant rather than by preflx. The Learner' Manual has extenelve Inforation on eyntax and in particular. on tonal alternatione which play art in the eyntax.

These booke are now belng offered et the very epeclel price of $\$ 3.00$ each. The two Igbo booke can be purchased as at at the greater bargaln of $\$ 5.00$ for the two. Uee the order blank below or facelinile. Prepayment in US dollare le required. Send ordere to

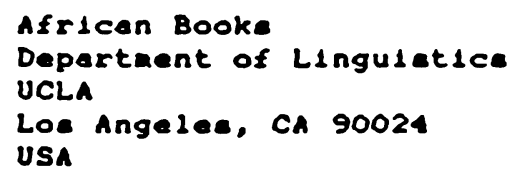

Pleace eend ae

coples of Iabo: A Learner'a Dlctlonary $\$ 3.00$ each coples of Iabo: A Learner'a Manual $\$ 3.00$ each cete of the two Igbo booke 0.5 .00 per et Book rate portage (eurface): $\$ 2.00$ for each book ordered Overeece ir nall poetage: 10.00 for each book ordered

TOTAL ENCLOSED

Name:

Addrese:

(Make chroke payable to Ruecell G. Schuh) 
LAURA F MEYERS

\section{-GanI ya EI Ji" \\ APECTS OF HAUSA TONE}

Thie diseertation, published in 2976 os UCLA Working Papere in Phonetice 132 , 1 a an Inetrumental atudy of consonantal and eyntectic effecte on tones and of non-phonemic tone perturbatione. It has been widely clted and remalna the nost complete etudy of 1 a kind.

Originaliy priced at $\$ 7.50$, it has been reduced for Inventory reduction to $\$ 3.00$, postage paidl

For this book and for other information on the Working Papere in Phonetice eerlea, write to

Working Papere in Phonetice

Phonetice Leboratory

Linguietice Department

UCLA

Loe Angelea, CA 90024

USA

Pleace eend ae

- coples of Meyer' Aepecte of Hause Tone $\$ 3.00 /$ copy

TOTAL ENCLOSED:

(Prepayment in US dollare must accompany all ordere; make checke payable to "The Regente of the Univerelty of Callfornia".)

Nane:

Addrees: 